\title{
Metabolism and Functions of Lipids and Fatty Acids in Teleost Fish
}

\section{Douglas R. Tocher}

\begin{abstract}
Lipids and their constituent fatty acids are, along with proteins, the major organic constituents of fish, and they play major roles as sources of metabolic energy for growth including reproduction, and movement including migration. Furthermore, the fatty acids of fish lipids are rich in $\omega 3$ long chain, highly unsaturated fatty acids (n-3 HUFA) that have particularly important roles in animal nutrition, including fish and human nutrition, reflecting their roles in critical physiological processes. Indeed, fish are the most important food source of these vital nutrients for man Thus, the long standing interest in fish lipids stems from their abundance and their uniqueness. This review attempts to summarise our present state of knowledge of various aspects of the basic biochemistry, metabolism and functions of fatty acids, and the lipids they constitute part of, in fish, seeking where possible to relate that understanding as much to fish in their natural environment as to farmed fish. In doing so, it highlights the areas that require to be investigated in greater depth and also the increasing application of molecular technologies in fish lipid metabolism which will fascilitate further advances through molecular biological and genetic techniques including genomics and proteomics.
\end{abstract}

KEY WORDS: Omega-3; Polyunsaturated; Biosynthesis; Catabolism; Digestion; Absorption; Marine; Freshwater. 


\section{Introduction}

\section{Digestion, Absorption and Transport}

\subsection{Digestion}

2.1.1. Triacylglycerol lipases

2.1.2. Phospholipases

2.1.3. Other lipolytic activities

\subsection{Absorption}

\subsection{Transport}

2.4.1 Extracellular

2.4.2 Intracellular

\section{Biosynthesis and Catabolism}

\subsection{Lipogenesis}

3.2. Unsaturated Fatty Acid Biosynthesis

3.2.1 Monounsaturated Fatty Acids

3.2.2 Polyunsaturated Fatty Acids

3.3. Phospholipid Biosynthesis

3.4. Phospholipid Turnover and Remodelling

3.5. Triacylglycerol Biosynthesis

3.6. Triacylglycerol Mobilisation

3.7. Fatty Acid Catabolism

\section{Functions}

4.1. Energy production.

\subsubsection{General}

4.1.2 Reproduction

4.1.3 Embryonic and yolk-sac larval development

4.2. Membranes

4.3. Eicosanoids

4.4. Transcriptional Control of Lipid Homeostasis

4.5. Other Lipid Mediators

5. Concluding Remarks

\section{References}




\section{Introduction}

The long standing interest in fish lipids stems from the important roles lipids play in the life histories and physiology of fish. Lipids and their constituent fatty acids are, along with proteins, the major organic constituents of fish, with carbohydrates being quantitatively much less prominent in fish. Indeed the lipid (oil) content of fish can markedly exceed the protein content. This reflects the major role lipids and specifically their constituent fatty acids play as sources of metabolic energy in fish, for growth including reproduction and movement including migration. Moreover, the fatty acids of fish lipids are rich in long chain, highly unsaturated fatty acids (HUFA) that have particularly important roles in animal nutrition, including fish and human nutrition, reflecting their particular roles in critical physiological processes. Indeed, fish are the most important food source of these vital nutrients, $\omega 3$ fatty acids (n-3HUFA), for Homo sapiens. Thus, the long standing interest in fish lipids stems from their abundance and their uniqueness. However, a major impetus in the last two decades in studying marine lipids has been the needs of the developing aquaculture industry to understand the lipid nutritional requirements of farmed fish so as to optimise farmed fish production. The lipid nutritional requirements of fish have been recently reviewed (Sargent et al., 2002) so that nutrition will not be a major feature of the present article. Rather it will attempt to summarise our present state of understanding of aspects of the basic metabolism and functions of fatty acids, and the lipids they constitute part of, in fish, seeking where possible to relate that understanding as much to fish in their natural environment as to farmed fish. This account will draw on various reviews on marine lipids, fish lipid metabolism and nutrition published by our laboratory over the last 15 years (Henderson and Tocher, 1987; Sargent et al., 1989, 1990, 1993a,b, 1995a,b,c,d, 1997, 1999a,b, 2002; Sargent, 1995a,b, 1997; Sargent and Henderson, 1995; Tocher, 1995; Henderson, 1996; Bell, 1998; Sargent and Tacon, 1999).

As with all molecules, a full appreciation of the roles of fatty acids and lipids in biological systems requires an understanding of their chemistry, which can be summarised as follows. Lipids can be defined as compounds soluble in organic solvents usually containing fatty acids esterified to alcohol groups in the case of the glycerides, and to amino groups in the case of the sphingolipids. Animal lipids, including fish lipids, can be divided into two groups, polar lipids composed principally of phospholipids and neutral lipids composed principally of triacylglycerols (triglycerides). At ambient temperature, triacylgycerols can be either solid, in which case they can be termed fats, or liquid, in which case they can be termed oils. Fish triacylgycerols are invariably oils.

Fatty acids are designated on the basis of their chain lengths, degree of unsaturation (number of ethylenic or "double" bonds) and the position of their ethylenic bonds (Fig.1). Thus, 14:0 and 16:0 designate 
fatty acids with 14 and 16 carbon atoms respectively and with no ethylenic bonds. 18:1n-9 and 18:1n-7 designate fatty acids with 18 carbon atoms whose single ethylenic bonds are, respectively, 9 and 7 carbon atoms from the methyl end of the molecule (Fig.1). In an alternative nomenclature, 18:1n-9 and 18:1n-7 can be written as $18: 1 \Delta 9$ and 18:1 $\Delta 11$, respectively, with $\Delta$ signifying the position of the ethylenic bond from the carboxyl end of the molecule. Ethylenic bonds in fish are nearly always in the cis rather than the trans configuration, although fatty acids with trans ethylenic bonds occasionally occur, e.g. elaidic acid, the trans isomer of 18:1n-9.

Polyunsaturated fatty acids (PUFA) contain two or more ethylenic bonds, with the ethylenic bonds generally interrupted by a single methylene $\left(\mathrm{CH}_{2}\right)$ group to generate "methylene - interrupted cis dienoic" structures. Consequently, the entire structure of a particular PUFA can be defined by specifying the position of the first ethylenic bond relative to the methyl terminus. Thus, in 18:3n-3 (equivalent to 18:3w3) the first ethylenic bond is situated three carbon atoms from the methyl end of the molecule, 18:3n-3 representing 18:3 $\Delta 9,12,15$ (Fig.1). Equally, 20:5n-3 represents 20:5 $\Delta 5,8,11,14,17$ and 22:6n-3 represents $22: 6 \Delta 4,7,10,13,16,19$. The $n$ - nomenclature is more convenient and more commonly used than the more precise but more cumbersome $\Delta$ nomenclature, although the $\Delta$ nomenclature is generally used for specifying fatty acid desaturase activities. Thus, fatty acid desaturases that introduce ethylenic bonds five or six carbons from the carboxyl end of the molecule are termed $\Delta 5$ and $\Delta 6$ desaturases, respectively. This nomenclature is used for fatty acid desaturases because these enzymes have traditionally been considered to recognise, and therefore to "count" from, the carboxyl terminus of the fatty acid. This is the case with most desaturases such as the cyanobacterial $\Delta 12$ desaturase which always inserts the ethylenic bond 12 carbons from the carboxyl terminus (Higashi and Murata, 1992). However, the same authors showed that the " $\Delta 15$ " desaturase in cyanobacteria always inserted the ethylenic bond 3 carbons from the methyl terminus making this enzyme a true n-3 desaturase (Higashi and Murata, 1992).

Fatty acids may also have a trivial English name such as palmitic acid (16:0), oleic acid (18:1n-9) and $\alpha$-linolenic acid (18:3n-3), often reflecting their first isolation from palm, olive and linseed oils, respectively. In this respect, the fatty acids gadoleic (20:1n-11) and cetoleic (22:1n-11) have trivial names that reflect their marine origin cod fish (Gadus morhua) and whale fat. Slightly more formalised, and useful, are their Greek-Latin names such as eicosapentaenoic acid (EPA; 20:5n-3) and docosahexaenoic acid (DHA; 22:6n-3) which reflect the numbers of carbon atoms (20 and 22) and ethylenic bonds (5 and 6) they contain.

The predominant saturated fatty acids that occur naturally in animal fats including fish lipids are 16:0 and 18:0 although a range of chain lengths from $\mathrm{C}_{12}$ to $\mathrm{C}_{24}$ can be found. However, phosphoglycerides that constitute animal cell membranes seldom contain significant amounts of saturated fatty acids other than 16:0, 18:0 and to a lesser extent 20:0, this restriction reflecting the relatively invariant geometry (width) of 
the phosphoglyceride - rich bilayers. Monounsaturated fatty acids also occur naturally in chain lengths from about $\mathrm{C}_{14}$ to $\mathrm{C}_{24}$ but, although they are characterised by having a single unsaturated bond, the position of the ethylenic bond within the carbon chain can vary even within a specific chain length, so that there are considerably more species of monousaturated fatty acids than saturated fatty acids. Again, phosphoglycerides seldom have chain lengths other than $\mathrm{C}_{16}, \mathrm{C}_{18}$ and to a lesser extent $\mathrm{C}_{20}$. However, sphingolipids are commonly rich in nervonic acid, 24:1n-9. Nonetheless, the predominant monounsaturated fatty acids in most lipids are 18:1n-9 and 16:1n-7. However, abundant fatty acids in many fish triacylglycerols are 20:1n-9 and 22:1n-11 which are derived from the corresponding 20:1n-9 and 22:1n-11 fatty alcohols in zooplanktonic wax esters (Ackman, 1989).

Marine organisms, especially algae, can contain a plethora of PUFA of chain lengths $\mathrm{C}_{16}$ (with 2-4 ethylenic bonds), $\mathrm{C}_{18}$ (with 2-5 ethylenic bonds), $\mathrm{C}_{20}$ (with 2-5 ethylenic bonds) and $\mathrm{C}_{22}$ (with 2-6 ethylenic bonds) (Sargent et al., 1995c). These PUFA are generally of the n-3 series, although representatives of the n6 and, in the case of $C_{16}$ PUFA, the n-1, n-4 and n-7 series also occur (Ackman, 1989). However, in fish the main PUFA to be considered are 20:4n-6 (arachidonic acid, AA) and its metabolic precursor 18:2n-6 (linoleic acid, LA), together with 20:5n-3 and 22:6n-3 and their metabolic precursor 18:3n-3 ( $\alpha$-linolenic acid, LNA). Another term in common usage, often without proper definition, is HUFA, which, in this laboratory at least, we define as highly unsaturated fatty acids having carbon chain lengths of $\geq \mathrm{C}_{20}$ and with $\geq 3$ ethylenic bonds.

Triacylglycerols constitute a major class of neutral lipid and consist of three molecules of fatty acids esterified to the three alcohol groups of glycerol (Fig.2A). When esterified, these positions are termed $s n 1$, $s n 2$ (middle position) and $s n 3$ due to the asymmetry induced by the enzymatic esterification. A single fatty acid may be esterified to all three positions of the glycerol, e.g. as in trioleoylglycerol, or two different fatty acids may be esterified as in dioleoyl - monopalmitoyl glycerol, or three different fatty acids may be esterified as in oleoyl-linoleoyl-palmitoyl glycerol. In fish lipids, generally saturated and monounsaturated fatty acids are preferentially located in the $s n 1$ and $s n 3$ positions, whereas PUFA are preferentially located in the sn2 position. However, many exceptions exist to this general rule, e.g. tridocosahexaenoyl (tri 22:6n-3) glycerol can be a major component of the triacylglycerols in the eye lipids of some fish (e.g. Nicol et al., 1972).

Wax esters constitute another class of neutral lipid consisting of a single molecule of a fatty acid esterified to a single molecule of a fatty alcohol (Fig.2B). This lipid class is very abundant in marine zooplankton, particularly in calanoid copepods and in euphausiids (red feed and krill, respectively) which form major natural foods for many species of marine fish. Wax esters can also be present in considerable amounts in the body tissues and eggs of some fish species. The fatty acids of marine wax esters can be of a variety of chain lengths and can be saturated, monounsaturated or polyunsaturated. However, the fatty 
alcohols are generally saturated or monounsaturated and, in the case of high latitude marine zooplankton, the alcohol moieties can be very rich in 20:1n-9 and 22:1n-11 structures. Wax esters are converted to triacylglycerols during the process of digestion and absorption in the intestinal tissue of zooplanktonivorous fish. Thus, the large amounts of 20:1n-9 and 22:1n-11 fatty acids in the triacylglycerols of many fish oils from the northern hemisphere, i.e. sand eel, herring and capelin oils, are derived directly from the oxidation of the corresponding fatty alcohols ingested from zooplankton wax esters (Sargent and Henderson, 1995). These fatty acids are present in much lower percentages in fish oils from the southern hemisphere, most notably anchovy oils, which are correspondingly richer in n-3 PUFA, especially 20:5n-3 (Sargent and Henderson, 1995).

Phosphoglycerides are a major class of polar lipid characterised by a common backbone of phosphatidic acid, which is L-glycerol 3-phosphate containing two esterified fatty acids (Fig.2C). Saturated and monounsaturated fatty acids are preferentially esterified on position sn-1 of the L-glycerol 3-phosphate with PUFA preferentially esterified on position $s n-2$. However, as with triacylglycerols, there are many exceptions to this generalisation, i.e. the di-docosahexaenoyl phosphoglycerides that are abundant in the retina of fish, specifically in rod outer membrane segments (Bell and Tocher, 1989; Bell and Dick, 1991). Phosphatidic acid is esterified to the "bases" choline, ethanolamine, serine and inositol to form the major phosphoglycerides of animal including fish tissues, viz. phosphatidylcholine (PtdCho), phosphatidylethanolamine (PtdEtn), phosphatidylserine (PtdSer) and phosphatidylinositol (PtdIns) (Fig.3). Phosphoglycerides are the most common of the phospholipids, a term often mistakenly equated with phosphoglycerides. Phospholipid is a more general term comprising all lipids containing phosphorus including sphingomyelin.

Sphingolipids are a group of complex polar lipids that contain as their backbone the long chain amino alcohol sphingosine, or a related base. In sphingolipids, a long chain, generally saturated or monounsaturated fatty acid, e.g. 24:1n-9, is linked to the amino group of sphingosine to form a ceramide, and different polar head groups are attached to sphingosine's primary alcohol group. For example, sphingomyelin contains phosphocholine esterified to the alcohol group of sphingosine (Fig.4A). An important group of sphingolipids are the cerebrosides in which the alcohol group of the sphingosine is linked to one or more sugars including glucose and galactose (Fig.4B).

The most important simple lipid (i.e. a lipid not containing fatty acids) in all animals including fish is cholesterol (Fig.5). This is the most common of the tetracyclic hydrocarbon compounds, collectively called sterols, and can exist unesterified as an essential component of cell membranes or in a neutral lipid storage form esterified to a fatty acid.

\section{Digestion, Absorption and Transport}


As noted above, marine animals can contain very large levels of lipid in the form of oil. For example, many high latitude zooplankton can routinely contain two thirds or more of their dry body weight as oil, largely wax esters. Capelin (Mallotus villosus) can routinely contain $20 \%$ or more of their wet body weight as oil, largely triacylglycerols. It is self evident, therefore, that fish consuming such oil - rich prey, e.g. capelin consuming zooplankton, or cod or salmon consuming capelin, are capable of efficiently digesting and assimilating large quantities of lipid, and often of depositing large quantities of oil in their body tissues. In general, however, lipid digestion, absorption and transport in fish is similar to that in mammals (see Sargent et al., 1989). Nonetheless, the complexity of the intestinal tract and marked anatomical differences between different species of fish, including highly variable numbers of pyloric caeca and the presence or lack of a discrete pancreas, have made this a challenging area for metabolic and enzymic studies. However, there has been increasing interest in this area in recent years that has been reflected in some substantial advances (Koven et al., 1994a,b, 1997; Olsen and Ringoe, 1998; Olsen et al., 1998, 1999).

\subsection{Digestion}

Lipolytic activity in fish is generally greatest in the proximal part of the intestine and the pyloric caeca if present, but can extend into the lower parts of the intestine with the activity deceasing progressively. Exceptions do occur though, as lipolytic activity is higher in the distal part of the intestine in turbot (Scophthalmus maximus) and plaice (Pleuronectes platessa) (Koven et al., 1994a; Olsen and Ringo, 1997). This may be an adaptation to a short digestive tract with few pyloric caeca as in turbot, although plaice have numerous pyloric caeca. Low lipolytic activity has also been found in the stomach of several fishes but Olsen and coworkers have shown that stomach lipases do not contribute significantly to lipid digestion in Arctic charr (Salvelinus alpinus) and cod (Olsen and Ringo, 1997), and so the physiological significance of gastric lipolytic activity in fish is unclear.

The pancreas or hepatopancreas is generally assumed to be the major source of digestive lipase enzymes in fish as it is in mammals (Kapoor et al., 1975; Fange and Grove, 1979). However, digestive lipases may also be secreted by the intestinal mucosa as several studies have found high lipase activity in mucous layers or intestinal segments of many fish species, although these lipase activities may actually be of pancreatic origin, resulting from adsorption of the pancreatic enzyme into the intestinal mucosa (Fänge and Grove, 1979; Smith, 1989a). However, in African catfish (Clarius gariepinus) and grass carp (Ctenopharyngodon idella), lipase activity was found in intestinal segments even after 48 and 24 hours starvation, respectively (Ghosh, 1976; Das and Tripathi, 1991). Other evidence, including that of substrate specificities, supports the view that intestinal cells can actively secrete lipolytic enzymes (Borlongon, 1990; Uematsu et al., 1992; Koven et al., 1994a). The lipolytic activity found in stomach is unlikely to be of 
pancreatic origin, suggesting that this tissue is also a source of lipases, and a bacterial origin for some lipolytic activities in the digestive tract of fish cannot be excluded (Olsen and Ringo, 1997).

2.1.1. Triacylglycerol lipases. Triacylglycerol is a major lipid class in the diet of marine fish and is generally the predominant lipid class in the diet of freshwater fish. In mammalian gut, triacylglycerol hydrolysis is effected by two main lipases, the pancreatic lipase-colipase system (EC 3.1.1.3) and the less specific bile salt-activated lipase (EC 3.1.1.1).

Evidence points to the presence of a bile salt-activated lipase in teleost fish. Stimulation of lipolytic activity in intestinal extracts by bile salts has been shown in many marine and freshwater fish (Olsen and Ringo, 1997). Other studies that have shown lipolytic activity in the absence of bile salts were usually carried out on crude extracts that were undoubtedly contaminated by bile salts. Tocher and Sargent (1984a) found that lipase activity in rainbow trout (Oncorhynchus mykiss) pyloric caecal extracts largely disappeared upon removal of bile salts by dialysis, was restored by exogenously added bile salts, and porcine colipase was unable to prevent the inhibition of lipolytic activities by cholate. Similarly, lipolytic activity in Atlantic salmon (Salmo salar) pyloric caeca had high specific activity in the presence of bile salt, and also hydrolysed 4-nitrophenyl esters suggesting that the main triacylglycerol lipase in salmon is also a bile saltactivated lipase (Olsen and Ringo, 1997). Supporting this, a cDNA sequence showing 58\% identity with mammalian bile salt-activated lipase was cloned from Atlantic salmon pancreas (Gjellesvik et al., 1994). A lipase from turbot pancreatic tissue showed very similar catalytic properties to that of the salmon bile saltactivated lipase (Olsen and Ringo, 1997). Activity of the turbot enzyme in crude extracts towards triolein in the absence of exogenous bile salts was only $30 \%$ of maximum activity and no activity was found in purified extracts. In larval turbot the bile salt-dependent activity was present from hatching and its synthesis was stimulated by the ingestion of prey (Hoehne-Reitan et al., 2001a,b). Bile-salt activated lipase has also been purified and characterised from the hepatopancreas of red sea bream (Pagrus major) (Iijima et al., 1998). However, the best characterised bile salt-activated lipase is from cod. Studies had indicated that the lipolytic activity in cod intestinal fluid was stimulated by bile salts and subsequently a bile-salt activated lipase from cod pyloric caeca was purified and extensively characterised (Gjellesvik, 1991a,b; Gjellesvik et al., 1989,1992). The enzyme was reportedly very similar to human bile salt-dependent lipase with only minor differences in fatty acid specificity (Gjellesvik, 1991b).

In contrast, evidence for a pancreatric lipase-colipase system in fish is sparse. In rainbow trout, an enzyme similar to pancreatic lipase was described based on activation by porcine colipase and a crude trout colipase preparation (Leger et al., 1977,1979). However, unlike mammalian pancreatic lipase, the trout enzyme had relatively low specific activity and level of colipase activation, its optimum activity required bile salts and it could hydrolyse unsaturated fatty acids in the sn-2 position (Leger et al., 1977; Gjellesvik, 
1991a). Consequently, the presence of two lipolytic enzymes in trout was postulated by Leger (1985) with Tocher and Sargent (1984a) suggesting that one enzyme predominantly hydrolysed triacylglycerol and the other predominantly hydrolysed wax and steryl esters. Overall, the data suggest that rainbow trout possess at least one bile salt-activated lipase, but the presence of a pancreatic lipase-colipase cannot be excluded. In an earlier study, a lipase that did not require bile salts for activity was reported in top minnow (Triportheus $s p$.) and it was suggested that it may be a true pancreatic lipase (Patton et al., 1978). However, it was in an acetone extract from mesenteric fat although, based on its high activity, the authors ruled out misidentification of adipose tissue lipase. A lipase that hydrolysed triolein in the absence of bile salts was also purified from sardine (Sardinella longiceps) hepatopancreas but inhibition by bile salts and colipase stimulation were not studied (Mukundan et al., 1985).

Substrate and positional specificities vary between different species and studies. Early studies indicated that lipolytic activity in cod intestinal fluid may give complete hydrolysis of triacylglycerol to free fatty acids and glycerol (Lie and Lambertsen, 1985; Lie et al., 1987). However, the purified cod bile saltdependent lipase possessed 1,3-specificity towards triacylglycerol, but also hydrolysed cholesteryl ester (Gjellesvik, 1991b; Gjellesvik et al., 1992). The positional specificity of the salmon bile salt-dependent lipase is unknown, but in vivo feeding studies suggest that complete hydrolysis to free fatty acids and glycerol is possible (Sigurgisladottir et al., 1992). The lipase purified from sardine hepatopancreas was 1,3specific and had relatively high activity towards tributyrin as well as triolein (Mukundan et al., 1985). Two lipase activities were reported in crude extracts from turbot gut contents; a 1,3-specific activity producing mainly free fatty acid and monoacylglycerol in the fore-gut, whereas the hind gut contained a non-specific lipase producing mainly free fatty acid and glycerol (Koven et al., 1994a,b). A lipase from hepatopancreas of common carp (Cyprinus carpio) was purified tenfold but the triacylglycerol hydrolase activity, assayed without bile salts, could not be separated from wax ester hydrolase and esterase activities, suggesting that they may all be due to one enzyme protein (Kayama et al., 1979).

Although studies are difficult to compare due to the wide range of substrate preparations and experimental conditions used, overall the data suggest that a bile salt-activated lipase is the main lipolytic enzyme in teleost fish, whereas the existence of a pancreatic lipase-colipase system is less certain. Of course, other lipases may yet be discovered and characterised. This may partly explain why the enzymes purified from trout, cod and turbot have 1,3-specificity, whereas in crude extracts or in vivo studies these fish as well as species like Atlantic salmon, Arctic char, striped bass (Morone saxatilis), anchovy (Engraulis mordax), pink salmon (Oncorhynchus gorbuscha) and speckled char (Salvelinus fontinalis) appear to effect complete hydrolysis of triacylglycerols to free fatty acids (Olsen and Ringo, 1997). 
2.1.2. Phospholipases. Phospholipids, particularly phosphoglycerides, form a substantial part of the dietary lipid in fish but there are relatively few studies on the intestinal digestion of phosphoglycerides. It is presumed that the mechanisms in fish are generally similar to those in mammals. Thus, dietary phosphoglycerides are presumably digested by pancreatic or intestinal phospholipases resulting in the formation of 1-acyl lyso-glycerophospholipids and free fatty acids that are absorbed by the intestinal mucosal cells (Henderson and Tocher, 1987; Sargent et al., 1989). Phospholipase $\mathrm{A}_{2}$ activity in carp hepatopancreas was found to be distributed in all subcellular fractions, with the highest activity located in the $10,000 \mathrm{x}$ g supernatant (Mankura et al., 1986). The activity was dependent upon $\mathrm{Ca}^{2+}$ - and bile salt, consistent with a pancreatic enzyme, but had a conflicting acidic $\mathrm{pH}$ optimum of 5.0. Whether this phospholipase activity reflected an intestinal activity or an intracellular phospholipase was unclear. Phospholipase $\mathrm{A}_{2}$ activity was also shown in intestinal cells of red sea bream by immuno-histochemical staining, but it was unclear whether this enzyme was secreted into the lumen or membrane bound (Uematsu et al., 1992). In a later study, two distinct phospholipase $A_{2}$ isoforms were purified from red sea bream hepatopancreas and characterisation confirmed them as low molecular weight, $\mathrm{Ca}^{2+}$-dependent group I (secretory) forms (Ono and Iijima, 1998). In a study of whole striped bass larvae, phospholipase $\mathrm{A}_{2}$ activity was observed, but whether the activity was located in the intestine or body mass was difficult to ascertain (Ozkizilcik et al., 1996). However, digesta from turbot rectum was shown to hydrolyse phosphatidylcholine, although at slower rates than triacylglycerol and sterol esters (Koven et al., 1994a).

2.1.3. Other lipolytic activities. It is not clear if fish possess a specific wax ester hydrolase since no specific enzyme has been purified or characterised. For instance, wax ester hydrolase activity could not be separated from triacylglycerol hydrolase in carp hepatopancreas (Kayama et al., 1979). In addition, the substrate specificities of triacylglycerol lipases in fish suggest that this enzyme activity will hydrolyse wax esters, although at a much slower rate than triacylglycerols. The bile salt-activated lipase found in teleost fish may be more specific for hydrolysing wax esters than pancreatic lipase (Patton et al., 1975), as has been indicated more recently (Gjellesvik, 1991a,b; Gjellesvik et al., 1989,1992). Whatever the enzyme responsible, wax ester hydrolysis has been demonstrated in many species of fish and the presence of free fatty alcohols derived from wax ester in intestinal contents has also suggested wax ester hydrolysis in rainbow trout, herring (Clupea harengus) and gourami (Trichogaster cosby) (Rahn et al., 1973; Sargent et al., 1979). Wax ester hydrolysis in the digestive juice from cod showed no specificity with respect to fatty alcohol composition (Lie and Lambertsen, 1985), but PUFA from zooplankton wax esters were more extensively absorbed than 20:1n-9 and 22:1n-11 in herring, rainbow trout, spot goby (Chaparrudo 
flavescens) and scad (Trachurus trachurus), possibly suggesting some fatty acid specificity in wax ester hydrolysis (Sargent et al., 1979; Prahl et al., 1985).

Cholesteryl ester hydrolase has been reported in trout (Tocher and Sargent, 1984a) and turbot (Koven et al., 1994a), and fatty acid methyl esters appeared to be efficiently hydrolysed in gilthead sea bream (Sparus aurata) juveniles although the enzyme responsible was unclear (Ibeas et al., 2000). So-called "esterase" activity has been reported in gastrointestinal extracts from various marine and freshwater fish species (Olsen and Ringo, 1997). In general, esterases are usually regarded as enzymes hydrolysing water soluble carboxylic esters, while lipases act on water insoluble neutral esters, usually in the absence of bile salts. The precise role(s) of esterase activities in lipid digestion is unclear, but the current understanding of both mammalian and fish bile salt-activated lipase suggests that it could be defined both as a lipase and esterase, depending on substrate used. For instance, the bile salt-activated lipase in cod hydrolysed triacylglycerols, 4-nitrophenyl esters and cholesterol esters (Gjellesvik et al., 1989,1992).

\subsection{Absorption.}

Based on the results of studies summarised above, the main products of lipid digestion in fish are free fatty acids produced by lipolytic action on all major lipid classes. In addition, there will be partial acyl glycerols, predominantly 2-monoacylglycerols, but perhaps also diacylglycerols and glycerol from the digestion of triacylglyerols, 1-acyl-lyso-glycerophospholipids from the digestion of phosphoglycerides, and cholesterol and long chain alcohols from the hydrolysis of cholesteryl and wax esters, respectively.

The absorption of the products of lipid digestion has not been extensively studied in fish but the basic physical processes including bile-enhanced emulsification and transport of the hydrolysed products are assumed to be generally similar to that in mammals. Thus, the main hydrolytic products are solubilised or emulsified in bile salt micelles, followed by diffusion to the intestinal mucosa where uptake into the enterocytes occurs, probably mainly by passive diffusion. Absorption generally proceeds at a much slower rate in fish compared to mammals, as a result of lower body temperature, which strongly influences the rate of nutrient digestibility (Kapoor et al., 1975). Recent studies on absorption of free fatty acids using isolated enterocytes from rainbow trout showed that the uptake of 20:4n-6, 20:5n-3 and 22:6n-3 was lower than that of 16:0, 18:1n-9, 18:2n-6 and 18:3n-3, with most of the fatty acids recovered in triacylglycerols, although the recovery of HUFA and 16:0 in phosphoglycerides was higher than that of the other fatty acids (Perez et al., 1999). As in mammals, lipid absorption in fish occurs predominantly in the proximal part of the intestine coinciding with the highest lipolytic activity. However, lipid can be absorbed along the entire length of the intestine, although, as with digestive function, in diminishing amounts.

In the intestinal mucosal cells, the predominant fate of the absorbed free fatty acids is re-esterification with glycerol, partial acyl glycerols and lysophospholipids to reform triacylglycerols and phosphoglycerides 
(Sargent et al., 1989). Sterol and wax esters may also partly reform although free cholesterol is easily transported from the mucosal cells and the vast majority of fatty alcohols are oxidised to the corresponding fatty acid in the epithelial cells (Bauermeister and Sargent, 1979). The majority of phosphoglycerides are digested and absorbed via 1-acyl lyso-phosphoglyceride intermediates with re-esterification before export from the intestinal cells. However, mechanisms may exist in fish intestinal mucosa for the synthesis of phosphoglycerides from moieties more degraded than lyso-phosphoglycerides, as studies showed that phosphoglyceride biosynthesis via PtdA and diacylglycerol intermediates also occurred in carp intestinal homogenates (Iijima et al., 1983).

\subsection{Transport.}

The following section summarizes the main aspects of lipid and fatty acid transport in fish, including lipoprotein structure and function. The reader is directed to several earlier, and more specific, reviews that collectively cover extracellular lipid transport in fish comprehensively and where the early literature can be found if required (Fremont and Leger, 1981; Leger, 1985; Sheridan, 1988; Babin and Vernier, 1989).

2.3.1. Extracellular. Lipids are exported from the intestine in the form of lipoproteins. The reesterification reactions occur primarily in the endoplasmic reticulum leading to the production of chylomicron - like and very low density lipoprotein (VLDL) - like particles in the lumen, as has been directly observed in freshwater species. The lipid load and degree of unsaturation affects lipoprotein production, with high dietary lipid and PUFA leading to the production of larger chylomicrons, whereas high dietary saturated fatty acids result in the production of smaller VLDL particles. In mammals, intestinal lipoproteins are transported from the intestine almost exclusively via the lymphatic system. Similarly, in fish the majority of the intestinal lipoproteins are transported via the lymphatic system before appearing in the circulatory system and being delivered to the liver (Sheridan et al., 1985). However, a portion of intestinal lipoproteins may be transported directly to the liver via the portal system.

Teleosts have a major plasma protein with the approximate size, solubility and electrophoretic mobility of mammalian serum albumin (De Smet, 1978). This protein presumably functions to transport free fatty acids in the blood from adipose tissue depots to peripheral tissues under appropriate physiological conditions, as it does in mammals (Sheridan, 1988). However, analysis of an albumin-like protein from carp plasma showed that it contained $22 \%$ lipid of which $15 \%$ was phospholipid, predominantly PtdCho (Nakagawa et al., 1976). This protein accounted for 50\% of total plasma lipid in carp, with the remainder being transported via the lipoproteins (Nakagawa, 1979). Fish plasma contains a similar range of lipoproteins to mammalian plasma, namely chylomicrons, VLDL, low density lipoproteins (LDL) and high density lipoproteins (HDL), the latter formed, in mammals at least, by the combined actions of lipoprotein 
lipase (LPL) and lecithin:cholesterol acyl transferase (LCAT) on LDL (Sheridan, 1988; Babin and Vernier, 1989). The lipoproteins vary in size, structure, protein:lipid ratios and in the relative proportions of the different lipid classes, leading to the density differences which are used to separate and classify the different types. Although there are differences in detail, the general size, structure and composition of the plasma lipoproteins are comparable throughout the vertebrates, including fish. Furthermore, the lipid composition of lipoproteins varies in detail among fish species but is grossly similar to that for mammals. Therefore, the proportion of total lipids and core lipids, the major neutral lipids triacylglycerol and steryl esters, decreases from chylomicrons through VLDL to LDL and HDL, whereas the proportion of surface components such as phospholipids, free cholesterol and protein, increases (Babin and Vernier, 1989). Thus, triacylglycerols constitute about $85 \%, 52 \%, 22 \%$ and $11 \%$ of chylomicrons, VLDL, LDL and HDL, respectively, in trout, whereas phospholipids account for $8 \%, 19 \%, 27 \%$ and $32 \%$ of the total weight of those lipoproteins (Babin and Vernier 1989). Generally, similar compositions were found in serum VLDL, LDL and HDL from Pacific sardine (Sardinops caerulea), HDL from pink salmon and chum salmon (Oncorhynchus keta), and serum lipoproteins from red sea bream and sea bass (Dicentrarchus labrax) (Ando and Hatano, 1988; Iijima et al., 1995; Santulli et al., 1997).

Chylomicrons are produced exclusively in the intestine but, although some VLDL can also be synthesized in the gut, the majority of VLDL in the plasma are synthesized in the liver. The major enzymes of lipoprotein metabolism and remodelling, including lipoprotein lipase (LPL) and hepatic lipase have been found in fish, including both marine and freshwater species. LCAT, which catalyses the esterification of cholesterol using fatty acid from PtdCho, has been demonstrated in the plasma of various freshwater species. Lecithin:alcohol acyltransferase, which catalyzes the transfer of an acyl group from PtdCho to long-chain alcohols has been shown in carp plasma and may be, at least partially, responsible for the relatively high level of circulating wax ester reported in that species (Mankura and Kayama, 1985; Mankura et al., 1987). In addition, intermediate density lipoprotein (IDL), a fraction with a density between that of VLDL and LDL, was fractionated from trout serum (Babin, 1987). The presence of the whole spectrum of lipoproteins, including IDL, and the above enzymes suggests that lipoprotein remodelling processes, as characterized in mammals, also occur in fish. Thus, triacylglycerols in chylomicrons and VLDL are hydrolyzed by LPL and hepatic lipase at peripheral tissue sites with the hydrolysis products being absorbed. Excess surface constituents "bud off" as nascent HDL particles (similar to $\mathrm{HDL}_{3}$ ), which can also be secreted by the liver. Nascent HDL or $\mathrm{HDL}_{3}$ can take up free cholesterol from peripheral tissues which is then esterified by the action of LCAT resulting in the production of mature HDL $\left(\mathrm{HDL}_{2}\right)$. Remnants of chylomicrons and VLDL hydrolysis can be taken up by the liver, but further action by LPL and hepatic lipase leads to the formation of LDL via IDL. 
As in mammals, the relative proportions of the plasma lipoproteins in fish can vary from species to species, but is a constant characteristic of each species depending upon dietary status. Early studies in trout confirmed that HDL is the predominant class followed by LDL and then VLDL. HDL was also the main lipoprotein class in carp (Amthauer et al., 1989), sea bass (Santulli et al., 1989), pink and chum salmon (Nakamura et al., 1985) and channel catfish (Ictalurus punctatus) (McKay et al., 1985). The relative amounts of VLDL, LDL and VLDL vary with age, nutrition and sexual cycle. For instance, the proportions of the different lipoproteins were altered by starvation in carp, with VLDL being absent in starved fish, although the lipid compositions of LDL and HDL were not greatly altered (Iijima et al., 1989). Surprisingly, VLDL disappeared rapidly after feeding in sea bass (Santulli et al., 1997).

As in most vertebrates, PtdCho is generally the predominant phosphoglyceride class in fish lipoproteins although there are few data on the precise phosphoglyceride class compositions of fish plasma lipoproteins or the metabolism of individual phosphoglycerides. With respect to fatty acid compositions, fish lipoproteins generally contain higher levels of PUFA, particularly n-3 PUFA, than the corresponding mammalian lipoproteins. In trout, the phosphoglyceride fractions from all lipoproteins were particularly rich in 16:0 and 22:6n-3, and total n-3 PUFA was higher and total n-6 PUFA lower in phosphoglycerides in comparison with triacylglycerols. However, the levels of n-3 PUFA in the cholesteryl ester fractions of LDL and HDL exceeded those of the phosphoglycerides. The exact fatty acid composition of fish plasma lipoproteins is affected by diet, both acutely, particularly with chylomicrons and VLDL after a meal, and chronically as seen with essential fatty acid deficiency.

The apoprotein compositions of fish lipoproteins are similar to mammalian lipoproteins with the major apoproteins being apoprotein A (I and II) in HDL, apo B in LDL and mixtures of apos B, C, and E in VLDL, and $\mathrm{A}, \mathrm{B}$ and $\mathrm{C}$ in chylomicrons. Although studies are few in fish, it is likely that the apoproteins have the same metabolic functions including receptor binding (apos B and E) and enzyme activation (AI and LCAT; CII and LPL) as in mammalian systems. Consistent with this, in trout adipose tissue LPL was activated by the apoprotein fraction of trout HDL (mainly AI and C) (Fremont et al., 1987). Trout apo CII has been cloned and found to be a functional activator of LPL, although it was structurally quite different from mammalian apo CII, possibly reflecting adaptation to function at lower temperatures (Shen et al., 2000). Similarly, a gene has been cloned from zebrafish (Danio rerio) which, upon analysis, has been found to be homologous to mammalian apo E, the first report of an apo E from a non-mammalian species (Durliat et al., 2000). Apo E expression correlated with endogenous lipid nutrition and lipoprotein synthesis during development of turbot (Poupard et al., 2000).

There are few studies on the tissue uptake of intact plasma lipoproteins in fish. However, by analogy with the system characterized in mammals, specific lipoproteins can probably be taken up into tissues by two or three main mechanisms. Quantitatively, the most important pathway is probably receptor-mediated 
endocytosis via B/E and E receptors. These are important pathways for the tissue uptake of LDL (apo B), VLDL and chylomicron-remnants (apo B and E) and HDL (apo E, especially in $\mathrm{HDL}_{1}$, an apo E-rich variant). These receptors are found in various tissues including liver and, as in mammals, the precise tissue distribution varies between species. In addition, probably all the lipoproteins, but particularly LDL and HDL, can be taken up by tissues via non-specific pinocytosis. For instance, in liver approximately $30 \%$ of LDL uptake is via a non-receptor-mediated pathway. Finally, it may be that surface components of VLDL and chylomicrons, including phospholipids and cholesterol, may be taken up or exchanged via direct interaction with the endothelial cell membranes in the tissues.

Another lipoprotein class in fish plasma is vitellogenin which is only found in mature oviparous females or estrogen-injected fish (see Wallace, 1985). Therefore, the assay of plasma vitellogenin level is useful in determining sexual maturity in female fish through blood sampling alone (Susca et al., 2001). Vitellogenin has a density higher than HDL generally containing about $80 \%$ protein and $20 \%$ lipid, and has also been termed very high density lipoprotein I (VHDL I). The cDNA of the vitellogenin protein has been cloned from several species of fish including fathead minnow (Pimephales promelas) (Korte et al., 2000), tilapia (Oreochromis aureus) (Lim et al., 2001) and haddock (Melanogrammus aeglefinus) (Reith et al., 2001). The lipid is predominantly phospholipid (about $65-70 \%$ of total lipid) and is rich in n-3 PUFA, particularly 22:6n-3 which accounts for $20 \%$ of total fatty acids in trout vitellogenin (Leger et al., 1981). Vitellogenin is synthesized in the liver and is transported to the ovary during the first stage of oogenesis termed vitellogenesis (Wallace, 1985). Vitellogenin is taken up intact by receptor-mediated micropinocytosis into the developing oocytes where it is cleaved into phosvitin and lipovitellin, phosphate- and lipid-rich proteins, respectively (Selman and Wallace, 1982). Trout egg lipovitellin is composed of 77\% protein and $23 \%$ lipid with a lipid class composition similar to HDL, whereas cod roe lipovitellin had a higher lipid content at over $40 \%$, with $70 \%$ of the lipid being phosphoglycerides (Tocher, 1985). Of the total phosphoglycerides in cod lipovitellin, 67\% was PtdCho and 22\% was PtdEth with 4\% each of PtdSer and PtdIns. During the early stages of vitellogenesis, VLDL in the plasma may also be increased in response to estrogen (Riazi and Fremont, 1988), and may also be taken up into the developing oocytes by receptormediated endocytosis (Wallace, 1985), at least in eggs with high triacylglycerol contents reflected in the presence of lipid droplets. Winter flounder (Pleuronectes americanus) contains a further high density lipoprotein (VHDL II), originally called Pk A (So and Idler, 1987), that is taken up in vivo by the ovary of vitellogenic females (Nagler and Idler, 1990).

2.3.2. Intracellular. The intracellular transport of free fatty acids in mammals is facilitated by specific low molecular weight and highly conserved cytoplasmic proteins that bind both long-chain fatty acids and 
other hydrophobic ligands. These fatty acid binding proteins (FABPs) are tissue specific and those from liver, intestine, adipose tissue, brain and heart, have been extensively characterised in mammals (Veerkamp and Maatman, 1995). Several FABPs have been described from fish tissues including elasmobranch livers (Bass et al., 1991; Baba et al., 1999; Cordoba et al., 1999). The FABP purified from the liver of the catfish (Rhamdia sapo) was more closely related to the chicken liver FABP than the FABPs of elasmobranchs or mammals (Dipietro et al., 1996). Intracellular FABPs were studied in various species of Antarctic fishes (Londraville and Sidell, 1995) and two distinct types were isolated from heart tissue, one with similarity to mammalian heart-type and the other similar to mammalian adipose tissue-type (Vayada et al., 1998). A muscle FABP with a molecular mass of 14,800 Da that binds fatty acids with 1:1 stoichiometry, and whose concentration is increased by cold acclimation, was isolated from striped bass (Londraville and Sidell, 1996). Muscle FABP has also been identified and characterised in Atlantic salmon (Torstensen, 2000). Recently, the molecular cloning and characterisation of cDNAs for the FABPs from trout heart and zebrafish intestine, liver and brain have been reported (Ando et al., 1998; Andre et al., 2000; Denovan-Wright et al., 2000a,b). The deduced protein sequence for the trout heart FABP was $75 \%$ identical to that of rat heart FABP (Ando et al., 1998). The zebrafish intestine FABP was strongly expressed in the anterior intestine of larvae and expression correlated with the intracellular storage of lipid droplets in the enterocyte and synthesis of VLDL particles (Andre et al., 2000). The zebrafish liver FABP was similar to the FABPs of catfish and chicken liver whereas the zebrafish brain was similar to the brain FABPs from other species (Denovan-Wright et al., 2000a,b). These findings support the general contention that intracellular transport of fatty acids in fish is essentially the same as that in higher vertebrates.

\section{Biosynthesis and Catabolism}

\subsection{Lipogenesis.}

Lipogenesis is the term used to describe the biosynthetic reactions for the formation of new endogenous lipid. The ultimate carbon source for the biosynthesis of new lipids is acetyl-CoA formed in mitochondria from the oxidative decarboxylation of pyruvate (carbohydrate source) or the oxidative degradation of some amino acids (protein source). The key pathway in lipogenesis is catalysed by the cytosolic fatty acid synthetase (FAS) multienzyme complex which occurs and has been characterised in fish (Sargent et al., 1989). The main products of FAS are the saturated fatty acids 16:0 (palmitic acid) and 18:0 (stearic acid)

which can be biosynthesised de novo by all known organisms, including fish (Sargent et al., 1989). Eight two-carbon acetyl units are required for the biosynthesis of 16:0 with one acetyl-CoA unit serving as a primer and the further 7 acetyl units being carboxylated by acetyl-CoA carboxylase to malonyl-CoA before being combined via FAS in a series of sequential condensation steps requiring NADPH (Henderson and 
Sargent, 1985). Other key pathways in lipogenesis are those that generate the reducing elements, NADPH, including enzymes of the pentose phosphate pathway and malate dehydrogenase, with the main NADPHgenerating enzyme in fish possibly being glucose-6-phosphate dehydrogenase (Dias et al., 1999).

The foregoing generalisation notwithstanding, it is the case that fish that naturally consume diets rich in lipid, e.g. capelin and their predators, and nearly all top predator marine fish, are not likely to biosynthesise fatty acids de novo to any significant extent, if they do so at all. Rather, the large lipid depots these fish frequently accumulate will be derived largely if not exclusively from dietary lipid. Indeed, it might be hypothesised that virtually all of the lipid in marine fish originates from the phytoplankton and zooplankton at the base of the marine food web. This is not to say, however, that marine fish are not capable of modifying their dietary lipid, e.g. by chain elongating or chain shortening their dietary fatty acids. Perhaps consistent with this view, it was recently shown that hepatic enzymes of lipogenesis including glucose-6-phosphate dehydrogenase, malic enzyme and acetyl-CoA carboxylase, showed surprisingly little response to increasing dietary lipid levels in turbot (Regost et al., 2001). This may suggest that these enzymes may not have an important role in lipogenesis in turbot or simply that lipogenesis is not a significant pathway in this species at all. The situation with freshwater fish may well be different since lipid - rich prey are much less common in fresh water than in the sea. This is reflected in the substantial lipogenic activity of, e.g. rainbow trout as shown by the high propensity of this species to accumulate visceral fat when fed diets rich in glucose.

Although adipose tissue has some lipogenic capability in rainbow trout, liver is quantitatively the principal site of lipogenesis in the species (Henderson and Sargent, 1985). Furthermore, in terms of carbon sources, the rate of fatty acid synthesis from alanine was considerably greater than that from glucose in trout liver suggesting that amino acids are the preferred carbon source for lipogenesis in this species, presumably a reflection of the high protein content and generally low carbohydrate content of the natural prey of fish in general, both in freshwater and in the sea. The rate of lipogenesis is regulated by a number of dietary/nutritional factors, especially in freshwater fish. In particular, dietary lipid suppresses lipogenesis. Thus, increasing dietary lipid to protein ratios depressed lipogenesis in common carp (Shimeno et al., 1995) and high lipid diets decreased the activities of the lipogenic enzymes in juvenile yellowtail (Seriola quinqueradiata) (Shimeno et al., 1996). Conversely, increasing dietary carbohydrate to lipid ratios increased lipogenesis from glucose in rainbow trout (Brauge et al., 1995). Related to high carbohydrate diets, insulin was reported to be an important up-regulator of lipogenesis in trout liver (Cowley and Sheridan, 1991,1993). Dietary n-3HUFA themselves reduced lipogenesis and amino acid catabolism in the hepatopancreas of carp (Shikata and Shimeno, 1994) and FAS activity was reduced by PUFA including 18:3n-3 and especially, 20:5n-3 and 22:6n-3 in rainbow trout hepatocytes (Alvarez et al., 2000). High fat diets decreased the $V_{\max }$, specific activity and catalytic efficiency of hepatic glucose-6-phosphate dehydrogenase in rainbow trout (Sanchez-Muros et al., 1996). 


\subsection{Unsaturated Fatty Acid Biosynthesis}

3.2.1 Monounsaturated fatty acids. In addition to saturated fatty acids, all organisms including fish are capable of desaturating 16:0 and 18:0 to yield, respectively, 16:1 ${ }^{9}=16: 1 \mathrm{n}-7$ (palmitoleic acid) and 18:1 ${ }^{9}$ $=18: 1 \mathrm{n}-9$ (oleic acid). Desaturation of fatty acids in fish, like all animals, takes place in the endoplasmic reticulum of cells of particular tissues via an aerobic process utilising CoA-linked substrates and requiring $\mathrm{NAD}(\mathrm{P}) \mathrm{H}$ and $\mathrm{O}_{2}$, catalysed by multicomponent systems comprising $\mathrm{NAD}(\mathrm{P}) \mathrm{H}$-cytochrome $\mathrm{b}_{5}$ reductase, cytochrome $b_{5}$ and terminal desaturase enzymes (Brenner, 1974). This reaction is of particular physiological importance in that the monounsaturated products formed (16:1n-7 and 18:1n-9) have markedly lower melting points (phase transition temperatures) than their saturated precursors (16:0 and 18:0). Hence $\Delta 9$ fatty acid desaturase provides a means of regulating the viscosity of cell membranes by altering the phase transition temperatures of the fatty acids in their constituent phosphoglycerides. The stearoyl $\Delta 9$ fatty acid desaturase (SCD) activity has been particularly well characterised and its gene cloned in several animal species including common carp (Tiku et al., 1996) and grass carp (Chang et al., 2001). Tiku et al. (1996) screened a carp hepatic cDNA library with a rat $\Delta 9$ SCD probe yielding several putative positive clones which were tested against cold-induced carp liver RNA samples using Northern blot analysis, and a $2.7 \mathrm{~kb}$ transcript was detected. One of the clones had an open reading frame which encoded a 292 residue polypeptide with calculated molecular weight of $33.6 \mathrm{kDa}$. The deduced amino acid sequence was homologous to those of rat liver, mouse liver, tick and yeast $\Delta 9$ desaturases $(55 \%, 53 \%, 47 \%$ and $20 \%$, respectively). Additionally, characteristic histidine residues were also conserved and the hydrophobicity profile of the carp polypeptide was very similar to that of the rat. The cold-induced expression of the carp $\Delta 9$ gene has been further studied, indicating an important role for this enzyme in cold acclimation in fish (Trueman et al., 2000). A further publication from the same group described an isothermal induction of the $\Delta 9$ desaturase specific activity in four day-old carp hepatocyte cultures at $30^{\circ} \mathrm{C}$ (Macartney et al., 1996). The induction was linked to increased transcript levels although it was not determined whether this was due to increased transcript stability or increased transcription. Addition of $5 \%$ fetal calf serum to the culture medium was associated with the induction but addition of oleate did not appear to produce the repression of transcription (Macartney et al., 1996).

Less well studied in fish is the extent to which 16:1n-7 and especially 18:1n-9 are chain elongated to higher homologues, including $18: 1 n-7,20: 1 n-9,22: 1 n-9$ and $24: 1 n-9$, by the conventional microsomal elongation pathway that occurs in higher terrestrial mammals (see section 3.2.2). It is known, however, that the 22:1n-11 fatty acid, which can be abundant in fish triacylglycerols, is derived from the corresponding fatty alcohol in the wax esters of zooplankton, and the same holds for the 20:1n-9 fatty acid in fish 
triacylglycerols. The 22:1n-11 alcohol in zooplankton is considered to be derived from the corresponding fatty acid biosynthesised in zooplankton by a $\Delta 9$ fatty acid desaturase acting on 20:0 to generate 20:1 $\Delta 9=$ 20:1n-11, which is then chain elongated to 22:1n-11 (see Sargent and Henderson, 1995). Irrespective of the special origin of 22:1n-11 and 20:1n-9 fatty acids in fish oils, the extent to which the pathways of saturated and monounsaturated fatty acid biosyntheses, including pathways of further elongation of these fatty acids, occur in fish is unclear. As noted above, many species of fish, including most marine species, are very well supplied with fatty acids in their natural diets and, under these conditions, endogenous de novo biosynthesis of fatty acids including their chain elongations is likely to be repressed. It is eminently possible, therefore, that all of the monounsaturated fatty acids in marine fish, including the 24:1n-9 in their sphingolipids, are derived preformed from their diet.

3.2.2 Polyunsaturated fatty acids. All vertebrates, including fish, lack $\Delta 12$ and $\Delta 15(\omega 3)$ desaturases and so cannot form 18:2n-6 and 18:3n-3 from 18:1n-9. Therefore, 18:2n-6 and 18:3n-3 are essential fatty acids in the diets of vertebrates. These dietary essential fatty acids can be further desaturated and elongated to form the physiologically essential $C_{20}$ and $C_{22}$ PUFA, 20:4n-6, 20:5n-3 and 22:6n-3 (Fig.6). The degree to which an animal can perform these conversions is dependent upon the relative activities of fatty acid elongases and desaturases, such as $\Delta 6$ and $\Delta 5$, in their tissues, and these activities in turn are dependent on the extent to which the species can or cannot readily obtain the end product $20: 4 n-6,20: 5 n-3$ and 22:6n-3 fatty acids preformed from their natural diets. For instance, an extreme carnivore such as the cat, which can obtain abundant preformed 20:4n-6, 20:5n-3 and 22:6n-3 from its natural prey, appears to lack, or express very low $\Delta 6$ and, possibly, $\Delta 5$ desaturases (Rivers et al., 1975). The tissues of both freshwater and marine fish are generally very rich in $\mathrm{C}_{20}$ and $\mathrm{C}_{22}$ fatty acids, especially 20:5n-3 and 22:6n-3, and so the origins of these fatty acids are of particular interest. It is now established that the pathway biosynthesising 20:5n-3 and 22:6n-3 from 18:3n-3 is present in rainbow trout, and probably in other species of freshwater fish. The pathway is complex but is now reasonably well understood and appears to be the same, at least qualitatively, in rainbow trout (Buzzi et al., 1996, 1997) as in rats (Voss et al., 1991) (Fig. 6). The major features of the pathway in rainbow trout and rats are summarised below:-

With one exception the reactions occur in the microsomal fraction of the liver and the same enzymes act on the n-3 and the n- 6 fatty acid series. However, the affinity of the enzymes, especially the desaturases, is higher for the $n-3$ than for the n-6 series.

The insertion of the last, $\Delta 4$, ethylenic bond in 22:6n-3 does not occur through direct $\Delta 4$ desaturation of its immediate precursor 22:5n-3. Rather, 22:5n-3 is chain elongated to $24: 5 n-3$ which is then converted by 
$\Delta 6$ desaturation to $24: 6 n-3$ which is then converted, by a chain shortening reaction in the peroxisomes, to 22:6n-3.

Whereas 22:6n-3 is the main end product of further desaturation and elongation of $18: 3 n-3,20: 4 n-6$ is the main end product of desaturation and elongation of 18:2n-6. However, 20:4n-6 can be further desaturated and elongated to $22: 5 n-6$ to some extent, with insertion of the last $\Delta 4$ ethylenic in 22:5n- 6 being achieved in the same manner as for 22:6n-3. The fact that fish and animals in general accumulate 22:6n-3 rather than $22: 5 n-6$ is possibly simply a reflection of the specificities of the enzymes involved. As described above, the activities of the enzymes in the desaturation pathway are higher for the equivalent n-3 fatty acid compared to the n-6 substrate and also the relative activity of each step of the pathway decreases as the chain length increases. In combination these effects can explain why 22:6n-3 can accumulate whereas $22: 5 n-6$ is produced to a much smaller extent.

The $\Delta 5$ fatty acid desaturation occurs at only one-step in the pathway, involving $20: 3 n-6$ or $20: 4 n-3$, whereas $\Delta 6$ fatty acid desaturation occurs at two steps, first involving 18:2n-6 or 18:3n-3 and second involving $24: 4 n-6$ or $24: 5 n-3$. It is not known whether the same $\Delta 6$ fatty acid desaturase catalyses each of these steps or whether different $\Delta 6$ desaturases (isoenzymes) are involved for the $\mathrm{C}_{18}$ and $\mathrm{C}_{24}$ PUFA.

While all the steps in the pathway from 18:3n-3 to 22:6n-3 in Fig. 6 have so far been established for fish only in rainbow trout hepatocytes (Buzzi et al., 1996, 1997), there is accumulating evidence that the same pathway occurs in hepatocytes from Atlantic salmon (Tocher et al., 1997), Arctic charr, brown trout (Salmo trutta) (Tocher et al., 2001a), zebrafish (Tocher et al., 2001b), and carp cells in culture (Tocher and Dick, 1999). There is also an extensive body of evidence based on direct feeding studies as well on the conversion of radioisotopes administered in vivo that the conversion of $18: 3 n-3$ to $20: 5 n-3$ and thence to 22:6n-3 occurs in many freshwater species of fish (see Sargent et al., 1989, 1995a, 2002). Equally there is a large body of evidence that the conversion of $18: 3 n-3$ to $20: 5 n-3$ and $22: 6 n-3$ occurs poorly if at all in those species of marine fish so far studied (see Sargent et al., 1989, 1995a, 2002). This difference is fundamental to determining the dietary essential fatty acid requirements of fish. It reflects the fact that $20: 5 n-3$ and 22:6n-3 are very abundant in the marine environment, originating mainly in diatoms and flagellates, respectively, at the base of the food web whence they are transmitted intact via zooplankton to fish. Marine fish, therefore, have a luxus of 20:5n-3 and 22:6n-3 in their natural diets. In contrast, the natural prey of many freshwaster fish, particularly their invertebrate prey, is not rich in 22:6n-3, being rich instead in 18:2n$6,18: 3 n-3$ and to a lesser extent 20:5n-3. Thus, although freshwater fish originally evolved in the ocean they returned to the terrestrial biosphere (freshwater) where conversion of $18: 3 n-3$ and $20: 5 n-3$ to $22: 6 n-3$ is necessary. Marine fish remained in an environment where such conversion is not necessary. However, recent evidence with marine fish shows that their situation is more complex than appears at first sight, 
particularly in terms of their expressing some of the enzyme activities necessary to convert $\mathrm{C}_{18}$ PUFA precursors to $\mathrm{C}_{22}$ PUFA products.

Early nutritional evidence suggested that 18:3n-3 and/or 18:2n-6 could satisfy the essential fatty acid requirements of freshwater fish, whereas the n-3 HUFA, i.e. 20:5n-3 and 22:6n-3, were required to satisfy the essential fatty acid requirements of marine fish (Yone, 1978; Watanabe, 1982; Kanazawa, 1985). Dietary conversion studies performed in turbot using radioactive substrates in vivo strongly suggested that this marine species was unable to produce 20:5n-3 and 20:4n-6 from 18:3n-3 and 18:2n-6 respectively (Owen et al., 1975; Cowey et al., 1976). However, these in vivo experiments were unable to locate precisely where and how the deficiency in the desaturation/elongation pathway occurred.

Cultured fish cell lines have been intensively studied to elucidate the problem (Tocher et al., 1989; Tocher et al., 1998). Early comparative studies with cultured cell lines of turbot (TF), Atlantic salmon (AS) and rainbow trout (RTG-2) established that the limited ability of turbot to convert $\mathrm{C}_{18}$ to $\mathrm{C}_{20}$ PUFA was due either to limited activities of the $\mathrm{C}_{18}$ to $\mathrm{C}_{20}$ fatty acid elongase, or the $\Delta 5$ fatty acid desaturase converting either 20:4n-3 to 20:5n-3 or 20:3n-6 to 20:4n-6 (Tocher et al., 1989; Tocher and Sargent, 1990). More recently, the availability of specific substrates such as $\left[\mathrm{U}-{ }^{14} \mathrm{C}\right] 18: 4 n-3$, (d5)18:4n-3, [U- $\left.{ }^{14} \mathrm{C}\right] 20: 4 n-3$ and (d5)20:4n-3 has further illuminated the problem. Thus, there is now compelling evidence that the turbot cell line has low $\mathrm{C}_{18}$ to $\mathrm{C}_{20}$ fatty acid elongating activity, whereas their $\Delta 5$ fatty acid desaturase activity is higher than that of the Atlantic salmon cell line (Ghioni et al., 1999). In contrast, an established cell line from gilthead sea bream had active $C_{18}$ to $C_{20}$ and $C_{20}$ to $C_{22}$ fatty acid elongase activities, but had very low $\Delta 5$ fatty acid desaturase activity (Tocher and Ghioni, 1999), as had earlier been indicated from in vivo studies (Mourente and Tocher, 1994).

These findings require to be confirmed in vivo in the species in question because there is no certainty that enzymes in the PUFA elongation/desaturation pathway continue to be expressed in cultured cells exactly as they are in vivo. Recent advances in the use of stable isotope techniques, as used for determining the rate of 22:6n-3 biosynthesis from deuterated (d5) 18:3n-3 in rainbow trout in vivo will expedite this (Bell et al., 2001). Irrespective, the results establish that both of the marine species studied have at least some activity for both the $\mathrm{C}_{18}$ to $\mathrm{C}_{20}$ fatty acid elongase and the $\Delta 5$ desaturase. This is consistent with the genes determining both enzymes being present in both species. Clearly, however, the expression of the genes differs in cultured cells from the different species. Thus, the $\Delta 5$ fatty acid desaturase gene but not the $\mathrm{C}_{18}-\mathrm{C}_{20}$ elongase gene is well expressed in turbot cells. In contrast, the $C_{18}-C_{20}$ and $C_{20}-C_{22}$ elongase gene(s) but not the $\Delta 5$ desaturase gene is well expressed in sea bream cells. Thus, it can be deduced that the apparent inability of marine fish to convert $18: 3 n-3$ to $20: 5 n-3$ and $22: 6 n-3$ is due not to the complete absence of the required genes in a particular species, but to one or more of the required genes not being sufficiently well expressed. The problem, therefore, may be how to switch on the recalcitrant genes rather than to introduce 
them by genetic engineering. In this context it is intriguing to note that all the marine species studied so far, whether in vivo or using cultured cells, have an active $\Delta 6$ fatty acid desaturase. The function of this enzyme in species that do not readily convert $18: 3 n-3$ to $20: 5 n-3$ and thence to $22: 6 n-3$ is not known.

Until recently and although the biochemical pathways involved in PUFA synthesis were described, little was known of the genes and enzymes involved and of the factors affecting their expression and function(s) respectively. However, significant progress has been made recently in characterising the desaturases and elongases involved in PUFA synthesis (Tocher et al., 1998). Full length cDNAs for $\Delta 6$ fatty acid desaturases have been isolated from the nematode worm Caenorhabditis elegans (Napier et al., 1998), rat (Aki et al., 1999), mouse and human (Cho et al., 1999a). Fatty acid $\Delta 5$ desaturase genes have been isolated from C.elegans (Michaelson et al., 1998; Watts and Browse, 1999) and human (Cho et al., 1999b; Leonard et al., 2000a). Very recently, a fatty acid desaturase has been cloned from zebrafish that has been shown to have both $\Delta 6$ and $\Delta 5$ desaturase activities (Hastings et al., 2001). This is in contrast to the other animal desaturases that have been cloned which have been shown to be either $\Delta 6$ or $\Delta 5$ desaturases, but not both. The zebrafish desaturase cDNA sequence of 1590 bp encoded a protein of 444 amino acids and contained an $\mathrm{N}$-terminal cytochrome $\mathrm{b}_{5}$ domain, a transmembrane domain and three histidine boxes, believed to be involved in catalysis, in common with other mammalian desaturases. Interestingly, phylogenetic analysis showed that the zebrafish desaturase clustered with animal $\Delta 6$ genes rather than $\Delta 5$ genes, with the amino acid sequence predicted by the zebrafish open reading frame indicating that the desaturase possessed $64 \%$ identity and $78 \%$ similarity to human $\Delta 6$ desaturase, and $58 \%$ identity and $75 \%$ similarity to human $\Delta 5$ desaturase. The activity of the zebrafish desaturase towards n-3 substrate fatty acids was more than twice that towards the equivalent n-6 substrates and the $\Delta 6$ activity was twice that of the $\Delta 5$ activity. Further desaturases have been cloned from rainbow trout (Seilez et al., 2001), carp, Atlantic salmon and cod (Hastings and Tocher, unpublished data) based on similarity with mammalian $\Delta 6$ desaturases, although these remain to be functionally characterised. The trout and salmon cDNAs were very similar and both encoded polypeptides of 454 amino acids, 10 more than other vertebrate desaturases. The amino acid sequence predicted by the salmon open reading frame indicated that the desaturase candidate possessed $83 \%$ identify and $86 \%$ similarity to the trout desaturase and $64 \%$ identity and $80 \%$ similarity to the zebrafish $\Delta 6 / \Delta 5$ desaturase.

Considerably less attention has been paid to fatty acid elongation, particularly in terms of regulation of PUFA biosynthesis. However, significant advances have been made recently. For instance, evidence from enzymatic studies in the arachidonic acid-producing fungus, $M$. alpina, have suggested that the $\mathrm{C}_{18-20}$ elongase, rather than $\Delta 6$ desaturase, may in fact be the rate-limiting step in the biosynthesis of 20:4n-6 in that organism (Wynn and Ratledge, 2000). Fatty acid elongation is a microsomal process effected in four steps each catalysed by a specific enzyme. The first step is a condensation reaction of the precursor fatty acyl 
chain with malonyl-CoA to produce a $\beta$-ketoacyl chain that is subsequently hydrogenated in three successive steps. This first condensation step determines the substrate specificity and is the rate-limiting step of the process and is therefore regarded as being the actual "elongase" enzyme. Genes involved in the elongation of saturated and monounsaturated fatty acids had been identified previously in yeast, but recently elongases specifically involved in the biosynthesis of long-chain PUFA have been cloned and characterised from $C$. elegans (Beaudoin et al., 2000), M. alpina (Parker-Barnes et al., 2000 and humans (Leonard et al., 2000b). Fatty acid elongases have also been cloned very recently from several freshwater and marine species including zebrafish, carp, Atlantic salmon and turbot (Agaba, personal communication). Functional expression of the zebrafish elongase in the yeast $S$. cerevisiae showed that it displayed $\mathrm{C}_{18-20}, \mathrm{C}_{20-22}$ and $\mathrm{C}_{22-24}$ PUFA elongating activities that converted $90 \%, 50 \%$ and $5 \%$ of the particular $n-3$ fatty acid substrate for each activity (Agaba and Tocher, unpublished data). The activities with the respective n-6 PUFA substrates were lower suggesting some specificity for n-3 fatty acids. Most interestingly, in contrast to the elongases from yeasts, worm (C. elegans) and humans, the zebrafish elongase appeared to have a broader substrate specificity and also displayed significant activity with saturated fatty acids and monounsaturated fatty acids, particularly 16:0 and 16:1n-7 (Agaba and Tocher, unpublished data).

\subsection{Phospholipid Biosynthesis.}

The pathways of de novo phosphoglyceride biosynthesis have not been extensively studied or elucidated in fish (Green and Selivonchick, 1987). However, the existing evidence strongly suggests that pathways are essentially the same in fish as in higher terrestrial mammals (Sargent et al., 1989). The activity of glycerol3-phosphate acyltransferase was demonstrated in the liver of rainbow trout (Holub et al., 1975a). When liver microsomes were incubated with $s n-\left[\mathrm{U}-{ }^{14} \mathrm{C}\right]$ glycerol-3-phosphate in the presence of activated fatty acid, palmitoyl-CoA, $77 \%$ of the radioactivity was recovered in total phosphoglycerides with the remainder recovered in neutral lipids. PtdA and lysoPtdA were also labelled, supporting the conclusion that phosphoglyceride biosynthesis in fish proceded via a PtdA intermediate. The presence of cytidine diphosphate(CDP)-choline-1,2-diacylglycerol choline phosphotransferase activity has been demonstrated in the microsomes of trout liver (Holub et al., 1975b) and brain, and liver from goldfish (Carassius auratus) (Leslie and Buckley, 1975). The synthesis of PtdCho from ${ }^{14} \mathrm{C}$-CDP-choline and 1,2-diacylglycerol (diolein) in the presence of $\mathrm{Mg}^{2+}$ established that the CDP-choline pathway for the biosynthesis of PtdCho, as studied in detail in mammals, also operated in fish (Holub et al., 1975b; Leslie and Buckley, 1975). There have been few studies in fish to fully characterize the biosynthetic pathways for PtdCho, PtdEtn, PtdSer, PtdIns and cardiolipin or the pathways, known in mammals, for interconversion between the phosphoglycerides. However, the de novo pathways of phosphoglyceride biosynthesis were investigated in 
trout hepatocytes and the activities of CDP-choline and CDP-ethanolamine phosphotransferases, PtdEtnmethyltransferase (PtdEtn ---> PtdCho) and PtdSer-decarboxylase (PtdSer --> PtdEtn) demonstrated (Hazel, 1990).

Thus, the pathways of de novo phosphoglyceride biosynthesis are essentially the same in fish as in higher terrestrial mammals. However, there is now considerable evidence that at least some species of fish larvae, both freshwater and marine, may have only a limited capacity to biosynthesise phosphoglycerides de novo (Geurden et al., 1995, 1997; Coutteau et al., 1997; Fontagne et al., 1998). This reflects the fact that many fish larvae receive an abundance of phosphoglycerides in their natural diets, whether from yolk sac lipids prior to first feeding or from natural prey at and after first feeding. The same situation may well hold for de novo biosyntheses of cholesterol and sphingolipids which have been scarcely studied in fish. Similarly, the synthesis of steryl esters has not been studied in fish although the biosynthesis of wax esters has been demonstrated in the liver of wax ester-rich myctophid species of fish (Seo et al., 2001).

\subsection{Phospholipid Turnover and Remodelling}

Apart from de novo biosyntheses, fatty acid retailoring by acyl exchange reactions is an important process determining the final fatty acid compositions of tissue phosphoglycerides. Administered fatty acids are readily incorporated into the phosphoglycerides of fish tissues, for instance as when incubated with hepatocytes or cell cultures (Buzzi et al., 1997), but the extent to which this reflects de novo biosyntheses (net formation of phosphoglycerides), or fatty acyl exchange reactions (turnover of existing phosphoglycerides), has not been determined in fish. Fission of cell membranes, such as occurs in the Golgi apparatus when forming vesicles, and fusion of cell membranes, as occurs in vesicle exocytosis at synaptic junctions, are both now known to be dependent on the formation of lysophosphoglycerides (Weigert et al., 1999; Schmidt et al., 1999), and particular roles for specific fatty acids, especially PUFA, may exist in these processes. Although the processes have not been studied in detail, many of the enzymic components of phosphoglyceride remodelling have been demonstrated in fish. A review of muscle lipase activities in various fish species indicated that the catalytic hydrolysis of phosphoglycerides was primarily under the control of phospholipases $\mathrm{A}_{1}$ and $\mathrm{A}_{2}$ (Shewfelt, 1981). Intracellular phospholipase $\mathrm{A}$ activities have been demonstrated in muscle tissue from rainbow trout (Jonas and Bilinski, 1967), pollock (Gadus pollachius) (Audley et al., 1978), winter flounder (Shewfelt et al., 1981) and cod (Chawla and Ablett, 1987). The activity of phospholipase $\mathrm{A}_{2}$ towards PtdCho has been studied in the microsomes of trout liver (Neas and Hazel, 1985), and cytosolic phospholipase $A_{2}$ was demonstrated to be the principal activity during zebrafish embryogenesis (Farber et al., 1999). The activity of phospholipase $\mathrm{C}$ has been demonstrated directly in isolated olfactory cilia from the channel catfish (Boyle et al., 1987) and has been implicated indirectly in 
other tissues by the demonstration of a phosphoinositide cycle (see section 4.5) (Simpson and Sargent, 1985; Arias and Barrantes, 1990). Trout liver microsomes have also been shown to express acylCoA: 1-acyl-snglycero-3-phosphorylcholine acyltransferase activity (Holub et al., 1976). Therefore, enzymes required for partial catabolism of phosphoglycerides and for the reacylation of lyso-phosphoglycerides, and thus for the turnover of phosphoglycerides, have been demonstrated in fish. The specificities of the enzymes involved in both de novo synthesis of the phosphoglycerides and in the turnover processes of deacylation/reacylation with respect to both head group and fatty acyl chains have important consequences in maintaining the normal phosphoglyceride class composition, the fatty acyl distribution among the phosphoglycerides, and in the adaptation to environmental changes.

\subsection{Triacylglycerol Biosynthesis.}

In mammals, triacylglycerols are formed by the sequential esterification of two fatty acids to glycerol3-phosphate to form lyso-PtA and PtA catalysed by glycerophosphate acyltransferase, followed by cleavage of the phosphate group (via phosphatidate phosphatase) to form diacylglycerol and the esterification of a further fatty acid (via diacylglycerol acyltransferase) to form triacylglycerol. Just as with phosphoglycerides, the pathway of de novo triacylglycerol biosynthesis has not been extensively studied in fish, but the little evidence available suggests that the pathways are generally the same in fish as in mammals (Sargent et al., 1989). The presence of glycerol-3-phosphate acyltransferase activity in the rainbow trout liver and the recovery of labelled PtdA, lysoPtdA and neutral lipids when liver microsomes were incubated with labelled glycerol-3-phosphate in the presence of palmitoyl-CoA support the conclusion that triacylglycerol biosynthesis in fish procedes via a PtdA intermediate (Holub et al., 1975a).

During feeding, excess dietary fatty acids are exported from the liver in the form of lipoproteins (VLDL) and are accumulated and stored in the form of triacylglycerols in specific lipid storage sites. The primary site for long-term storage in many fish is the mesenteric adipose tissue, although some fish also store significant amounts of fat within the white (light) muscle (adipose tissue within the myosepta) and between skin and muscle which can account for a large proportion of the fish's total reserves (Henderson and Tocher, 1987). Red (dark) muscle, which usually has a higher lipid content than white muscle, contains most of the lipid as finely dispersed oil droplets within the muscle fibres themselves (Sheridan, 1994). The processes of transport, tissue uptake and lipoprotein remodelling via the action of the key enzymes lipoprotein lipase, hepatic lipase and LCAT were described in detail in section 2.4.1. Moderate amounts of lipid can also be stored in liver in many fish although this is generally shorter-term storage compared to the adipose tissues. However, in some fish such as the gadoids and some flatfish, the liver can be the primary lipid storage site (Sargent et al., 1989). 


\subsection{Triacylglycerol Mobilisation.}

Triacylglycerols are stored in adipose tissue fundamentally as a long term source of energy that can be used when the energy requirements of the animal exceed the energy available from the diet, particularly when the energy requirements of the animal are very high. Apart from starvation, a particular example of this in fish is during reproduction when the production of very large numbers of gametes, particularly eggs, during the relatively short period of of reproduction, is very energy intensive. A further example is the migration, often long distance, that precedes reproduction in many fish since the energy requirements of the swimming red muscles are provided largely by fatty acids. Lipid is probably mobilised initially from the main adipose tissue, although in the longer term it, it will be also mobilised from the secondary lipid storage sites such as muscle and liver.

A key enzyme in triacylglycerol mobilisation is the "hormone-sensitive" lipase (HSL) whose activity is regulated by various hormones through reversible phosphorylations by the action of kinases and phosphatases under the influence of various activators and inhibitors. Direct enzymic studies on HSL in fish are few but the process of triacylglycerol mobilisation is known to be under hormonal control, at least in the liver, indirectly implying the presence of a HSL in fish (Sheridan, 1994). Later studies established that TAG mobilisation in trout was regulated by the phosphorylation state of the triacylglycerol lipase in both liver and adipose tissue (Sheridan, 1994). Thus, in starvation or periods of non-feeding, lipid mobilisation from liver and adipose tissue in fish, as in mammals, is under $\beta$-adrenergic control, with adrenalin (epinephrin) and noradrenalin (norepinephrine) stimulating triacylglycerol hydrolysis and an increase in plasma free fatty acids in salmonids and various other fish species, although the potency of the two catecholamines varies between different species (Sheridan, 1994; Fabbri et al., 1998). In addition, various other hormones stimulate lipid mobilisation in depot organs, especially liver, through activation of HSL, including glucagon, cortisol, ACTH, growth hormone, somatostatin, thyroxine, and prolactin, resulting in triacylglycerol breakdown and secretion of free fatty acids, whereas insulin inhibits the activity of HSL (Sheridan, 1994). Recently, desacetyl- $\alpha-\mathrm{MSH}$, a derivative of MSH, was shown to be a potent stimulator of lipid mobilization through increased hepatic lipase activity and consequently increased plasma free fatty acid levels in rainbow trout (Yada et al., 2000). Of particular importance during gonadogenesis and egg production is the activation of HSL by oestrogen resulting in the mobilisation of fatty acids from adipose tissue to liver where they serve both as energy sources and substrates for the production of the specific lipoproteins for egg production (see sections 2.4.1 and 4.1.2). Mobilised fatty acids are probably transported from adipose tissue stores mainly bound to the albumin-like protein known to be a major plasma protein in teleosts (De Smet, 1978).

\subsection{Fatty Acid Catabolism.}


Fatty acid catabolism is the major source of energy by far in many species of fish. Whereas the biosynthesis of fatty acids occurs in the cytosol, the catabolism of fatty acids occurs in the cellular organelles, mitochondria (and peroxisomes) via a completely different set of enzymes. The process is termed $\beta$-oxidation and involves the sequential cleavage of two-carbon units, released as acetyl-CoA, through a cyclic series of reactions catalysed by several distinct enzyme activities rather than a multi-enzyme complex. Briefly, activated fatty acids are transported into the mitochondrion in the form of fatty acylcarnitine esters formed through the action of carnitine acyltransferase, converted back into fatty acylCoA derivatives and then undergo a round of dehydrogenation, hydration, second hydrogenation and cleavage steps to produce acetyl-CoA and NADH. The acetyl-CoA can then be metabolised via the tricarboxylic cycle to produce more NADH. The NADH produced from the oxidation of fatty acids can then provide metabolic energy in the form of ATP through the process of oxidative phosphorylation. Under certain conditions such as fasting, acetyl-CoA can be exported from the liver in the form of ketone bodies, acetoacetate and 3-hydroxybutyrate, which are used by peripheral tissues as fuel through oxidation back to acetyl-CoA.

The processes of mitochondrial $\beta$-oxidation and ketone body formation have all been established in fish although ketone bodies are probably only important energy in elasmobranchs and not in teleost fish other than perhaps sturgeons (Acipenser sp.) (Henderson and Sargent, 1985; Singer et al., 1990). Fatty acid oxidation is an important source of energy in several tissues in fish in addition to liver, including heart and red muscles and, recently, white muscle has been reported as playing a significant role in overall fatty acid oxidation in Atlantic salmon (Froyland et al., 1998,2000). At a cellular level, peroxisomes are another site of $\beta$-oxidation in mammals where they are possibly specifically utilised in the initial chain shortening prior to conventional $\beta$-oxidation of very long chain, highly unsaturated or unusual fatty acids. The available evidence is consistent with all saturated and monounsaturated fatty acids, including 22:1n-11, being readily catabolised by mitochondrial $\beta$-oxidation in fish (Sargent et al., 1989). However, $\beta$-oxidation of PUFA is variable between different PUFA molecules and can be more complicated. In mammals, 20:5n-3 is readily $\beta$-oxidised by mitochondria and, indeed, induces formation of mitochondria in rats (Madsen et al., 1999). However, 22:6n-3 is a poor substrate for mitochondrial $\beta$-oxidation in rats where its catabolism requires peroxisomal $\beta$-oxidation (Madsen et al., 1999). This is because, as insertion of the $\Delta 4$ ethylenic bond in 22:6n-3 requires a special mechanism (described above), so does its removal. Thus, the initial 2,3 ( $\alpha, \beta)$ dehydrogenation of 22:6n-3, the first step in the $\beta$-oxidation of all fatty acids, requires that it be followed in the case of 22:6n-3 by an NADPH - dependent 2,4-dienoyl CoA reductase and then by a 3 cis - 2trans isomerase so as to enable completion of oxidation of its $\beta$ carbon. These processes, which are well evolved in peroxisomes, have yet to be studied in fish. However, relatively high levels of peroxisomal $\beta$-oxidation 
were observed in red muscle of Atlantic salmon (Froyland et al., 2000). Peroxisomal $\beta$-oxidation may account for significant amounts (up to 30\%) of total hepatic $\beta$-oxidation under certain conditions such as in Antarctic fish (Crockett and Sidell, 1993). Further work is required to fully elucidate the relative roles of mitochondria and peroxisomes, and the tissue sites, of fatty acid oxidation in fish.

\section{Functions}

\subsection{Energy production}

4.1.1 General. As noted above, a major role of lipids in fish is for the storage and provision of metabolic energy in the form of ATP provided through the $\beta$-oxidation of fatty acids (Sargent et al., 1989; Froyland et al., 2000). Lipids, and specifically fatty acids, are the preferred source of metabolic energy for growth, reproduction and swimming in fish, especially marine fish, as evidenced by the very high oil levels (more than $20 \%$ of the wet weight) that can be achieved by fish such as capelin and herring. Current knowledge of the relative importance of individual fatty acids in energy provision is partly based on experiences in aquaculture. Thus, given that fish oil is the major lipid component of current fish feeds, the fatty acids that are the predominant sources of potential metabolic energy include 16:0 and 18:1n-9, the 20:1n-9 and 22:1n-11 that are particularly abundant in the so-called northern fish oils, and the n-3 HUFA 20:5n-3 and 22:6n-3. Undoubtedly 16:0, 18:1n-9, 20:1n-9 and 22:1n-11 are heavily catabolised for energy in fish because they are all consumed in large amounts during the growth of farmed fish species such as the salmonids, and, specifically, during formation of roe by female fish (Henderson et al., 1984a,b; Henderson and Almater, 1989). Indeed, the long-chain monoene 22:1n-11 seldom if ever exists in significant amounts in phosphoglycerides so that its only role in fish is as a source of metabolic energy. In Antarctic fish tissues, monoeneoic fatty acids were preferentially oxidised for energy compared to long-chain saturated fatty acids (Sidell et al., 1995). As alluded to above, 20:5n-3 can be readily $\beta$-oxidised, but 22:6n-3 catabolism requires peroxisomal and mitochondrial $\beta$-oxidation, at least in rats (Madsen et al., 1999). There is no reason to believe that the mechanism for oxidising 22:6n-3 is different in fish and rats, and as peroxisomes are present in fish tissues including liver (Cancio and Cajaraville, 2000), it is likely that 22:6n-3 can serve as a source of energy in fish if necessary.

The use of medium chain triacylglycerols (MCT) containing 6:0, 8:0, 10:0 and 12:0 as alternative sources of energy had been studied in the past in fish, but recently has been reinvestigated along with the use of short chain fatty acids (SCFA), acetic (C2), propionic (C3) and butyric (C4). Actually, all of the fatty acids in the triacylglycerols used in these studies could be correctly termed short chain fatty acid. Studies in Atlantic salmon showed that 8:0 and 10:0 were highly digestible (99.6\% and $96.7 \%$, respectively) and were 
mainly absorbed in the pyloric region, but they appeared to reduce pyloric absorption of other fatty acids (Roesjoe et al., 2000). This may not be necessarily be a direct result of the fatty acid per se. Rather it may be a consequence of the unusual structure of the 2-acyl monoacylglycerols produced during digestion of MCT with short chain fatty acids which may have different physical properties. Growth and survival of carp larvae was reduced by feeding 8:0 (tricaprylin) in comparison with 12:0 (in the form of coconut oil) and triolein (Fontagne et al., 1999). In another trial, both 6:0 (tricaproin) and 8:0 initially stimulated growth in carp larvae in the first week but later 8:0 decreased growth compared to triolein (Fontagne et al., 2000a), and survival was decreased by feeding 8:0 compared to the other MCT (Fontagne et al., 2000b). Sea bass larvae fed 6:0 or 8:0 showed better growth rates than fish fed 10:0 (tricaprin) or triolein and fish fed 8:0 showed better survival (Fontagne et al., 2000c). Feeding MCT appear to decrease body fat levels as they reduced body neutral lipids in carp (Fontagne et al., 2000a) and fat in the muscle of salmon (Roesjoe et al., 2000). Similarly, increasing dietary levels of mixed MCT, 8:0 and 10:0 reduced intraperitoneal fat deposition in juvenile red drum (Sciaenops ocellatus) (Craig and Gatlin, 1997; Davis et al., 1999). Feeding MCT did not affect greatly the fatty acid composition of fish tissues. In sea bass, there was only very low deposition (1$3 \%$ ) of MCT and, in carp larvae, deposition of 6:0 was not observed but there was significant deposition of both 8:0 and 10:0 in neutral lipids but not polar lipid, with 8:0 also being significantly elongated to 10:0 (Fontagne et al., 1999, 2000a,b,c). Therefore, there is some evidence that MCT may be potentially useful as alternative energy sources in fish and may also have a beneficial effect in lowering body fat levels. However, SCFA have had little positive effect since inclusion of SCFA up to $2 \%$ of total diet dry weight in Atlantic salmon diets had no effect on growth, mortality, lipid levels or fatty acid composition (Bjerkeng et al., 1999).

As alluded to above, the specificity of fatty acid oxidation in fish is important in determining the fatty acid composition of triacylglycerols deposited in fish adipose tissue. This composition in turn is important not only for the well being of the fish, particularly its successful reproduction, but also for the consumer, particularly in terms of the levels of the health promoting 20:5n-3 and 22:6n-3 fatty acids in fish. Thus, those species of fish which can be extremely rich in lipid at particular periods in their life cycle have long been the source of a major world commodity, fish oil. Detailed coverage of fish oil compositions and seasonal effects is outwith the scope of this article but the reader is directed to several other comprehensive reviews (Ackman, 1967,1980,1982,1989; Henderson and Tocher, 1987; Ackman and McLeod, 1988; Sargent, 1989; Moffat and McGill, 1993). In general though, fish oils fall into two broad categories, the body oils, produced by the processing of mainly pelagic species that deposit oil in the flesh, including sardines, anchovy, menhaden (Brevoortia tyrannus), capelin, mackeral and herring, and liver oils, produced from mainly demersal species that deposit oil in the liver, predominantly cod and halibut (Hippoglossus hippoglossus) liver oils. All fish oils are highly polyunsaturated, characterised by high but variable levels of 
n-3 HUFA, predominantly 20:5n-3 and 22:6n-3, with 20:4n-6 as the major n-6 PUFA, and with 16:0 followed by $18: 0$ as the predominant saturated fatty acids, and all contain substantial amounts of the monoene 18:1n-9. Northern hemisphere fish body oils, such as those from herrin, menhaden and capelin, contain particularly high levels of monenes due to the presence of high levels of 20:1n-9 and 22:1n-11 fatty acids produced by the oxidation of the 20:1 and 22:1 fatty alcohol moieties of wax esters that predominate in the lipids of the calanoid copepods that constitute a large part of their diet. These oils tend to have 20:5n-3 : 22:6n-3 ratios of around 1.0 to 1.5, whereas fish oils from the Southern hemisphere have only low levels of 20:1 and 22:1 and so have higher proportions of n-3 HUFA with an 20:5n-3:22:6n-3 ratio of up to 2 . These Southern hemisphere oils include the sardine, anchovy and pilchard (Sardinops sagax and ocellatus) oils that form the basis of the "18:12" (20:5n-3:22:6n-3) formulations marketed as human health supplements. Liver oils tend to have lower 20:5n-3:22:6n-3 ratios and intermediate levels of 20:1 and 22:1.

Interestingly, fish oils with substantially higher levels of 22:6n-3 than 20:5n-3 are rare, an exception being tuna oils including body oil, and orbital oil which originates from the fat pad associated with the eye socket (Sawada et al., 1993). Tuna lipids in general, including both triacylglycerols and phosphoglycerides, consistently have much higher levels of 22:6n-3 than 20:5n-3 (Murase and Saito, 1996). For instance, muscle phospholipids of Atlantic northern bluefin (Thunnus thynnus) and yellowfin (T. albacares) tunas displayed 22:6n-3 : 20:5n-3 ratios of up to 7.4 and 11.3, respectively (Medina et al., 1995). In Pacific yellowfin tuna, total n-3 HUFA can account for between $30 \%$ and 37\% of total fatty acids with 22:6n-3 alone accounting for between 25\% and 30\% (Sunarya et al. 1995). Pacific northern bluefin showed flesh 22:6n-3 levels of between $25 \%$ and $36 \%$ with $22: 6 n-3: 20: 5 n-3$ ratios of $3.4-5.8$, whereas the stomach contents showed a 22:6n-3 : 20:5n-3 ratio of just 3.2 (Ishihara and Saito, 1996). Similarly, the average 22:6n-3 : 20:5n-3 ratio in Pacific yellowfin flesh varied between 7.4 and 7.8 wheres the stomach contents seldom exceeded 4 (Saito et al., 1996). Therefore, the relatively high level of 22:6n-3 and the high 22:6n-3 : 20:5n-3 ratio in tuna appears to be an inherant characteristic of tuna species as it does not correlate with dietary input. Although the lipid biochemistry underpinning the high levels of 22:6n-3 and the high 22:6n-3 : 20:5n-3 ratios is unclear, it has generally been assumed that tuna must selectively accumulate and/or retain 22:6n-3 in their tissues (Saito et al., 1996; Ishihara and Saito, 1996). However, the data also appear to be consistent with selective metabolism of $20: 5 n-3$, through both conversion to $22: 6 n-3$ via elongation and desaturation and also by catabolism via $\beta$-oxidation.

Therefore, tuna species appear to demonstrate selective catabolism of fatty acids, in this case, selective catabolism of $20: 5 n-3$ relative to $22: 6 n-3$. This may be related to the fact that tunas like certain scombroid fish are "warm-blooded" and have active brain and eye heating systems that demonstrate extremely high aerobic oxidative capacities which are likely to be fuelled by fatty acid oxidation (Tullis et al., 1991). Thus 
selective catabolism could contribute to the accumulation of 22:6n-3 by fishes with heater tissues if 20:5n-3, but not 22:6n-3, is readily oxidised by mitochondria in heat generating tissues. Other examples of selective catabolism of fatty acids include Antarctic fish in which selective oxidation of monounsaturated fatty acids and, to a lesser extent, saturated fatty acids, rather than PUFA has been shown (Sidell et al., 1995). Furthermore, the maximal swimming speed of salmon has been positively correlated with muscle levels of $\mathrm{C}_{18}$ fatty acids including 18:1n-9 and 18:2n-6, perhaps suggesting that these fatty acids rather than PUFA are the preferred fuels in swimming muscles (McKenzie et al., 1998). Thus, selective oxidation of saturated and monounsaturated fatty acids, and perhaps also 20:5n-3, by swimming muscles leading to the selective retention of 22:6n-3 may be a more general feature of fish (see section 4.1.2 below). Consistent with this, the ratio of $22: 6 n-3: 20: 5 n-3$ is consistently higher in the lipids deposited in the flesh of farmed Atlantic salmon compared with the fish oils currently used in salmon feeds (Brodtkorb et al., 1997; Bell et al., 1998).

4.1.2. Reproduction. Fatty acids are not only the major source of metabolic energy in fish for growth from the egg to the adult fish (Tocher et al., 1985a,b), they also are the major source of metabolic energy for reproduction (Henderson et al., 1984a,b; Sargent et al., 1989). Indeed, the very high oil levels in those industrial fish species from which fish oil is extracted, exist largely in pre-spawning fish for reproduction (Sargent et al., 1995a). This has recently been emphasised by the clear correlation that exists between oil levels and fecundity and, therefore, recruitment in wild populations of cod (Marshall et al., 1999). Furthermore, very recently, the failure of the cod population in Newfoundland waters to recover was related to the presence or absence of oil-rich capelin in their diet (Rose, 2001). The distribution of capelin has shifted such that they no longer form a significant part of the diet of the cod population on the continental shelf. As a result, the cod population on the continental shelf are in poor condition, have poor reproductive potential and the population is not recovering. In contrast, the cod population in the coastal area, where capelin still form a key component of the diet, have made a better recovery (Rose, 2001).

Thus, for successful reproduction, the stored oil must support not only the immediate energy requirements of the parent fish but also the future requirements of the progeny. For instance, of the large amounts body oils mobilised during formation of the ovaries and their constitutent eggs in capelin, some $60 \%$ is catabolised to provide metabolic energy, with the remainder being transferred to the eggs. However, the fatty acid compositions of egg lipids are quite different from those of the body oils consistent with selective catabolism of certain fatty acids and/or selective transfer of other fatty acids to the eggs. Selective oxidation of 20:1n-9 and 22:1n-11 in triacylglycerol depots certainly occurs in capelin during formation of roe since these fatty acids are abundant in depot triacylglycerols of the parent fish but present in roe in only very small amounts (Henderson et al., 1984a,b). In addition, the higher ratio of 22:6n-3:20:5n-3 in the roe of capelin (Henderson et al., 1984a) and in fish roe in general (Tocher and Sargent, 1984b; Tocher et al., 
1985a,b), as compared to body triacylglycerols, is consistent with selective catabolism of 20:5n-3 relative to 22:6n-3 in fatty acid oxidative processes producing energy for gonadogenesis, resulting in selective transfer of $22: 6 n-3$ to the eggs.

4.1.3 Embryonic and yolk-sac larval development. The utilisation of lipids and fatty acids for energy during embryogenesis and early larval development in many species of fish has some unique and interesting features that require special mention. To appreciate these features, some description of fish egg lipid composition and the species differences is required.

In terms of lipid content and lipid class composition, fish eggs can fall into basically two categories. Eggs with relatively low lipid contents (<5\% of wet weight) which are predominantly polar lipids $(60-90 \%$ of total lipid on average), and eggs that have higher lipid contents ( $>5 \%$ of wet weight) that generally have higher levels of neutral lipids, often in the form of oil globules or droplets, in addition to the phospholipidrich yolk lipid (Sargent et al., 1989; Wiegand, 1996a). Eggs from marine fish tend to be smaller, of lower lipid and phospholipid-rich compared to eggs from freshwater species but there are many exceptions to this generalisation. Marine fish eggs with relatively low levels of lipid include those from herring, haddock, whiting (Merlangus merlangus), saithe (Pollachius virens) (Tocher and Sargent, 1984b), cod (Fraser et al., 1988) and halibut (Falk-Petersen et al., 1989), but freshwater species such as perch (Perca fluviatilis), northern pike (Esox lucius), tilapia and roach (Leucisus rutilis) also have low lipid eggs (Henderson and Tocher, 1987). In contrast, eggs from salmon, rainbow trout, striped bass and whitefish (Coregonus albula) have higher lipid contents, and eggs from the marine fish gilthead sea bream (Mourente and Odriozola, 1990; Ronnestad et al., 1994), Senegal sole (Solea senagalensis) (Vazquez et al., 1994), common dentex (Dentex dentex) (Mourente et al., 1999a), sea bass (Ronnestad et al., 1998) and turbot (Silversand et al., 1996) all have higher levels of neutral lipids ( $>50 \%$ of total lipid), with the eggs from all these species having oil globules similar to those found in the relatively lipid - rich eggs of sand eel (Ammodytes lancea) and capelin (Tocher and Sargent, 1984b). The polar lipids of most fish eggs are dominated by phosphoglycerides, particularly PtdCho, followed by PtdEtn, PtdSer and PtdIns. Exceptions to this pattern are striped bass eggs, whose phospholipids are reported to contain predominantly PtdIns (Gallagher et al., 1998), and sturgeon eggs, which have relatively high PtdEtn (Gershanovich, 1991). The neutral lipids are mainly triacylglycerols with smaller amounts of cholesterol although some lipid - rich eggs have globules that are predominantly steryl and/or wax esters as in gourami or some freshwater Perciformes and striped bass (Anderson et al., 1990; Wiegand, 1996a).

The total lipid of eggs from most fish studied are generally rich in n-3 HUFA (Sargent et al., 1989). Egg phosphoglycerides, like phosphoglycerides in other tissues, are generally higher in HUFA than neutral lipids so that egg HUFA levels partly reflect the relative amounts of polar and neutral lipid. Thus, marine 
eggs tend to have higher n-3 HUFA levels than freshwater species (Rainuzzo, 1993; Wiegand, 1996a). In contrast, the eggs of most freshwater fish contain higher levels of n-6 PUFA, particularly 20:4n-6 and 18:2n6, than marine fish eggs (Anderson et al., 1990; Wiegand, 1996a). In general, the fatty acid compositions of eggs are more resistant to dietary changes than the fatty compositions of other tissues. However, the eggs of wild striped bass and chinook salmon (Oncorhynchus tshawytscha) both contained higher levels of n-3 HUFA and higher n-3 : n-6 ratios than eggs from equivalent cultured populations (Ashton et al., 1993; Harrell and Woods, 1995). Eggs from cultured Atlantic salmon had an increased level of 20:5n-3 and a decreased level of 20:4n-6 which greatly increased the ratio of 20:5n-3:20:4n-6 in the cultured eggs as compared to wild eggs (Pickova et al., 1999). Decreased 20:4n-6 in eggs from cultured fish in comparison with wild fish was also observed in striped bass (Gallagher et al., 1998). In contrast, the above study with Atlantic salmon recorded similar levels of 22:6n-3 in the eggs of wild and cultured fish (Pickova et al., 1999). Also levels of 22:6n-3 in walleye (Stizostedion Vitreum) eggs from different geographical populations, including a domesticated population, were more conserved than levels of other HUFA (Czesny and Dabrowski, 1998). Therefore, there appears to be selection pressure to maintain levels of 22:6n-3 in eggs within a species - specific range (Wiegand, 1996a). For instance, the levels of 22:6n-3 and total n-3 HUFA were almost identical between eggs from wild and captive turbot, whereas the levels of 18:2n-6 and, to a lesser extent, 20:1n-9 were much higher in eggs from captive fish (Silversand et al., 1996). The effects of broodstock diet on the fatty acid composition of fish roe and its relationship to egg quality criteria are described elsewhere (Sargent et al., 2002).

The utilisation of lipids and fatty acids during embryonic and early larval development varies considerably between fish species. Lipids were utilised as an energy source mainly after hatching in goldfish (Wiegand, 1996b), sturgeon (Gershanovich, 1991), red sea bream and winter flounder (Sargent et al., 1989), whereas in pike (Desvilettes et al., 1997), striped bass (Chu and Ozkizilcik, 1995), Atlantic herring and cod, lipids were utilised during both embryogenesis and early larval development (Tocher et al., 1985a; Fraser et al., 1988). The specific classes utilised again depends largely on the type of eggs, with neutral lipid-rich eggs primarily utilising neutral lipids as in red sea bream, red drum, striped bass (Chu and Ozkizilcik, 1995) and sturgeon (Gershanovich, 1991), whereas phosphoglyceride-rich eggs such as those from herring, cod and African catfish primarily utilised PtdCho (Sargent et al., 1989; Verreth et al., 1994). Therefore, the catabolism of phosphoglycerides for energy may be a common characteristic of fish eggs that are rich in phosphoglycerides. Consistent with this, PtdCho was primarily catabolised in the phosphoglyceride - rich eggs of halibut and plaice, but not in turbot eggs where neutral lipids account for more than $50 \%$ of total lipid (Rainuzzo et al., 1992; Finn et al., 1995; Ronnestad et al., 1995). In contrast, in marine pelagic eggs that contain higher lipid levels, reflecting high levels of neutral lipid in oil globules or otherwise, such as from sea bream, sea bass, Senegal sole and dentex, lipids are utilised primarily after hatching and mainly as 
neutral lipid, whether from the oil globule or otherwise (Ronnestad et al., 1994, 1998; Mourente and Vazquez, 1996; Mourente et al., 1999a). Phosphoglyceride was also the predominant lipid catabolised in goldfish (Wiegand, 1996b) but in pike, PtdCho, triacylglycerol and steryl esters were all catabolised (Desvilettes et al., 1997). In rainbow trout, phosphoglyceride was slowly and continuously metabolised, but triacylglycerol was not utilised until after hatching, whereas in Atlantic salmon, triacylglycerol was catabolised throughout development. Another relatively common feature observed during development is the conservation and/or synthesis of PtdEtn relative to PtdCho, as reported in the phosphoglyceride-rich eggs of cod (Fraser et al., 1988), plaice and halibut (Rainuzzo et al., 1992; Ronnestad et al., 1995), the neutral lipid-rich eggs of turbot (Rainuzzo et al., 1992), Senegal sole (Mourente and Vazquez, 1996), dentex (Mourente et al., 1999a) and Atlantic salmon and the freshwater species, pike and African catfish (Verreth et al., 1994; Desvilettes et al., 1997). This results in a decrease and normalisation of the PtdCho:PtdEtn ratio as development proceeds, from the high values seen in most fish eggs, particularly from marine species, to values normally observed in fish tissues. This is particularly the case in the phosphoglyceride - rich eggs, dominated by PtdCho, where PtdCho is catabolised during embryogenesis, but it has also been noted in Atlantic salmon (Henderson and Tocher, 1987).

Therefore it appears that, in general, lipid utilisation occurs to a greater extent after hatching, particularly in species with neutral lipid-rich eggs, possibly reflecting the greater energy demands of the mobile, free-swimming yolk sac larvae as compared to the embryonic egg phase. Two main patterns of lipid class utilisation are apparent, related to egg lipid compositions. Phosphoglyceride-rich eggs tend to utilise phosphoglycerides, particularly PtdCho, whereas neutral lipid-rich eggs utilise primarily triacylglycerols and also steryl and wax esters where present. Irrespective of which class, catabolism of lipids results in the release of free fatty acids which can either be utilised for energy or re-acylated back into lipid pools for other uses which, during embryogenesis and early larval development, can be for the formation of rapidly developing larval tissues. In n-3 HUFA-rich marine eggs, it is perhaps obvious that PUFA and HUFA will be catabolised for energy, particularly in phosphoglyceride-rich eggs. Catabolism of HUFA, both 20:5n-3 and 22:6n-3, for energy has been reported in cod (Finn et al., 1995), halibut (Ronnestad et al., 1995), Senegal sole (Vazquez et al., 1994; Mourente and Vazquez, 1996) and dentex (Mourente et al., 1999a). In dentex, PUFA in both PtdCho and triacylglycerol were utilised, along with other fatty acids, generally in line with their order of abundance (Mourente et al., 1999a). Similarly, in cod the fatty acids in PtdCho were catabolised non-selectively (Finn et al., 1995). However, in herring and goldfish, much of the PUFA liberated by the catabolism of PtdCho was selectively retained in the neutral lipid pool (Tocher et al., 1985b; Wiegand, 1996b). Although also utilised for energy, PUFA were relatively conserved in comparison with saturated and monounsaturated fatty acids during development of Senegal sole (Mourente and Vazquez, 1996) and in cod, monounsaturated fatty acids in triacylglycerol were selectively catabolised in comparison 
with PUFA (Finn et al., 1995). During yolk sac absorption in pike, PUFA released by the hydrolysis of PtdCho were incorporated into the larval body (Desvilettes et al., 1997). In the neutral lipid-rich eggs from both trout cod, Maccullochella macquariensis and Murray cod, Maccullochella peelii peelii, n-3 HUFA and especially 20:4n-6 tended to be conserved during development (Gunasekera et al., 1999), whereas saturated and monounsaturated fatty acids were primarily utilised during catabolism of triacylglycerols in sturgeon (Gershanovich, 1991). In halibut, 22:6n-3 was a quantitatively important fuel with almost 40\% of the 22:6n3 from PtdCho hydrolysis being catabolised, but with over $60 \%$ of the 22:6n-3 being selectively retained at the same time in PtdEtn (38\%) and neutral lipids (23\%) (Ronnestad et al., 1995). Fraser et al. (1988) had earlier reported that about 33\% of the 22:6n-3 released during PtdCho catabolism in cod eggs was incorporated into triacylglycerols and steryl esters. Similar retention of 22:6n-3 in PtdEtn was observed in Senegal sole and dentex (Mourente and Vazquez, 1996; Mourente et al., 1999a). Some selective retention of 20:5n-3 was also reported in halibut (Ronnestad et al., 1995) and 20:4n-6 was selectively retained during development of Senegal sole (Mourente and Vazquez, 1996). Based on studies mainly with plaice, Rainuzzo (1993) suggested that utilisation of HUFA, including 22:6n-3, occurred mainly in earlier stages of development when yolk was still present whereas later, in non-feeding larvae, 22:6n-3 and 20:4n-6 were selectively retained in PtdEtn, at the expense of other fatty acids, including 20:5n-3, which were mainly catabolised. Thus, HUFA, as well as having clearly established roles in membrane structure and function, can also serve as important energy sources during embryonic and early larval development of fish, especially marine species.

\subsection{Membrane structure and functions.}

The net result of the metabolic pathways discussed in Section 3 is the tissue composition of phosphoglycerides and their fatty acid compositions. Phosphoglycerides and their fatty acid compositions have a major and very well established role in maintaining the structure and function of cellular biomembranes. Although metabolism is a very dynamic situation, the membrane phosphoglyceride and fatty acid compositions are relatively more stable than triacylglycerol (fish oil) compositions provided the environmental conditions and diet are reasonably constant. A review of the phosphoglyceride and fatty acid compositions of fish tissues including dietary and seasonal influences is outside the scope of this article but several other reviews provide comprehensive coverage of this area (Henderson and Tocher, 1987; Sargent, 1989; Sargent et al., 1989, 2002; Tocher, 1995). Further reviews can provide the reader with detailed accounts of the experimental data and the literature relating to environmental effects, especially temperature, on membrane lipid compositions (Cossins, 1983; Hazel, 1984, 1988; Cossins and Raynard, 1988; Hazel and Williams, 1990; Hochachka and Mommsen, 1995). 
There are few data that directly demonstrate a clearly defined role for specific fatty acids in membrane functions in fish. However, the importance of 22:6n-3 in neural tissues of all vertebrates, including fish, has recently been the subject of considerable interest (see Sargent et al., 2002). Thus, in fish, dietary deficiency of 22:6n-3 resulted in larval herring having an impaired ability to capture prey at natural light intensities (Bell et al., 1995) and impaired schooling behaviour in yellowtail (Masuda et al., 1998; Ishizaki et al., 2001) and Pacific threadfin (Polydactylus sexfilis) (Masuda et al., 2001). These recent studies imply a critical role for 22:6n-3 in the functioning of neural tissue (brain and eye) in fish and also demonstrate the importance of dietary 22:6n-3 in marine fish.

However, although essential for membrane function, PUFA are also very susceptible to attack by oxygen (oxygen radicals) and other organic radicals. The resultant oxidative damage to PUFA in membrane phosphoglycerides can have serious consequences for cell membrane structure and fluidity, with potential pathological effects on cells and tissues. Fish cellular membranes with their uniquely high levels of n-3 HUFA which are constituents vital for maintaining the structure and function of membranes are particularly at risk from oxidative attack and damage. The mechanisms, consequences and nutritional implications of lipid and fatty acid peroxidation and antioxidant protection in fish have been reviewed very recently and so will not be covered here (Sargent et al., 2002). However, recent studies have begun to elucidate the possible roles that endogenous enzyme mechanisms may have in protecting membrane HUFA from oxidative damage in fish.

The protective enzyme system comprises a series of enzyme scavengers of oxyradicals and other free radicals. Superoxide dismutase (SOD) comprises a group of metalloenzymes that disproportionates $\mathrm{O}_{2}{ }^{-}$to $\mathrm{H}_{2} \mathrm{O}_{2}$ as indicated in equation 1 :

$$
2 \mathrm{O}_{2}^{-} \cdot 2 \mathrm{H}^{+} \rightarrow \mathrm{H}_{2} \mathrm{O}_{2}+\mathrm{O}_{2}(1)
$$

SOD is considered to play a pivotal antioxidant role; it occurs in all aerobic organisms examined and catalyzes the removal of $\mathrm{O}_{2}^{-} \cdot$ at rates near to difussion limits, making it among the most active enzymes described. Specific isozymes are typically found in cytosol and mitochondria. Numerous studies have indicated induction of SOD in many organisms by factors associated with increased oxyradical production, such as elevated $\mathrm{O}_{2}$ and exposure to redox-active contaminants. The product of SOD activity, $\mathrm{H}_{2} \mathrm{O}_{2}$, can be removed by the activities of catalase (equation 2) or peroxidases such as glutathione peroxidase (Gpx) (equation 3):

$$
\begin{gathered}
2 \mathrm{H}_{2} \mathrm{O}_{2} \rightarrow 2 \mathrm{H}_{2} \mathrm{O}+\mathrm{O}_{2}(2) \\
\mathrm{H}_{2} \mathrm{O}_{2}+2 \mathrm{GSH} \rightarrow \underset{36}{2 \mathrm{H}_{2} \mathrm{O}+\operatorname{GSSG}(3)}
\end{gathered}
$$


Catalase is associated primarily with peroxisomes, where it detoxifies $\mathrm{H}_{2} \mathrm{O}_{2}$ arising as a by-product of fatty acid oxidation. Gpx is a cytosolic enzyme, and in addition to reducing $\mathrm{H}_{2} \mathrm{O}_{2}$, it can reduce lipid peroxides $(\mathrm{ROOH})$ to their corresponding alcohols $(\mathrm{ROH})$, an important reaction for quenching lipid-peroxidizing chain reactions. Glutathione-S-transferases (GST) constitute a multigene superfamily of enzymes that are also involved in removing reactive intermediates of oxidative stress through conjugation with glutathione. GST-A has been cloned from several species of fish and conservation of its sequence suggests an important function for this enzyme in fish (Henson et al., 2000). The enzyme glutathione reductase (GR) plays an important antioxidant role by maintaining the reduced:oxidised glutathione ratio by catalysing the reduction of GSSG to GSH at the expense of NADPH (equation 4):

$$
\mathrm{GSSG}+\mathrm{NADPH}+\mathrm{H}^{+} \rightarrow 2 \mathrm{GSH}+\mathrm{NADP}^{+}(4)
$$

Studies in which these enzyme activities have been measured in fish have often focussed on their role in pollutant detoxification (Livingstone et al., 1992; Peters et al., 1994; Martinez-Lara et al., 1996) or developmental aspects (Aceto et al., 1994; Otto and Moon, 1996; Peters and Livingstone, 1996; Mourente et al., 1999b,c). Other studies failed to demonstrate a clear relationship between oxidation stress and the activities of the enzyme systems. For instance, no interactions were observed between dietary vitamin E and antioxidant defence enzyme activities in Atlantic salmon (Lygren et al., 2000) and no clear relationship between dietary or tissue PUFA/vitamin E ratios and liver enzyme defence activities were observed in gilthead sea bream (Mourente et al., 2000). However, feeding high HUFA diets resulted in signs of increased peroxidative stress in juvenile marine fish, as evidenced by increased levels of tissue lipid peroxidation products, and some moderate effects on liver antioxidant defence enzyme activities were observed (Tocher et al., 2002a). In a very recent study using diets containing very high levels of n-3 HUFA and pre-oxidised oil, the activity of the enzyme defence system was clearly demonstrated to be increased by feeding oxidised oil and reduced by supplementing the diets with vitamin E in sea bream (Mourente et al. 2002). In a related comparative study, the liver antioxidant defence enzymes did not respond to dietary oxidised oil or vitamin $\mathrm{E}$ in halibut as occurred in sea bream and turbot suggesting that there may be species differences in this defence system perhaps related to temperature or developmental stage (Tocher et al., 2002b).

\section{$\underline{4.3 . ~ E i c o s a n o i d s ~}$}


In contrast to the non-enzymatic, and potentially damaging, oxidation of PUFA which must be controlled as discussed above, the regulated, dioxygenase enzyme-catalysed oxidation of HUFA to produce highly bioactive molecules is central to a major functional role of HUFA. The two main enzymes involved are cyclooxygenase which produces cyclic oxygenated derivatives or prostanoids, including prostaglandins (PG), prostacyclins (PG I) and thromboxanes (TX), and lipoxygenases which produce linear oxygenated derivatives including hydroperoxy- and hydroxy fatty acids, leukotrienes (LT) and lipoxins (LX). Collectively these fatty acid derivatives are termed eicosanoids, so named because they are derived primarily from the $C_{20}$ PUFA 20:3n-6, 20:4n-6 and 20:5n-3. The eicosanoids are autocrines, i.e. hormone - like compounds produced by cells to act in their immediate vicinity with a short half-life. Virtually every tissue in the body produces eicosanoids and they have a wide range of physiological actions, e.g. in blood clotting, the immune response, the inflammatory response, cardiovascular tone, renal function, neural function and reproduction. Recently, specific eicosanoids, including $\mathrm{LTB}_{4}$ and 15 -deoxy $\Delta^{12,14}-\mathrm{PGJ}_{2}$, have been postulated to be the natural ligands for a group of nuclear hormone receptors termed peroxisome proliferator-activated receptors (PPAR) that have established functions in the regulation of lipid metabolism in mammals (Schoonjans et al., 1997; Forman et al., 1997; Kliewer et al., 1997) (see section 4.4). The pathway from extracellular stimulus to the production of eicosanoids forms a cascade termed the "arachidonic acid cascade" as arachidonic acid (20:4n-6) is the primary precursor fatty acid in mammals. Briefly, activation of cell surface receptors results in the production of free precursor acid either via phospholipase $\mathrm{A}_{2}$ activity or via the sequential action of phospholipase $\mathrm{C}$ and diacylglycerol lipase. The activation of phospholipase $\mathrm{A}_{2}$ may occur through elevation of intracellular $\mathrm{Ca}^{2+}$ (it is activated in vitro by high $\mathrm{Ca}^{2+}$ levels) or it may be regulated by a $\mathrm{G}$ protein, as phospholipase $\mathrm{C}$ appears to be in the phosphoinositide cycle (Burgoyne et al., 1987). It appears that the increased concentration of the free precursor acid is itself the key stimulus for the activity of the cyclooxygenase or lipoxygenase enzymes (Smith, 1989b).

The subsequent pathways for the synthesis of individual eicosanoids from fatty acid precursors are complex with many different steps (Smith, 1989b). In fish, there is little mechanistic data on any of the steps involved in the cascade but, due to the obvious differences in the $\mathrm{C}_{20}$ PUFA composition of the phosphoglycerides between mammals and fish, there has been considerable interest in the general production of eicosanoids in fish. The following offers only a very brief summary of the existing knowledge of eicosanoids in fish focussing where possible on advances made since an earlier review of eicosanoid metabolism in fish where the original references can be found if required (Tocher, 1995).

Eicosanoids have been found in a large range of freshwater and marine fish, and virtually every tissue so far studied has shown cyclooxygenase and/or lipoxygenase activity with gills generally being the most 
active. Fish produce the same range of eicosanoids as in mammals with the prostanoids, PGE, PGF and PGD, and TXB and 6-keto-PGF $1 \alpha$, the respective stable metabolites of TXA and $\mathrm{PGI}_{2}$, all being reported in fish. In addition, 5-, 12- and 15-lipoxygenase activities have all been described as has the presence their respective monohydroxy-products, leukotriene B (LTB), the peptido-leukotrienes, LTC, D and E, and the lipoxins, LXA and LXB.

In mammals, 20:4n-6 is the chief precursor of the eicosanoids, generating 2-series prostanoids and 4series leukotrienes. However, 20:5n-3 competes with 20:4n-6 in eicosanoid production, and is itself converted to 3-series prostanoids and 5-series leukotrienes, which are generally less biologically active than the corresponding 2-series prostanoids and 4-series leukotrienes produced from 20:4n-6. Thus, eicosanoid actions are determined by the ratio of $20: 4 n-6: 20: 5 n-3$ in cellular membranes, this in turn being determined by the dietary intake of n-6 and n-3 PUFA (Fig.7.). There is considerable evidence supporting the hypothesis that high incidences of cardiovascular and inflammatory conditions, and some cancers, in developed societies are associated with an excessive dietary intake of 18:2n-6 relative to 18:3n-3, which generates high levels of 20:4n-6 in cells and consequently pathological levels of eicosanoids (Okuyuma et al., 1997). Dietary supplementation with 20:5n-3, as fish or fish oil, can be beneficial by damping down excess eicosanoid production from 20:4n-6 (Anon., 1999). The evidence from fish is consistent with the situation described above for mammals. Thus, although both 20:4n-6 and 20:5n-3 serve as eicosanoid precursors in fish tissues, 20:4n-6 is the preferred substrate despite the preponderance of 20:5n-3 in the tissue phosphoglycerides. It has also been established in fish that 20:5n-3 and dihomo- $\gamma$-linoleic acid, 20:3n-6, which can also serve as a substrate for fish cyclooxygenase enzymes, competitively depress the production of eicosanoids from 20:4n6 (Bell et al., 1994), as does 20:4n-3 (Ghioni and Tocher, unpublished data) which can be produced by elongation of stearidonic acid, 18:4n-3, a significant constituent of many fish oils. Therefore, in fish, as in mammals, eicosanoid production is influenced by the cellular ratio of 20:4n-6:20:5n-3 although the optimal ratio of 20:4n-6 : 20:5n-3 for eicosanoid production is probably lower in fish than in mammals. Irrespective of details, an imbalanced ratio of 20:4n-6 :20:5n-3 appears to be as damaging in fish as in mammals.

The source of 20:4n-6 for eicosanoid synthesis in fish is perhaps the most intriguing aspect of eicosanoid metabolism in fish as the the vast majority of species have membrane phosphoglycerides containing a large excess of 20:5n-3 relative to 20:4n-6. Despite this, 20:4n-6 is the chief source of eicosanoids in fish where it is concentrated in phosphoinositides and thus it is tempting to conclude that the phosphoinositides are the origin of the 20:4n-6 used to produce eicosanoids in fish. However, as noted some 7 years ago, there was no clear experimental evidence to support this conclusion and it appeared that one phosphoglyceride class may not be the sole supplier of eicosanoid precursor in fish (Tocher, 1995). It is frustrating to report that no definitive answer to this problem has been found and, similarly, whether the 
specificity for 20:4n-6 is the result of a 20:4n-6-specific phospholipase $A_{2}$ or from the specificity of the cyclooxygenase and lipoxygenase enzymes also remains unresolved. These fundamental questions are not the only ones that remain unanswered as the natural stimuli for eicosanoid production in fish are largely unknown as there have been few studies of eicosanoid production using potentially physiological stimuli. Finally, other than reproduction, in which the roles of eicosanoids in fish are well known and have been comprehensively reviewed (Stacey and Goetz, 1982; Goetz, 1991), there are relatively few studies on the functions of eicosanoids in fish. The presence of TXA and PGI in fish indirectly suggests that a TXA/PGI balance in the control of blood clotting and haemostasis operates in fish as in mammals and certainly series-2 prostanoids have been shown to have cardiovascular and vasoactive properties. There is similar indirect evidence that suggests lipoxygenase products play similar roles in inflammatory and immune processes in fish as in mammals. However, there have been few more definitive studies to add significantly to what was known several years ago (Tocher, 1995).

\subsection{Transcriptional Control of Lipid Homeostasis}

Lipid homeostasis can be described as the balance between lipid uptake, transport, storage, biosyntheis, metabolism and catabolism and each of these processes has to be controlled independently and in a cell specific manner, in addition to being regulated on a tissue and whole body level. A very large number of genes are involved in these processes and there must be mechanisms for regulating these genes at the transcriptional level, in response to feedback and feed-forward signals, in order to maintain optimal lipid homeostasis. In mammals, it has been established that fatty acids, particularly PUFA, are involved in the regulation of hepatic gene transcription (Jump and Clarke, 1999). However, PUFA can potentially affect gene transcription by a number of direct and indirect mechanisms including changes in membrane composition, eicosanoid production, oxidant stress, nuclear receptor activation or covalent modification of specific transcription factors (Jump et al., 1999). Much work has gone into elucidating these mechanisms and, in particular, PUFA are now known to directly influence the activities of a variety of transcription factors which have in turn been shown to be critical regulators of a growing list of genes involved in lipid homeostatic processes (Jump, 2002). Although fish species are only beginning to be studied from this molecular viewpoint, but it has been shown that fish possess genes for the pivotally important peroxisome

proliferator-activated receptors (PPARs). PPARs were first discovered in rodents as the factors responsible for the massive peroxisome proliferation observed in liver after treatment with a diverse range of chemicals including hypolipidemic drugs such as clofibrate, and environmental contaminants such as phthalate esters and some herbicides (Isseman and Green 1990). PPARs belong the nuclear hormone receptor family of 
transcriptional regulators which include, among many others, estrogen receptors and retinoid receptors. A particular characteristic of this group of proteins is their ability to bind and be activated by small hydrophobic molecules such as steroid hormones or retinoids. PPARs bind and are activated by unsaturated fatty acids and certain eicosanoids. In mammals there are three genes for PPARs and their products are termed PPAR $\alpha$, $\operatorname{PPAR} \beta$ (or $\delta$ ) and PPAR $\gamma$. Each of these receptors binds a distinct but overlapping range of PUFA, with a preference for n-3 series over n-6 series PUFA. This, together with their distinct tissue distributions, is believed to result in the tissue specific, fatty acid-dependent transcriptional regulation of genes containing sequence specific response elements (termed peroxisomal proliferator response elements or PPREs) for binding PPARs.

For example PPAR $\alpha$ is predominantly found in mammalian liver and has a particular affinity for $\mathrm{LTB}_{4}$ and 8S-hydroxyeicosatetraenoic acid (8S-HETE) as well as PUFA and also specific chemicals such as fibrates. Treatment with these compounds results in the upregulation of genes such as acyl-CoA oxidase, bifunctional enzyme, thiolase and long-chain fatty acid acyl-CoA synthetase all of which have been shown to be regulated via PPAR $\alpha$ (Dreyer et al., 1992; Zhang et al., 1992; Lee et al., 1995; Schoonjans et al., 1995). In addition PPAR $\alpha$ is involved in the control of fatty acid transport and uptake, by stimulating the genes encoding the fatty acid transport protein (FATP), the fatty acid translocase (FAT/CD36)and the liver cytosolic fatty acid-binding protein (L-FABP) (Motojima et al., 1998). Furthermore, PPAR $\alpha$ upregulates apolipoproteins A-I and A-II in humans, which leads to an increase in plasma HDL cholesterol. Additional $\operatorname{PPAR} \alpha$ target genes participate in mitochondrial fatty acid metabolism (Mascaro et al., 1998; Brandt et al., 1998), in ketogenesis (Rodriguez et al., 1994) and in microsomal fatty acid $\omega$-hydroxylation by cytochrome P450 w-hydroxylases that belong to the CYP4A family (Muerhoff et al.,1992; Aldridge et al., 1995).

In contrast PPAR $\gamma$ is predominantly expressed in adipose tissue, indeed its expression is required for the development of an adipocyte phenotype. The two markers of terminal adipocyte differentiation, aP2, a fatty acid binding protein, and phosphoenolpyruvate carboxykinase, an enzyme of the glyceroneogenesis pathway, are regulated by PPAR $\gamma$ (Tontonoz et al., 1995). Similarly, PPAR $\gamma$ also regulates the expression of the genes coding for lipoprotein lipase, fatty acid transport protein, and the fatty acid translocase (Motojima et al., 1998). 15-deoxy $\Delta^{12,14} \mathrm{PGJ}_{2}$ is a high affinity ligand for PPAR $\gamma$. Treatment of preadipocytes with 15deoxy $\Delta^{12,14} \mathrm{PGJ}_{2}$ or over-expression of PPAR $\gamma$ results in differentiation to fat storing adipocytes (Kliewer et al., 1995; Forman et al., 1995). In common with a number of other nuclear hormone receptors PPARs act as dimers. In the case of the PPARs they act as heterodimers with the cis-retinoic acid receptor alpha $(\mathrm{RXR} \alpha)$ and cis-retinoic acid acts synergistically with peroxisome proliferators to promote target gene transcription (Wahli et al., 1995).

Recently PPAR genes have been identified in Atlantic salmon and plaice (Ruyter et al., 1997; Leaver et al., 1998) and these are homologues of the mammalian $\operatorname{PPAR} \alpha, \operatorname{PPAR} \beta$ and PPAR $\gamma$ genes, suggesting that all 
three PPAR isoforms were shared by a common ancestor of fish and mammals and, therefore, PPARS might be expected to have essentially conserved functions across these phyla. However, in salmon at least, it appears that there are multiple genes for PPAR $\beta$ isoforms (Leaver, personal communication) and since there is only one PPAR $\beta$ gene in mammals, there yet may be some divergence in the functions of PPARs between fish and mammals. Interestingly, although PPAR $\beta$ is probably the least well studied PPAR isoform, it has recently been shown that PPAR $\beta$ may function as a negative regulator of PPAR $\alpha$ and PPAR function by competing for binding at gene regulatory elements and then recruiting proteins involved in depressing transcriptional activity (Shi et al., 2002).

The list of genes regulated by PPARs in mammals contains many of great relevance to a number of issues in fish lipid metabolism and biosynthesis. One such gene is peroxisomal acyl-CoA oxidase (ACO), responsible for peroxisomal chain shortening of very long chain fatty acids in mammals and postulated to catalyse the final step in DHA biosynthesis. ACO mRNA and activity is increased in salmon by treatment with fibrates, a well know class of peroxisomal proliferators. A number of studies have suggested that fatty acid desaturases are regulated by PPARs in mammals, for example stearoyl CoA $\Delta 9$ desaturase genes have been shown to be directly regulated by PPARs by virtue of PPREs in their upstream regulatory regions. In addition, in rodents peroxisomal proliferators are known to up-regulate fatty acyl $\Delta 6, \Delta 5$ and $\Delta 9$ desaturases (Kawashima et al., 1990; Gronn et al., 1992; Alegret et al., 1995) and clofibrate has been shown to increase the desaturation of 20:5n-3 in rainbow trout (Tocher and Sargent, 1993). Fish are also known to respond to peroxisomal proliferators such as fibrate and partially hydrogenated fish oil by an increase in peroxisomal fatty acid $\beta$-oxidation (Ruyter et al., 1997). Taken together these observations suggest that in fish, as well as in mammals, PPARs will prove to have critical roles in regulating genes involved in lipid homeostasis, by acting as fatty acid sensors and signal transducers.

Interestingly, in mammals, the suppression of hepatic lipogenic enzyme gene transcription does not appear to require PPAR $\alpha$ or cyclooxygenase activity (prostanoids) and so must involve a different pathway or mechanism to that described above (Jump et al., 1999). It remains to be elucidated if the regulation of lipogenic enzyme activity by PUFA in fish, as described in section 3.1, is similar to that in mammals. In addition, saturated and unsaturated long chain fatty acids are also now known to positively induce the transcription of some genes in a physiologically relevant manner, including liver type FABP and carnitine palmitoyltransferase-1 (Dupluss et al., 2000). Again it is not known if the expression of the genes for these proteins, important in lipid and fatty acid homeostasis, is induced or regulated by dietary fatty acids in fish as in mammals but it is an area of considerable interest that will hopefully be elucidated in the near future. 
The phosphoinositide cycle, in which phosphorylated derivatives of PtdIns such as PtdIns4,5P $\mathrm{P}_{2}$ are converted by the action of phospholipase $\mathrm{C}$ into two intracellular second messengers, diacylglycerol and inositol phosphates (e.g. InsP $\mathrm{P}_{3}$ ), in response to various hormones and effectors is well characterised in mammals (Berridge, 1987). Similarly, platelet-activating factor (PAF), 1-O-alkyl-2-acetyl-sn-glycero-3phosphocholine, a biologically active phospholipid synthesized by inflammatory cells, is implicated in mammals in the activation and/or aggregation of platelets and leukocytes and may be a mediator of hypotensive activities, as well as causing increased vascular permeability, vasoconstriction and contraction of smooth muscle (Snyder, 1987). Although the basic components of the phosphoinositide cycle and PAF pathway are known to occur in fish, there has been very little further significant advances in these areas since an earlier review (Tocher, 1995).

\section{Concluding Remarks}

The more applied aspects of lipid and fatty acid metabolism in fish, specifically those pertaining to nutrition and aquaculture, including qualitative and quantitative requirements, antioxidants and lipid peroxidation , and alternatives to fish oil had been covered by a very recent review (Sargent et al., 2002) and so were not included here. Rather, this review has attempted to focus on the basic biochemistry that underpins these practical aspects and the very considerable body of applied research that has grown exponentially along with the rapidly expanding aquaculture industry. It may be that the overriding impression readers take from this review is therefore, a) that there is relatively little known about the details of many fundamental pathways of lipid and fatty acid metabolism in fish and, b) that what is known indicates that the basic metabolic pathways are generally similar in fish to those more fully characterised in mammals and, c) that much of our current knowledge of basic biochemistry of lipid and fatty acid metabolism in fish has been relatively static over the last few years and not progressed significantly. However a more positive way to look at this is to express satisfaction that much of the early work on lipid and fatty acid metabolism in fish has proved robust and that many of the conclusions are as valid today as they were some years ago! Hopefully, though, this review will also have shown clearly the areas that still require to be investigated in much greater depth so that the problems, currently the focus of so much attention in fish nutrition and aquaculture, can be tackled in a more pure science driven manner, rather than in the trial and error approach so prevalent today. These problems include those associated with the use of high energy (fat) diets to increase growth through protein sparing and improved feed efficiency, such as increased adiposity and tissue lipid deposition. In addition, the problem of finding suitable, sustainable and environmentally acceptable alternatives to fish oil in aquaculture 
is dominated by the need to maintain the high levels of 20:5n-3 and 22:6n-3 and prevent over high levels of 18:2n-6 in fish, and thus preserve the highly prized beneficial quality of fish as a food. Thus, a deeper understanding of the control mechanisms that regulate lipid catabolism and tissue deposition, and of the factors affecting fatty acid desaturation and elongation and the production of 20:5n-3 and 22:6n-3 from 18:3n-3 found in some vegetable oils, is essential. In this respect, the present article has also highlighted the increasing application of molecular biological techniques to these fundamentally important areas, with the resultant cloning of the genes in fish for, among others, lipoprotein apoproteins, FABPs, PPARs and fatty acid desaturase and elongase enzymes, perhaps being among the most important developments. The application of molecular technologies in the area of fish lipid metabolism now opens the door for further advances to be made through molecular genetics, genomics and, consequently, proteomics. Identification of specific genes and metabolic pathways influencing phenotypic traits that are important in terms of efficiency and sustainability of farm production, welfare of farmed stocks, and quality and nutritional value of products for the consumer will undoubtedly follow. Depending on the problem addressed, sets of "indicator" genes can be selected from among those identified, which could then form the basis of DNA microarrays or "chips" for monitoring health and performance. Ultimately therefore, it is probable that stock selection based on specific genes or gene traits will be used to produce strains of fish with improved and desirable production characteristics, including increased production and/or retention of nutrients of particular importance in achieving balanced diets, such as 20:5n-3 and 22:6n-3. Although these technologies may be developed first for use in aquaculture, it is likely that the same technologies in a broader sense could be applied to assist efforts to understand, and possibly reverse, the ongoing decline in wild fish populations. Therefore, with this realisation, I hope the reader will appreciate that we are on the brink of a new era in understanding lipid metabolism in fish and that the next few years promise to be an exciting and illuminating time not only for all of us working in this field but for everyone with an interest in fish, even if it is just eating them!

\section{References}

Aceto, A., F. Amicarelli, P. Sacchetta, B. Dragani, T. Bucciarelli, L. Masciocco, M. Miranda and C. Di Ilio. Developmental aspects of detoxifying enzymes in fish (Salmo iridaeus). Free Rad. Res., 21: 285-294 (1994).

Ackman, R. G. Characteristics of the fatty acid composition and biochemistry of some fresh water fish oils and lipids in comparison with marine oils and lipids. Comp. Biochem. Physiol., 22: 907-922 (1967).

Ackman, R. G. Fish lipids, Part.1.pp. 87-103 In: Advances in Fish Science and Technology. (Connell, J. J. Ed.). Farnham, England: Fishing News Books (1980). 
Ackman, R. G. Fatty acid composition of fish oil. pp. 25-88 In: Nutritional Evaluation of Long Chain Fatty Acids in Fish Oil. (Barlow, S. M., and M. E. Stansby, Eds.). London, England: Academic Press (1982).

Ackman, R. G. (Editor). Marine Biogenic Lipids, Fats and Oils. Florida: CRC Press (1989).

Ackman, R. G. and C. McLeod. Total lipids and nutritionally important fatty acids of some Nova Scotia fish and shellfish food products. Can. Inst. Food Sci. Technol. J., 21: 390-398 (1988).

Aki, T., Y. Shimada, K. Inagaki, H. Higashimoto, S. Kawamoto, S. Shigeta, K. Ono, K. and O. Suzuki. Molecular cloning and functional characterization of rat $\Delta-6$ fatty acid desaturase. Biochem. Biophys. Res. Commun., 255: 575-579 (1999).

Aldridge T.C., J. D. Tugwood and S. Green. Identification and characterization of DNA elements implicated in the regulation of CYP4A1 transcription. Biochem. J., 306: 473-479 (1995).

Alegret, M., E. Cerqueda, R. Ferramdo, M. Vazquez, R.M. Sanchez, T. Adzet, M. Merlos and J. C. Laguna. Selective modification of rat hepatic microsomal fatty acid chain elongation and desaturation by fibrates: relationship with peroxisomal proliferation. Br.J. Pharmacol., 114: 1351-1358 (1995).

Alvarez, M. J., A. Diez, C. Lopez-Bote, M. Gallego and J. M. Bautista. Short-term modulation of lipogenesis by macronutrients in rainbow trout (Oncorhynchus mykiss) hepatocytes. B. J. Nutr., 84: 619-628 (2000).

Amthauer, R., J. Villanueva, M. I. Vera, M. Concha, and M. Krauskopf. Characterization of the major plasma apolipoproteins of the high density lipoprotein in the carp (Cyprinus carpio). Comp. Biochem. Physiol., 92B: 787-793 (1989).

Anderson, A. J., A. H. Arthington and S. Anderson, S. Lipid classes and fatty acid composition of the eggs of some Australian fish. Comp. Biochem. Physiol., 96B: 267-270 (1990).

Ando, S. and M. Hatano. Isolation of apolipoproteins from carotenoid-carrying lipoprotein in the serum of chum salmon, Oncorhynchus keta. J. Lipid Res., 29: 1264-1271 (1988).

Ando, S., X. -H. Xue, G. F. Tibbits and N. H. Haunerland. Cloning and sequencing of complementary DNA for fatty acid binding protein from rainbow trout heart. Comp. Biochem.Physiol., 119B, 213-217 (1998).

Andre, M., S. Ando, C. Ballagny, M. Durliat, G. Poupard, C. Briancon, C. and P. J. Babin. Intestinal fatty acid binding protein gene expression reveals the cephalocaudal patterning during zebrafish gut morphogenesis. Int. J. Dev.Biol., 44: 249-252 (2000).

Anon. Fatty acids and lipids from cell biology to human disease. Proc. $3^{\text {rd }}$ Congr. ISSFAL. Lipids, 34 (Supplement): S1-S350 (1999).

Arias, H. R. and F. J. Barrantes. Phosphoinositides and inositol phosphates in Discopyge tschudii electrocyte membranes. Int. J. Biochem., 22: 1387-1392 (1990).

Ashton, H. J., D. O. Farkvam and B. E. March. Fatty acid composition of lipids in the eggs and alevins from wild and cultured chinook salmon (Oncorhynchus tshawytscha). Can. J. Fish. Aquat. Sci., 50: 648-655 (1993). 
Audley, M. A., K. J. Shetty and J. E. Kinsella. Isolation and properties of phospholipase A from pollock muscle. J. Food. Sci., 43: 1771-1775 (1978).

Baba, K., Y. Takahashi, Y. Aoyagi and S. Odani. The amino acid sequence of a lamprey (Entosphenus japonicus) liver fatty acid-binding protein identified its close relationship to cardiac fatty acid-binding proteins of Mammalia. Comp. Biochem. Physiol., 123B: 223-228 (1999).

Babin, P. J. Plasma lipoprotein and apolipoprotein distribution as a function of density in the rainbow trout (Salmo gairdneri). Biochem. J., 246: 425-429 (1987).

Babin, P. J., and J. -M. Vernier. Plasma lipoproteins in fish. J. Lipid Res., 30: 467-489 (1989).

Bass, N.M., J. A. Manning and C. A. Luer. Isolation and characterization of fatty acid binding protein in the liver of the nurse shark, Ginglymostoma cirratum. Comp. Biochem. Physiol., 98A: 355-362 (1991).

Bauermeister, A. E. M. and J. R. Sargent. Biosynthesis of triacylglycerols in the intestines of rainbow trout (Salmo gairdnerii ) fed marine zooplankton rich in wax esters. Biochim. Biophys. Acta, 575: 358-364 (1979).

Beaudoin, F., L. V. Michaelson, S. J. Hey, M. J. Lewis, P. R. Shewry, O. Sayanova and J. A. Napier. Heterologous reconstitution in yeast of the polyunsaturated fatty acid biosynthetic pathway. Proc. Natl. Acad.Sci. USA, 97: 6421-6426 (2000).

Bell, J. G. (1998). Current aspects of lipid nutrition in fish farming. pp. 114-145. In: Biology of Farmed Fish. (K. Black and A. D. Pickering, Eds.). Sheffield, U.K.:Sheffield Academic Press (1998).

Bell, J. G., J. McEvoy, J. L.Webster, F. McGhee, R. M. Millar and J. R. Sargent. Flesh lipid and carotenoid composition of Scottish farmed Atlantic salmon (Salmo salar). J. Agric. Food Chem., 46: 119-127 (1998).

Bell, J. G., D. R. Tocher and J. R. Sargent. Effects of supplementation with 20:3(n-6), 20:4(n-6) and 20:5(n3) on the production of prostaglandins E and F of the 1-, 2- and 3-series in turbot (Scophthalmus maximus) brain astroglial cells in primary culture. Biochim. Biophys. Acta, 1211: 335-342 (1994).

Bell, M. V. and J. R. Dick. Molecular species composition of the major diacyl glycerophospholipids from muscle, liver, retina and brain of cod (Gadus morhua). Lipids, 26: 565-573 (1991).

Bell, M. V. and D. R. Tocher. Molecular species composition of the major phospholipids in brain and retina from rainbow trout (Salmo gairdneri). Biochem. J., 264: 909-915 (1989).

Bell, M. V., R. S. Batty, J. R. Dick, K. Fretwell, J. C. Navarro, J. C. and J. R. Sargent. Dietary deficiency of docosahexaenoic acid impairs vision at low light intensities in juvenile herring (Clupea harengus L.). Lipids, 30: 443-449 (1995).

Bell, M. V., J. R. Dick and A. E. A. Porter. Biosynthesis and tissue deposition of docosahexaenoic acid (22:6n-3) in rainbow trout (Oncorhynchus mykiss). Lipids, 36: 1153-1159 (2001). 
Berridge, M. J. Inositol trisphosphate and diacylglycerol: Two interacting second messengers. Ann. Rev . Biochem., 56: 159-194 (1987).

Bjerkeng, B., T. Storebakken and E. Wathne. Cholesterol and short-chain fatty acids in diets for Atlantic salmon Salmo salar (L.): effects on growth, organ indices, macronutrient digestibility, and fatty acid composition. Aquacult. Nutr., 5: 181-191 (1999).

Borlongan, I. G. Studies on the digestive lipases of milkfish, Chanos chanos. Aquaculture, 89: 315-325 (1990).

Boyle, A. G., Y. S. Park, T. Huque and R. C. Bruch. Properties of phospholipase C in isolated olfactory cilia from the channel catfish (Ictalurus punctatus). Comp. Biochem. Physiol., 88B: 767-776 (1987).

Brandt J.M., F. Djouadi and D. P. Kelly. Fatty acids activate transcription of the muscle carnitine palmitoyltransferase I gene in cardiac myocytes via the peroxisome proliferator-activated receptor alpha. J. Biol. Chem., 273: 23786-23792 (1998).

Brauge, C., G. Corraze, G. and F. Medale. Effects of dietary levels of carbohydrate and lipid on glucose oxidation and lipogenesis from glucose in rainbow trout, Oncorhynchus mykiss, reared in freshwater or in seawater. Comp. Biochem Physiol., 111A: 117-124 (1995).

Brenner, R.R. The oxidative desaturation of unsaturated fatty acids in animals. Mol. Cell. Biochem., 3: 41-52 (1974).

Brodtkorb, T., G. Rosenlund, G. and O. Lie. Effects of dietary levels of 20:5n-3 and 22:6n-3 on tissue lipid composition in juvenile salmon, Salmo salar, with emphasis on brain and eye. Aquacult. Nutr., 3: 175 187 (1997).

Burgoyne, R. D., T. R. Cheek and A. J. O'Sullivan. Receptor activation of phospholipase $\mathrm{A}_{2}$ in cellular signalling. Trends Biochem. Sci., 12: 332-333 (1987).

Buzzi, M., R. J. Henderson and J. R. Sargent. The desaturation and elongation of linolenic acid and eicosapentaenoic acid by hepatocytes and liver microsomes from rainbow trout (Oncorhyncus mykiss) fed diets containing fish oil or olive oil. Biochim. Biophys. Acta, 1299: 235-244 (1996).

Buzzi, M., R. J. Henderson and J. R. Sargent. Biosynthesis of docosahexaenoic acid in trout hepatocytes proceeds via 24-carbon intermediates. Comp. Biochem. Physiol., 116: 263-267 (1997).

Cancio, I. and M. P. Cajaraville. Cell biology of peroxisomes and their characteristics in aquatic organisms. Internatl. Rev.Cytol., 199: 201-293 (2000).

Chang, B. E., S. L. Hsieh and C. M. Kuo. Molecular cloning of full-length cDNA encoding $\Delta-9$ desaturase through PCR strategies and its genomic organisation and expression in grass carp (Ctenopharyngodon idella). Mol. Reprod. Develop., 58: 245-254 (2001). 
Chawla, P. and R. F. Ablett. Detection of microsomal phospholipase activity in myotomal tissue of Atlantic cod (Gadus morhua). J. Food Sci., 52: 1194-1197 (1987).

Cho, H. P., M. T. Nakamura and S. D. Clarke. Cloning, expression, and nutritional regulation of the mammalian s-6 desaturase. J. Biol. Chem., 274: 471-477 (1999a).

Cho, H. P., M. T. Nakamura and S. D. Clarke. Cloning, expression, and fatty acid regulation of the human $\Delta^{-}$ 5 desaturase. J. Biol. Chem., 274: $37335-37339$ (1999b).

Chu, F. -L. E. and S. Ozkizilcik. Lipid and fatty acid composition of striped bass (Morone saxatilis) larvae during development. Comp. Biochem. Physiol., 111B: 665-674 (1995).

Cordoba, O.L., E. I. Sanchez and J. A. Santome. The main fatty acid-binding protein in the liver of the shark (Halaetunus bivius) belongs to the liver basic type. Isolation, amino acid sequence determination and characterization. Eur. J. Biochem., 265: 832-838 (1999).

Cossins, A. R. Adaptive responses of fish membranes to altered environmental temperature. Biochem. Soc. Trans., 11: 332-333 (1983).

Cossins, A. R. and R. S. Raynard. Adaptive responses of animal cell membranes to temperature. pp. 95-111. In: Temperature in Animal Cells. (Bowler, K. and B. J. Fullen, Eds.). Cambridge, UK: Cambridge University Press (1988).

Coutteau, P., I. Geurden, I., M. R. Camara, P. Bergot and P. Sorgeloos. Review on the dietary effects of phospholipids in fish and crustacean larviculture. Aquaculture, 155: 149-164 (1997).

Cowey, C. B., J. W. Adron, J. M. Owen and R. J. Roberts. The effect of different dietary oils on tissue fatty acid composition and tissue pathology in turbot, Scophthalmus maximus. Comp. Biochem. Physiol., 53B: 399-403 (1976).

Cowley, D. J. and M. A. Sheridan. Insulin and glucagon regulate hepatic lipid biosynthesis in rainbow trout. Am.Zool., 31: 55A (1991).

Cowley, D. J. and M. A. Sheridan. Insulin stimulates hepatic lipogenesis in rainbow trout, Oncorhynchus mykiss. Fish. Physiol. Biochem., 11: 421-428 (1993).

Craig, S. R. and D. M. Gatlin. Growth and body composition of juvenile red drum (Sciaenops ocellatus) fed diets containing lecithin and supplemental choline. Aquaculture, 151: 259-267 (1997).

Crockett, E. L. and B. D. Sidell. Substrate selectivities differ for hepatic mitochondrial and peroxisomal boxidation in an Antarctic fish, Notothenia gibberifrons. Biochem. J., 289: 427-433 (1993).

Czesny, S. and K. Dabrowski. The effect of egg fatty acid concentrations on embryo viability in wild and domesticated walleye (Stizostedion vitreum). Aquat. Living Resour., 11: 371-378 (1998).

Das, K.M. and S. D. Tripathi. Studies on the digestive enzymes of grass carp, Ctenopharyngodon idella (Val.).Aquaculture, 92: 21-32 (1991). 
Davis, D. A., J. P. Lazo and C. R. Arnold. Response of juvenile red drum (Sciaenops ocellatus) to practical diets supplemented with medium chain triglycerides. Fish Physiol. Biochem., 21: 235-247 (1999).

Denovan-Wright, E. M., M. Pierce, M. K. Sharma and J. M. Wright. cDNA sequence and tissue-specific expression of a basic liver-type fatty acid binding protein in adult zebrafish (Danio rerio). Biochim. Biophys. Acta, 1492: 227-232 (2000b).

Denovan-Wright, E. M., M. Pierce and J. M. Wright. Nucleotide sequence of cDNA clones coding for a brain-type fatty acid binding protein and its tissue-specific expression in adult zebrafish (Danio rerio). Biochim. Biophys. Acta, 1492: 221-226 (2000a).

De Smet, W.H.O. Study of the serum albumin and globulin of vertebrates. Acta zool. Pathol. Antverpiensia, 70: $57-83$ (1978).

Desvilettes, C., G. Bourdier and J. C. Breton. Changes in lipid class and fatty acid composition during development in pike (Esox lucius L) eggs and larvae. Fish Physiol. Biochem., 16: 381-393 (1997).

Dias, J., G. Corraze, J. Arzel, M. J. Alvarez, J. M. Bautista, C. Lopez-Bote and S. J. Kaushik. Nutritional control of lipid deposition in rainbow trout and European seabass: effect of dietary protein/energy ratio. Cybium, 23: (suppl.), 127-137 (1999).

Dipietro, S. M., E. C. Dellangelica, C. H. Schleicher and J. A. Santome. Purification and structural characterization of a fatty acid-binding protein from the liver of the catfish Rhamdia sapo. Comp. Biochem. Physiol., 113B: 503-509 (1996).

Dreyer C., G. Krey, H. Keller, F. Givel, G. Helftenbein and W. Wahli. Control of the peroxisomal betaoxidation pathway by a novel family of nuclear hormone receptors. Cell, 68: 879-887 (1992).

Duplus, E., M. Glorian and C. Forest. Fatty acid regulation of gene transcription. J. Biol. Chem., 275: 3074930752 (2000).

Durliat, M., M. Andre and P. J. Babin. Conserved protein motifs and structural organization of a fish gene homologous to mammalian apolipoprotein E. Eur. J. Biochem., 267: 549-559 (2000).

Fabbri, E., A. Capuzzo and T. W. Moon. The role of circulating catecholamines in the regulation of fish metabolism: An overview. Comp. Biochem. Physiol., 120C: 177-192 (1998).

Falk-Petersen, S., J. R. Sargent, C. Fox, I. -B. Falk-Petersen, T. Haug and E. Kjoersvik. Lipids in Atlantic halibut (Hippoglossus hippoglossus) eggs from planktonic samples in northern Norway. Mar. Biol., 101: 553-556 (1989).

Fänge, R. and D. Grove. Digestion. pp. 161-260. In: Fish Physiology, Vol. VIII. (Hoar,W.S., D. J. Randall and J. R. Brett, Eds.). New York: Academic Press (1979).

Farber, S. A., E. S. Olson, J. D. Clark and M. E. Halpern. Characterization of $\mathrm{Ca}^{2+}$ dependent Phospholipase $\mathrm{A}_{2}$ Activity during Zebrafish Embryogenesis. J. Biol. Chem., 274: 19338-19346 (1999). 
Finn, R. N., J. R. Henderson and H. J. Fyhn. Physiological energetics of developing embryos and yolk-sac larvae of Atlantic cod (Gadus morhua). 2. Lipid metabolism and enthalpy balance. Mar. Biol., 124: 371379 (1995).

Fontagne, S., L. Burtaire, G. Corraze and P. Bergot. Effects of dietary medium-chain triacylglycerols (tricaprylin and tricaproin) and phospholipid supply on survival, growth and lipid metabolism in common carp (Cyprinus carpio L.) larvae. Aquaculture, 190: 289-303 (2000a).

Fontagne, S., G. Corraze and P. Bergot. Tricaproin, tricaprin and trilaurin are utilized more efficiently than tricaprylin by carp (Cyprinus carpio L.) larvae. J. Nutr., 130: 2009-2015 (2000b).

Fontagne, S., I. Geurden, A. -M. Escaffre and P. Bergot. Histological changes induced by dietary phospholipids in intestine and liver of common carp (Cyprinus carpio L.) larvae. Aquaculture, 161: 213223 (1998).

Fontagne, S., T. Pruszynski, G. Corraze and P. Bergot. Effect of coconut oil and tricaprylin vs. triolein on survival, growth and fatty acid composition of common carp (Cyprinus carpio L.) larvae. Aquaculture, 179: 241-251 (1999).

Fontagne, S., J. Robin, G. Corraze and P. Bergot. Growth and survival of European sea bass (Dicentrarchus labrax) larvae fed from first feeding on compound diets containing medium-chain triacylglycerols. Aquaculture, 190: 261-271 (2000c).

Forman, B.M., J. Chen and R. M. Evans. Hypolipidemic drugs, polyunsaturated fatty acids, and eicosanoids are ligands for peroxisome proliferator-activated receptors $\alpha$ and $\delta$. Proc. Natl. Acad. Sci. USA., 94: 4312-4317 (1997).

Forman, B. M., P. Tontonoz, J. Chen, R. P. Brun, B. M. Spiegelman and R. M. Evans. 15-deoxy- $\Delta 12,14-$ prostaglandin $\mathrm{J}_{2}$ is a ligand for the adipocyte determination factor PPAR $\gamma$. Cell, 83: 803-812 (1995).

Fraser, A. J., J. C. Gamble and J. R. Sargent. Changes in lipid content, lipid class composition and fatty acid composition of developing eggs and unfed larvae of cod (Gadus morhua). Mar. Biol., 99: 307-313 (1988).

Fremont, L. and C. Leger. The transport of plasma lipids. pp. 263-282. In: Nutrition des Poissons, Actes du Colloque CNERNA, Paris, 1979. (M. Fontaine, Ed.). Paris, France: Centre National de la Recherche Scientifique (1981).

Fremont, L., V. Duranthon, M. T. Gozzelino and S. Mahe. Activation of trout adipose tissue lipoprotein lipase by trout apoproteins. Biochimie, 69: 773-780 (1987).

Froyland, L., L. Madsen, K. M. Eckhoff, O. Lie and R. K. Berge. Carnitine palmitoyltransferase I, carnitine palmitoyltransferase II, and acyl-CoA oxidase activities in Atlantic salmon (Salmo salar). Lipids, 33: 923-930 (1998). 
Froyland, L., O. Lie and R. K. Berge. Mitochondrial and peroxisomal $\beta$-oxidation capacities in various tissues from Atlantic salmon Salmo salar. Aquacult. Nutr., 6: 85-89 (2000).

Gallagher, M. L., L. Paramore, D. Alves and R. A. Rulifson. Comparison of phospholipid and fatty acid composition of wild and cultured striped bass eggs. J. Fish Biol., 52: 1218-1228 (1998).

Gershanovich, A. D. Lipid mobilization during early development of sturgeons. pp. 41-52. In: Proc. First Internatl. Symp. Sturgeon. Bordeaux (Gironde, France), Oct. 1989. (1991).

Ghioni, C., D. R. Tocher, M. V. Bell, J. R. Dick and J. R. Sargent. Low $\mathrm{C}_{18}$ to $\mathrm{C}_{20}$ fatty acid elongase activity and limited conversion of stearidonic acid, 18:4n-3, to eicosapentaenoic acid, 20:5n-3, in a cell line from the turbot, Scophthalmus maximus. Biochim. Biophys. Acta, 1437: 179-181 (1999).

Ghosh, A. Digestive enzymes and their correlation with the food habits in the catfish Clarius batrachus (Linn.). J. Inland. Fish. Soc. India, 8: 137-139 (1976).

Gjellesvik, D.R. Enzymatic lipid digestion in teleosts : bile salt-dependent lipase as major lipolytic enzyme in cod pancreas. Dr. scient Thesis, University of Bergen, Norway. ISBN no. 82-7558-006-4 (1991a).

Gjellesvik, D.R. Fatty acid specificity of the bile salt-dependent lipase - enzyme recognition and super substrate effects. Biochim. Biophys. Acta, 1086: 167-172 (1991b).

Gjellesvik, D. R., D. Lombardo and B. T. Walther. Pancreatic bile salt dependent lipase from cod (Gadus morhua): purification and properties. Biochim. Biophys. Acta, 1124: 123-134 (1992).

Gjellesvik, D. R., J. B. Lorens and R. Male. Pancreatic carboxylester lipase from Atlantic salmon (Salmo salar) cDNA sequence and computer-assisted modelling of tertiary structure. Eur. J. Biochem., 226: 603-612 (1994).

Gjellesvik, D. R., A. J. Raae and B. T. Walther. Partial purification and characterisation of a triglyceride lipase from cod (Gadus morhua). Aquaculture, 79: 177-184 (1989).

Goetz, F. W. Compartmentalization of prostaglandin synthesis within the fish ovary. Amer. J. Physiol., 260: R862-R865 (1991).

Greene, D. H. S. and D. P. Selivonchick. Lipid metabolism in fish. Prog. Lipid Res., 26: 53-85 (1987).

Gronn, M., E. Christensen, T. -A. Hagve and B. O. Christophersen. Effects of clofibrate feeding on essential fatty acid desaturation and oxidation in isolated rat liver cells. Bichim. Biophys. Acta, 1123: 170-176 (1992).

Geurden, I., J. Radunz-Neto and P. Bergot. Essentiality of dietary phospholipids for carp (Cyprinus carpio L.) larvae. Aquaculture, 131: 303-314 (1995).

Geurden, I., N. Charlon, D. Marion and P. Bergot. Influence of purified soybean phospholipids on early development of common carp. Aquacult. Internatl., 5: 137-149 (1997). 
Gunasekera, R. M., S. S. De Silva and B. A. Ingram. Early ontogeny-related changes of the fatty acid composition inthe Percichthyid fishes trout cod, Maccullochella macquariensis and Murray cod, Maccullochella peelii peelii. Aquat. Living Resour., 12: 219-227 (1999).

Harrell, R. M. and L. C. Woods. Comparative fatty acid composition of eggs from domesticated and wild striped bass (Morone saxatilis). Aquaculture, 133: 225-233 (1995).

Hastings, N., M. Agaba, D. R. Tocher, M. J. Leaver, J. R. Dick, J. R. Sargent and A. J. Teale. A vertebrate fatty acid desaturase with $\Delta 6$ and $\Delta 5$ activities. Proc. Natl. Acad. Sci. USA., 98: 14304-14309 (2001).

Hazel, J. R. Effects of temperature on the structure and metabolism of cell membranes in fish. Am.J. Physiol., 246: R460-R470 (1984).

Hazel, J. R. Homeoviscous adaptation in animal cell membranes. pp. 149-188. In: Advances in Membrane Fluidity - Physiological Regulation of Membrane Fluidity, Vol.3, (Aloia, R. C., C. C. Curtain and L. M. Gordon, Eds.). New York, NY: Alan R. Liss Inc. (1988).

Hazel, J. R. Adaptation to temperature: phospholipid synthesis in hepatocytes of rainbow trout. Am.J. Physiol., 258: R1495-1501 (1990).

Hazel, J. R. and E. E. Williams. The role of alterations in membrane lipid composition in enabling physiological adaptation of organisms to their physical environment. Prog. Lipid Res., 29: 167-227 (1990).

Henderson, R. J. Fatty acid metabolism in freshwater fish with particular reference to polyunsaturated fatty acids. Arch. Animal Nutrition, 49: 5-22 (1996).

Henderson, R. J. and S. Almatar. Seasonal changes in the lipid composition of herring Clupea harengus in relation to gonad maturation. J. Mar. Biol. Ass. U.K., 69: 323-334 (1989).

Henderson, R. J. and J. R. Sargent. Fatty acid metabolism in fish. pp. 349-364. In: Nutrition and Feeding in Fish. (Cowey, C. B., A. M. Mackie and J. G. Bell, Eds.). London, England: Academic Press (1985)

Henderson, R. J. and D. R. Tocher. The lipid composition and biochemistry of freshwater fish. Prog. Lipid Res., 26: 281-347 (1987).

Henderson, R. J., J. R. Sargent and C. C. E. Hopkins. Changes in the content and fatty acid composition of lipid in an isolated population of the capelin, Mallottus villosus, during sexual maturation and spawning. Mar. Biol., 78: 255-263 (1984a).

Henderson, R. J., J. R. Sargent and B. J. S. Pirie. Fatty acid catabolism in the capelin Mallottus villosus (Muller) during sexual maturation. Mar. Biol. Letters, 5: 115-126 (1984b).

Henson, K. L., K. M. Sheehy and E. P. Gallagher. Conservation of a glutathione $S$-transferase in marine and freshwater fish. Mar. Environ. Res., 50: 17-21 (2000).

Higashi, S. and N. Murata. An in vivo study of substrate specificities of acyl-lipid desaturases and acyltransferases in lipid synthesis in Synechocystis PCC6803. Plant Phyiol., 102: 1275-1278 (1992). 
Hochachka, P. W. and T. P. Mommsen (Eds.). Biochemistry and Molecular Biology of Fishes,

Environmental and Ecological Biochemistry, Vol. 5. Amsterdam, Netherlands: Elsevier Press (1995).

Hoehne-Reitan, K., E. Kjorsvik and D. R. Gjellesvik. Development of bile salt-dependent lipase in larval turbot. J. Fish Biol., 58: 737-745 (2001a).

Hoehne-Reitan, K., E. Kjorsvik and K. I. Reitan. Bile salt-dependent lipase in larval turbot as influenced by density and lipid content of fed prey. J. Fish Biol., 58: 746-754 (2001b).

Holub, B. J., J. T. H. Connor and S. J. Slinger. Incorporation of glycerol-3-phosphate into hepatic lipids of rainbow trout, Salmo gairdneri. J. Fish. Res. Board Can., 32: 61-64 (1975a).

Holub, B. J., K. Nilsson, J. Piekarski and S. J. Slinger. Biosynthesis of lecithin by the CDP-choline pathway in liver micosomes of rainbow trout, Salmo gairdneri. J. Fish. Res. Board Can., 32: 1633-1637 (1975b).

Holub, B. J., J. Piekarski, C. Y. Cho and S. J. Slinger. Incorporation of fatty acids into phosphatidylcholine by acyl-CoA: 1-acyl-sn-glycero-3-phosphorylcholine acyltransferase in liver of rainbow trout, Salmo gairdneri. J. Fish. Res. Board Can., 33: 2821-2826 (1976).

Ibeas, C., C. Rodriguez, P. Badia, J. R. Cejas, F. J. Santamaria and A. Lorenzo. Efficacy of dietary methyl esters of n-3 HUFA vs. triacylglycerols of n-3 HUFA by gilthead seabream (Sparus aurata L.) juveniles. Aquaculture, 190: 273-287 (2000).

Iijima, N., M. Aihara, M. Kayama, M. Okazaki and I. Hara. Comparison of carp plasma lipoproteins under starved and fed conditions. Nippon Suissan Gakkaishi, 55: 2001-2007 (1989).

Iijima, N., T. Gotou and M. Kayama. Isolation and characterization of serum lipoproteins in red sea bream. Fish. Sci., 61: 297-303 (1995).

Iijima, N., S. Tanaka and Y. Ota. Purification and characterization of bile salt-activated lipase from the hepatopancreas of red sea bream, Pagrus major. Fish Physiol. Biochem., 18: 59-69 (1998).

Iijima, N., K. Zama and M. Kayama. Effect of oxidized lipids on the metabolic pathway of lipid biosynthesis in the intestine of the carp. Bull. Jap. Soc. Sci. Fish., 49: 1465-1470 (1983).

Ishihara, K. and H. Saito. The docosahexaenoic acid content of the lipid of juvenile bluefin tuna Thunnus thynnus caught in the sea off Japanese coast. Fisheries Sci., 62: 840-841 (1996).

Ishizaki, Y., R. Masuda, K. Uematsu, K. Shimizu, M. Arimoto and T. Takeuchi. The effect of dietary docosahexaenoic acid on schooling behaviour and brain development in larval yellowtail. J. Fish Biol., 58: 1691-1703 (2001).

Issemann, I. and S. Green. Activation of a member of the steroid hormone receptor superfamily by peroxisome proliferators. Nature, 347: 645-650 (1990).

Jonas, R. E. E. and E. Bilinski. Phospholipase A activity in rainbow trout muscle. J. Fish. Res. Board Can., 24: 2555-2562 (1967).

Jump, D. B. The biochemistry of n-3 polyunsaturated fatty acids. J. Biol. Chem., 277: 8755-8758 (2002). 
Jump, D. B. and S. D. Clarke. Regulation of gene expression by dietary fat. Annu. Rev. Nutr., 19: 63-90 (1999).

Jump, D. B., A. Thelen, B. Ren and M. Mater Multiple mechanisms for polyunsaturated fatty acid regulation of hepatic gene transcription. Prostaglandins Leukotrienes Essent. Fatty Acids, 60: 345-349 (1999).

Kanazawa, A. Essential fatty acid and lipid requirement of fish. pp. 281-298. In: Nutrition and Feeding of Fish. (Cowey, C. B., A. M. Mackie and J. G. Bell, Eds.). London: Academic Press (1985).

Kapoor,B.G., H. Smit and I. A. Verighina. The alimentary canal and digestion in teleosts. Adv.Mar.Biol., 13: 109-239 (1975).

Kawashima, Y., K. Musoh and H. Kozuka. Peroxisome proliferators enhance linoleic acid meatbolism in rat liver. Increased biosynthesis of $\omega 6$ polyunsaturated fatty acids. J. Biol. Chem., 265: 9170-9175 (1990).

Kayama,M., M. Mankura and Y. Ikeda. Hydrolysis and synthesis of wax esters by different systems of carp hepatopancreas preparation. J.Biochem., 85: 1-6 (1979).

Kliewer, S. A., J. M. Lenhard, T. M. Willson, I. Patel, D. C. Morris and J. M. Lehmann. A prostaglandin $\mathrm{J}_{2}$ metabolite binds peroxisomal proliferator-activated receptor $\mathrm{g}$ and promotes adipocyte differentiation. Cell, 83: 813-819 (1995).

Kliewer, S. A., S. S. Sundseth, S. A. Jones, P. J. Brow, G. B. Wisely, C. S. Koble, P. Devchand, W. Wahli, T. M. Willson, J. M. Lanhard and J. M. Lehmann. Fatty acids and eicosanoids regulate gene expression through direct interaction with peroxisome proliferator-activated receptors $\alpha$ and $\gamma$. Proc. Natl. Acad. Sci. USA, 94: 4318-4323 (1997).

Korte, J. J., M. D. Khal, K. M. Jensen, M. S. Pasha, L. G. Parks, G.A. LeBlanc and G. T. Ankley. Fathead minnow vitellogenin: Complementary DNA sequence and messenger RNA and protein expression after 17- $\beta$-estradiol treatment. Environ. Toxicol. Chem., 19: 972-981 (2000).

Koven, W. M., R. J. Henderson and J. R. Sargent. Lipid digestion in turbot (Scophthalmus maximus). 1: Lipid class and fatty acid composition of digesta from different segments ofthe digestive tract. Fish Physiol. Biochem., 13: 69-79 (1994a).

Koven,W. M., R. J. Henderson and J. R. Sargent. Lipid digestion in turbot (Scophthalmus maximus). 2. Lipolysis in vitro of ${ }^{14} \mathrm{C}$-labelled triacylglycerol, cholesterol ester and phosphatidylcholine by digesta from different segments of the digestive tract. Fish Physiol. Biochem., 13: 275-283 (1994b).

Koven, W. M., R. J. Henderson and J. R. Sargent. Lipid digestion in turbot (Scophthalmus maximus): Invivo and in-vitro studies of the lipolytic activity in various segments of the digestive tract. Aquaculture, 151: 155-171 (1997).

Leaver, M. J., J. Wright and S. G. George. A peroxisome proliferator activated receptor gene from the marine flatfish, the plaice (Pleuronectes platessa). Mar. Env. Res., 46: 75-79 (1998) 
Lee S. S., T. Pineau, J. Drago, E. J. Lee, J. Owens, D. L. Kroetz, P. M. Fernandez-Salguero, H. Westphal and F. J. Gonzalez. Targeted disruption of the alpha isoform of the peroxisome proliferator-activated receptor gene in mice results in abolishment of the pleiotropic effects of peroxisome proliferators. Mol. Cell. Biol., 15: 3012-3022 (1995).

Leger, C. Digestion, absorption and transport of lipids. pp. 299-331. In: Nutrition and Feeding in Fish, (Cowey, C. B., A. M. Mackie and J. G. Bell, Eds.). London, England: Academic Press (1985).

Leger, C., D. Bauchart and J. Flanzy. Some properties of pancreatic lipase in Salmo gairdnerii Rich: $\mathrm{K}_{\mathrm{m}}$, effects of bile salts and $\mathrm{Ca}^{2+}$, gel filtrations. Comp. Biochem. Physiol., 57B: 359-363 (1977).

Leger, C., V. Ducruet and J. Flanzy. Lipase et colipase de la truite arc-en-ciel. Quelques resultats recents. Ann. Biol. Anim. Biochim. Biophys., 19: 825-832 (1979).

Leger, C., L. Fremont, D. Marion, I. Nassour and M. F. Desfarges. Essential fatty acids in trout serum lipoproteins, vitellogenin and egg lipids. Lipids, 16: 593-600 (1981).

Leonard, A. E., E. G. Bobik, J. Dorado, P. E. Kroeger, L. -T. Chuang, J. M. Thurmond, J.M. Parker-Barnes, T. Das, Y. -S. Huang and P. Mukerji. Cloning of a human cDNA encoding a novel enzyme involved in the elongation of long-chain polyunsaturated fatty acids. Biochem. J., 350: 765-770 (2000b).

Leonard, A. E., B. Kelder, E. G. Bobik, L. -T. Chuang, J. M. Parker-Barnes, J. M. Thurmond, P. E. Kroeger, J. J. Kopchick, Y. -S. Huang and P. Mukerji. cDNA cloning and characterization of human $\Delta 5$ desaturase involved in the biosynthesis of arachidonic acid. Biochem. J., 347: 719-724 (2000a).

Leslie, J. M. and J. T. Buckley. Phospholipid composition of goldfish (Carassius auratus L.) liver and brain and temperature-dependence of phosphatidyl choline synthesis. Comp. Biochem. Physiol., 55B: 335-337 (1975).

Lie, Ø. and Lambertsen, G. 1985. Digestive lipolytic enzymes in cod (Gadus morhua): fatty acid specificity. Comp. Biochem. Physiol., 80B: 447-450 (1985).

Lie, Ø., E. Lied and G. Lambertsen. Lipid digestion in cod (Gadus morhua). Comp. Biochem. Physiol., 88B: 697-700 (1987).

Lied, E. and G. Lambertsen. Apparent availability of fat and individual fatty acids in Atlantic cod (Gadus morhua). Fisk. Dir. Skr. Ser. Ernar., II: 63-75 (1982).

Lim, E. H., B. Y. Teo, T. J. Lam and J. L. Ding. Sequence analysis of a fish vitellogenin cDNA with a large phosvitin domain. Gene, 277: 175-186 (2001).

Livingstone D. R, S. Archibald, J. K. Chipman and J. W. Marsh. Antioxidant enzymes in liver of dab Limanda limanda from the North Sea. Mar. Ecol.Prog. Ser., 91: 97-104 (1992).

Londraville, R.L. and B. D. Sidell. Fatty-acid-binding proteins in antarctic fishes. Antarct. J. U.S., 30: 177179 (1995). 
Londraville, R.L. and B. D. Sidell. Cold acclimation increases fatty acid-binding protein concentration in aerobic muscle of striped bass, Morone saxatilis. J. Exp. Zool., 275: 36-44 (1996).

Lygren, B., K. Hamre and R. Waagbo. Effect of induced hyperoxia on the antioxidant status of Atlantic salmon Salmo salar L. fed three different levels of dietary vitamin E. Aquaculture Res., 31: 401-407 (2000).

McKay, M. C., R. F. Lee and M. A. K. Smith. The characterization of the plasma lipoproteins of the channel catfish Ictalurus punctatus. Physiol. Zool., 58: 693-704 (1985).

McKenzie, D. J., D. A. Higgs, B. S. Dosanjh, G. Deacon and D. J. Randall. Dietary fatty acid composition influences swimming performance in Atlantic salmon (Salmo salar) in seawater. Fish Physiol.Biochem., 19: 111-122 (1998).

Macartney, A.L., P. E. Tiku and A. R. Cossins. An isothermal induction of $\Delta 9$-desaturase in cultured carp hepatocytes. Biochim. Biophys. Acta, 1302: 207-216 (1996).

Madsen, L., A. C. Rustan, H. Vaagenes, K. Berge, E. Dyroy and R. K. Berge. Eicosapentaenoic and docosahexaenoic acid affect mitochondrial and peroxisomal fatty acid oxidation in relation to substrate preference. Lipids, 34: 951-963 (1999).

Mankura, M. and M. Kayama. Wax ester synthesis and hydrolysis in carp plasma. Bull. Jap. Soc. Sci. Fish., 51: 69-74 (1985).

Mankura, M., N. Iijima, M. Kayama and S. Aida. Plasma transport form and metabolism of dietary fatty alcohol and wax ester in carp. Nippon Suisan Gakkaishi, 53: 1221-1230 (1987).

Mankura, M., M. Kayama and N. Iijima. The role of phospholipase $A_{2}$ on wax ester synthesis in carp hepatopancreas preparations. Bull. Jap. Soc. Sci. Fish., 52: 2107-2114 (1986).

Marshall, C. T., N. A. Yaragina and Y. Lambert. Total lipid energy as a proxy for total egg production by fish stocks. Nature, 402: 288-290 (1999).

Martinez-Lara, E. F. Toribio, J. López-Barea and J. A. Barcena. Glutathione-S-transferase isoenzyme patterns in the gilthead seabream (Sparus aurata) exposed to enviromental contaminants. Comp. Biochem. Physiol., 113C: 215-220 (1996).

Mascaro C., E. Acosta, J. A. Ortiz, P. F. Marrero, F. G. Hegardt and D. Haro. Control of human muscle-type carnitine palmitoyltransferase I gene transcription by peroxisome proliferator-activated receptor. J. Biol. Chem., 273: 8560-8563 (1998).

Masuda, R., T. Takeuchi, T. Tsukamoto, Y. Ishizaki, M. Kanematsu and K. Imaizumi. Critical involvement of dietary docosahexaenoic acid in the ontogeny of schooling behaviour in the yellowtail. J. Fish Biol., 53: 471-484 (1998). 
Masuda, R., D. A. Ziemann and A. C. Ostrowski. Patchiness formation and development of schooling behaviour in pacific threadfin Polydactylus sexfilis reared with different dietary highly unsaturated fatty acid contents. J. World Aquacult. Soc., 32: 309-316 (2001).

Medina, I., S. P. Aubourg and R. P. Martin. Composition of phospholipids of white muscle of six tuna species. Lipids, 30: 1127-1135 (1995).

Michaelson, L. V., C. M. Lazarus, G. Griffiths, J. A. Napier and A. K. Stobart. Isolation of a $\Delta 5$-fatty acid desaturase gene from Mortierella alpina. J. Biol. Chem., 273: 19055-19059 (1998).

Moffat, C. F. and A. S. McGill. Variability of the composition of fish oils: significance for the diet. Proc. Nutr. Soc., 52: 441-456 (1993).

Motojima, K., P. Passilly, J. M. Peters, J. M., and F. J. Gonzalez. Expression of putative fatty acid transporter genes are regulated by peroxisome proliferator-activated receptor alpha and gamma activators in a tissue- and inducer-specific manner. J. Biol. Chem., 273: 16710-16714 (1998).

Mourente, G. and J. M. Odriozola. Effect of broodstock diets on lipid classes and their fatty acid composition in eggs of gilthead sea bream (Sparus aurata L.). Fish Phsiol. Biochem., 8: 93-101 (1990).

Mourente, G. and D. R. Tocher. In vivo metabolism of $\left[1-{ }^{14} \mathrm{C}\right]$ linolenic acid (18:3n-3) and [1${ }^{14}$ C] eicosapentaenoic acid (20:5n-3) in a marine fish. Time course of the desaturation/elongation pathway. Biochim. Biophys. Acta, 1212: 109-118 (1994).

Mourente, G. and R. Vazquez. Changes in the content of total lipid, lipid classes and fatty acids of developing eggs and unfed larvae of the Senegal sole, Solea senegalensis Kaup. Fish Physiol. Biochem., 15: 221-235 (1996).

Mourente, G., E. Díaz-Salvago, J. G. Bell and D. R. Tocher. Increased activities of hepatic antioxidant defence enzymes in juvenile gilthead sea bream (Sparus aurata L., Osteichthyes, Sparidae) fed dietary oxidised oil: Attenuation by dietary vitamin E. Aquaculture, in press (2002).

Mourente, G., E. Diaz-Salvago, D. R. Tocher and J. G. Bell. Effects of dietary vitamin E/polyunsaturated fatty acid (tocopherol/PUFA) ratio on antioxidant systems in juvenile gilthead sea bream (Sparus aurata L., Osteichthyes, Sparidae). Fish Physiol. Biochem., 23: 337-351 (2000).

Mourente, G., A. Rodriguez, A. Grau and E. Pastor, E. Utilization of lipids by Dentex dentex L. (Osteichthyes, Sparidae) larvae during lecitotrophia and subsequent starvation. Fish Physiol. Biochem., 21: 45-58 (1999a).

Mourente, G., D. R. Tocher, E. Díaz, A. Grau and E. Pastor. Relationships between antioxidant enzyme activities and lipid peroxidation products during early development in Dentex dentex eggs and larvae. Aquaculture, 179: 309-324 (1999b). 
Mourente, G., D. R. Tocher, E. Díaz-Salvago, A. Grau and E. Pastor. Study of the n-3 highly unsaturated fatty acids requirement and antioxidant status of Dentex dentex at Artemia feeding stage. Aquaculture, 179: 291-307 (1999c).

Muerhoff A.S., K. J. Griffin and E. F. Johnson. The peroxisome proliferator-activated receptor mediates the induction of CYP4A6, a cytochrome P450 fatty acid omega-hydroxylase, by clofibric acid. J. Biol. Chem., 267: 19051-19053 (1992).

Mukundan, M. K., K. Gopakumar and M. R. Nair. Purification of a lipase from the hepatopancreas of oil sardine (Sardinella longiceps Linnaeus) and its characteristics and properties. J. Sci. Food Agric., 36: 191-203 (1985).

Murase, T. and H. Saito. The docosahexaenoic acid content in the lipid of albacore Thunnus alalunga caught in two separate localities. Fish. Sci., 62: 634-638 (1996).

Nagler, J. J. and D. R. Idler. Ovarian uptake of vitellogenin and another very high density lipoprotein in winter flounder (Pseudopleuronectes americanus) and their relationship with yolk proteins. Biochem. Cell Biol., 68: 330-335 (1990).

Nakagawa, H. Biochemical studies on carp plasma protein -II. Characterization of lipoproteins of globulin fraction. Bull. Jap. Soc. Sci. Fish., 45: 219-224 (1979).

Nakagawa, H., M. Kayama and S. Asakawa. Biochemical studies on carp plasma protein. I - Isolation and nature of an albumin. Bull. Jap. Soc. Sci. Fish., 42: 677-685 (1976).

Nakamura, K., H. Iida, T. Tokunga, M. Hata and M. Hata. Study on chum salmon, Oncorhynchus keta, serum lipoproteins. Bull. Tokai Reg. Fish. Res. Lab./Tokaisuikenho, 116: 13-19 (1985).

Napier, J. A., S. J. Hey, D. J. Lacey and P. R. Shewry. Identification of a Caenorhabditis elegans $\Delta-6$ fatty acid-desaturase by heterologous expression in Saccharomyces cerevisiae. Biochem. J., 330: 611-614 (1998).

Neas, N. P. and J. R. Hazel. Phospholipase $A_{2}$ from liver microsomal membrane of thermally acclimated rainbow trout. J. Exp. Zool., 233: 51-60 (1985).

Nicol, J. A. C., H. J. Arnott, G. R. Mizuno, E. C. Ellison and J. R. Chipault. Occurrence of glyceryl tridocosahexaenoate in the eye of the sand trout Cynoscion arenaruis. Lipids, 7: 171-177 (1972).

Okuyama, H., T. Kobayashi and S. Watanabe. Dietary fatty acids - the n- $6 / n-3$ balance and chronic elderly diseases. Excess linoleic acid and relative n-3 deficiency syndrome seen in Japan. Prog. Lipid Res., 35 : 409-457 (1997).

Olsen, R. E. and E. Ringoe. Lipid digestibility in fish: A review. Recent Res. Devel. in Lipids Res., 1: 199265 (1997).

Olsen, R. E. and E. Ringoe. The influence of temperature on the apparent nutrient and fatty acid digestibility 
of Arctic charr, Salvelinus alpinus L. Aquaculture Res., 29: 695-701 (1998).

Olsen, R. E., R. J. Henderson and E. Ringoe. The digestion and selective absorption of dietary fatty acids in Arctic charr, Salvelinus alpinus. Aquacult. Nutr., 4: 13-21 (1998).

Olsen, R. E., R. Myklebust, T. Kaino and E. Ringoe. Lipid digestibility and ultrastructural changes in the enterocytes of Arctic char (Salvelinus alpinus L.) fed linseed oil and soybean lecithin. Fish Physiol. Biochem., 21: 35-44 (1999).

Ono, H. and N. Iijima. Purification and characterization of phospholipase $\mathrm{A}_{2}$ isoforms from the hepatopancreas of red sea bream, Pagrus major. Fish Physiol. Biochem., 18: 135-147 (1998).

Otto, D. M. E. and T. W. Moon. Endogenous antioxidant systems of two teleost fish, the rainbow trout and the black bullhead, and the effect of age. Fish Physiol. Biochem., 15: 349-358 (1996).

Owen, J. M., J. A. Adron, C. Middleton and C. B. Cowey. Elongation and desaturation of dietary fatty acids in turbot (Scophthalmus maximus) and rainbow trout (Salmo gairdneri). Lipids, 10: 528-531 (1975).

Ozkizilcik, S., F. -L. E. Chu and A. R. Place. Ontogenetic changes of lipolytic enzymes in striped bass (Morone saxatilis). Comp. Biochem. Physiol., 113B: 631-637 (1996).

Parker-Barnes, J. M., T. Das, E. Bobik, A. E. Leonard, J. M. Thurmond, L. -T. Chaung, Y. -S. Huang and P. Mukerji. Identification and characterization of an enzyme involved in the elongation of n-6 and n-3 polyunsaturated fatty acids. Proc. Natl. Acad. Sci. USA, 97: 8284-8289 (2000).

Patton, J. S., M. S. Haswell and T. W. Moon. Aspects of lipid synthesis, hydrolysis, and transport studied in selected Amazon fish. Can. J. Zool., 56: 787-792 (1978).

Patton, J. S., J. C. Nevenzel and A. A. Benson. Specificity of digestive lipases in hydrolysis of wax esters and triglycerides studied in anchovy and other selected fish. Lipids, 10: 575-583 (1975).

Perez, J. A., C. Rodriguez and R. J. Henderson. The uptake and esterification of radiolabelled fatty acids by enterocytes isolated from rainbow trout (Oncorhynchus mykiss). Fish Physiol. Biochem., 20: 125-134 (1999).

Peters, L.D. and D. R. Livingstone. Antioxidant enzyme activities in embryologic and early larval stages of turbot. J. Fish Biol., 49: 986-997 (1996).

Peters, L.D., C. Porte, J. Albaiges and D. R. Livingstone. 7-Ethoxyrosorufin O-deethylase (EROD) and antioxidant enzyme activities in larvae of sardine (Sardina pilchardus) from the North coast of Spain. Mar. Pollut. Bull., 28: 299-304 (1994).

Pickova, J., A. Kiessling, A. Pettersson and P. C. Dutta. Fatty acid and carotenoid composition of eggs from two nonanadromous Atlantic salmon stocks of cultured and wild origin. Fish Physiol. Biochem., 21: 147156 (1999). 
Poupard, G., M. Andre, M. Durliat, C. Ballagny, G. Boeuf and P. J. Babin. Apolipoprotein E gene expression correlates with endogenous lipid nutrition and yolk syncytial layer lipoprotein synthesis during fish development. Cell Tissue, 300: 251-261 (2000).

Prahl, F. G., G. Eglinton, E. D. S. Conner and S. C. M. O`Hara. Faecal lipids released by fish feeding on zooplankton. J. Mar. Biol. Assoc.U.K., 65: 547-560 (1985).

Rahn, C. H., D. M. Sand and H. Schlenk. Wax estaers in fish, absorption and metabolism of oleyl alcohol in the gourami (Trichogaster cosby). J. Nutr., 103: 1441-1447 (1973).

Rainuzzo, J. R. Fatty acid and lipid composition of fish egg and larvae. pp. 43-49. In: Fish Farming Technology. Proceedings of the First International Conference on Fish Farming Technology, Trondheim, Norway, 9-12 August 1993. Rotterdam (Netherlands): Balkema (1993)

Rainuzzo, J. R., K. I. Reitan and L Joergensen. Comparative study on the fatty acid and lipid composition of four marine fish larvae. Comp. Biochem.Physiol., 103B: 21-26 (1992).

Regost, C., J. Arzel, M. Cardinal, J. Robin, M. Laroche and S. J. Kaushik. Dietary lipid level, hepatic lipogenesis and flesh quality in turbot (Psetta maxima). Aquaculture, 193: 291-309 (2001).

Reith, M., J. Munholland, J. Kelly, R. N. Finn and H. J. Fyhn. Lipovitellins derived from two forms of vitellogenin are differentially processed during oocyte maturation in haddock (Melanogrammus aeglefinus). J. Exp. Biol., 291: 58-67 (2001).

Riazi, A. and L. Fremont. Serum vitellogenin and yolk proteolipid complex composition in relation to ovarian growth in rainbow trout Salmo gairdneri (Rich.). Comp. Biochem. Physiol., 89B: 525-530 (1988).

Rivers, J. P. W., A. J. Sinclair and M. J. Crawford. Inability of the cat to desaturate essential fatty acids. Nature, 285: 171-173 (1975).

Rodriguez J. C., G. Gil-Gomez, F. G. Hegardt and D. Haro. Peroxisome proliferator activated receptor mediates induction of the mitochondrial 3-hydroxy-3-methylglutaryl-CoA synthase gene by fatty acids. J. Biol. Chem., 269: 18767-18772 (1994).

Roesjoe, C., S. Nordrum, J. J. Olli, A. Krogdahl, B. Ruyter and H. Holm. Lipid digestibility and metabolism in Atlantic salmon (Salmo salar) fed medium-chain triglycerides. Aquaculture, 190: 65-76 (2000).

Ronnestad, I., R. N. Finn, I. Lein and O. Lie. Compartmental changes in the contents of total lipid, lipid classes and their associated fatty acids in developing yolk-sac larvae of Atlantic halibut, Hippoglossus hippoglossus (L.). Aqacult. Nutr., 1: 119-130 (1995).

Ronnestad, I., W. M. Koven, A. Tandler, M. Harel and H. J. Fyhn. Energy metabolism during development of eggs and larvae of gilthead sea bream (Sparus aurata). Mar. Biol., 120: 187-196 (1994). 
Ronnestad, I., W. M. Koven, A. Tandler, M. Harel and H. J. Fyhn. Utilisation of yolk fuels in developing eggs and larvae of European sea bass (Dicentrarchus labrax). Aquaculture, 162: 157-178 (1998).

Rose, G. A. Can Newfoundland cod stocks recover without capelin? ICES CIEM Newsletter, 38: 8 (2001).

Ruyter, B. O. Andersen, A. Dehli, A. -K. Ostlund Farrants, T. Gjoen and M. S. Thomassen. Peroxisome proliferator activated receptors in Atlantic salmon (Salmo salar): effects on PPAR transcription and acylCoA oxidase activity in hepatocytes by peroxisome proliferators and fatty acids. Biochim. Biophys. Acta, 1348: 331-338 (1997).

Saito, H., K. Ishihara and T. Murase. Effect of prey fish lipids on the docosahexaenoic acid content of total fatty acids in the lipid of Thunnus albacares yellowfin tuna. Biosci. Biotechnol. Biochem., 60: 962-965 (1996).

Sanchez-Muros, M. J., L. Garcia-Rejon, J. A. Lupianez and M. De la Higuera. Long-term nutritional effects on the primary liver and kidney metabolism in rainbow trout (Oncorhynchus mykiss). 2. Adaptive response of glucose 6-phosphate dehydrogenase activity to high-carbohydrate/low-protein and highfat/non-carbohydrate diets. Aquacult. Nutr., 2: 193-200 (1996).

Santulli, A., A. Curatolo, A. Modica, L. D'Amelio and V. D'Amelio. Serum lipoproteins of sea bass (Dicentrarchus labrax L.). Purification and partial characterization by density gradient ultracentrifugation and agarose column chromatography. Comp. Biochem. Physiol., 94B: 613-620 (1989).

Santulli, A., C. M. Messina and V. D’Amelio. Variations of lipid and apolipoprotein content in lipoproteins during fasting in European sea bass (Dicentrarchus labrax L.). Comp. Biochem. Physiol., 118A: 12331239 (1997).

Sargent, J. R. Ether-linked glycerides in marine animals. pp. 175-198. In: Marine Biogenic Lipids, Fats and Oils, (Ackman, R. G., Ed.). Bacon Raton, Florida: CRC Press (1989).

Sargent, J. R. Origins and functions of lipids in fish eggs: nutritional implications. pp. 353-372. In: Broodstock Management and Egg and Larval Quality. (Bromage, N. R. and R. R. Roberts, Eds.). Oxford: Blackwell Science (1995a).

Sargent, J. R. (n-3) Polyunsaturated fatty acids and farmed fish. pp. 67-94. In: Fish Oil: Technology, Nutrition and Marketing. (Hamilton, R. J. and R. D. Rice, Eds.). High Wycombe, England: P. J. Barnes \& Associates (1995b).

Sargent, J. R. Fish oils and human diet. Brit. J. Nutr., 78: Suppl. 1, S5-S13 (1997).

Sargent, J. R. and R. J. Henderson. Marine (n-3) polyunsaturated fatty acids. pp. 32-65. In: Developments in Oils and Fats. ( Hamilton, R. J., Ed.). London: Blackie Academic and Professional (1995).

Sargent, J. R. and A. G. J. Tacon. Development of farmed fish: a nutritionally necessary alternative to meat. Proc. Nutr. Soc., 58: 377-383 (1999). 
Sargent, J., G. Bell, L. McEvoy, D. Tocher and A. Estevez. Recent developments in the essential fatty acid nutrition of fish. Aquaculture, 177: 191-199 (1999a).

Sargent, J. R., J. G. Bell, M. V. Bell, R. J. Henderson and D. R. Tocher. The metabolism of phospholipids and polyunsaturated fatty acids in fish. pp. 103-124. In: Aquaculture: Fundamental and Applied Research, Vol. 43, Coastal and Estuarine Studies. (Lahlou, B. and P. Vitiello, Eds.). Washington, D.C.: American Geophysical Union (1993a).

Sargent, J. R., J. G. Bell, M. V. Bell, R. J. Henderson and D. R. Tocher. Requirement criteria for essential fatty acids. Symposium of European Inland Fisheries Advisory Commission. J. Appl. Ichthyol., 11: 183198 (1995a).

Sargent, J. R., J. G. Bell, M. V. Bell, R. J. Henderson and D. R. Tocher. Dietary origins and functions of long-chain (n-3) polyunsaturated fatty acids in marine fish. J. Mar. Biotechnol., 3: 26-28 (1995d).

Sargent, J. R., M. V. Bell, J. G. Bell, R. J. Henderson and D. R. Tocher. Evolution and roles of (n-3) polyunsaturated fatty acids in marine organisms. pp. 248-259. In: Phospholipids: Characterization, Metabolism and Novel Biological Applications. (Cevc, G. and F. Paltauf, Eds.). Champaign, IL: Amer. Oil Chem. Soc. Press. (1995b).

Sargent, J. R., M. V. Bell, R. J. Henderson and D. R. Tocher. Polyunsaturated fatty acids in marine and terrestrial food webs. pp. 11-23. In: Comparative Physiology, Vol. 5, Animal Nutrition and Transport Processes: Nutrition in Wild and Domestic Animals. (Mellinger, J., J. P. Truchot and B. Lahlou, Eds.). Basel: Karger (1990)

Sargent, J. R., M. V. Bell and R. J. Henderson. Protists as sources of essential (n-3) polyunsaturated fatty acids for predator development. Europ. J. Protistology, 31: 460-461 (1995c).

Sargent, J. R., M. V. Bell and D. R. Tocher. Docosahexaenoic acid and the development of brain and retina in fish. pp. 139-149. In: Omega-3 Fatty Acids: Metabolism and Biological Effects. (Drevon, C. A., I. Baksaas and H. E. Krokan, Eds.). Basel, Switzerland: Birkhauser Verlag (1993b).

Sargent, J. R., R. J. Henderson and D. R. Tocher. The lipids. pp.153-218. In: Fish Nutrition, second edition. (Halver, J. E., Ed.). New York: Academic Press (1989).

Sargent, J. R., L. A. McEvoy and J. G. Bell. Requirements, presentation and sources of polyunsaturated fatty acids in marine fish larval feeds. Aquaculture, 155: 119-129 (1977).

Sargent, J., L. McEvoy, A. Estevez, G. Bell, M. Bell, J. Henderson and D. R. Tocher. Lipid nutrition of marine fish during early development: current status and future directions. Aquaculture, 179: 217-229 (1999b).

Sargent, J. R., R. McIntosh, A. E. M. Bauermeister and J. H. S. Blaxter. Assimilation of the wax esters of marine zooplankton by herring (Clupea harengus) and rainbow trout (Salmo gardnerii). Mar.Biol., 51: 203-207 (1979). 
Sargent, J. R., D. R. Tocher and J. G. Bell. The lipids. pp. 181-257. In: Fish Nutrition, 3rd Edition, Ch.4. (Halver, J. E., Ed.). San Diego: Academic Press (2002).

Sawada, T., K. Takahashi and M. Hatano. Triglyceride composition of tuna and bonito orbital oils. Nippon Suisan Gakkaishi, 59: 285-290 (1993).

Schmidt, A., M. Wolde, C. Thiele, W. Fest, H. Kratzin, A. V. Podtelejnikov, W. Witke, W. B. Huttner and H. D. Soling. Endophilin I mediates synaptic vesicle formation by transfer of arachidonate to lysophosphatidic acid. Nature, 401: 133- 141 (1999).

Schoonjans, K., G. Martin, B. Staels and J. Auwerx. Peroxisome proliferator-activated receptors, orphans with ligands and functions. Curr. Opinion Lipidology, 8: 159-166 (1997).

Schoonjans K., M. Watanabe, H. Suzuki, A. Mahfoudi, G. Krey, W. Wahli, P. Grimaldi, B. Staels, T. Yamamoto and J. Auwerx. Induction of the acyl-coenzyme A synthetase gene by fibrates and fatty acids is mediated by a peroxisome proliferator response element in the $\mathrm{C}$ promoter. J. Biol. Chem., 270: 19269-19276 (1995).

Seiliez, I., S. Panseat, S. Kaushik and P. Bergot. Cloning, tissue distribution and nutritional regulation of a 46-desaturase-like enzyme in rainbow trout. Comp. Biochem. Physiol., 130B: 83-93 (2001).

Selman, K. and R. A. Wallace. The inter- and intracellular passage of proteins through the ovarian follicle in teleosts. pp. 151-154. In: Proc. Int. Symp. Reprod. Physiol. Fish. (Richter, C. J. J. and H. J. Th. Goos, Eds.). Wageningen, Netherlands: Puduc Press (1982).

Seo, H. S., Y. Endo, M. Moku, K. Kawaguchi and K. Fujimoto. Wax ester biosynthesis in the liver of myctophid fishes. Lipids, 36: 389-393 (2001).

Shen, Y., A. Lindberg and G. Olivecrona. Apolipoprotein CII from rainbow trout (Oncorhynchus mykiss) is functionally active but structurally very different from mammalian apolipoprotein CII. Gene, 254: 189$198(2000)$.

Sheridan, M. A. Lipid dynamics in fish: Aspects of absorption, transportation, deposition and mobilization. Comp. Biochem. Physiol., 90B: 679-690 (1988).

Sheridan, M. A. Regulation of lipid metabolism in poikilothermic vertebrates. Comp. Biochem. Physiol., 107B: 495-508 (1994).

Sheridan, M. A., J. K. L. Friedlander and W. V. Allen. Chylomicra in the serum of post-prandial steelhead trout (Salmo gairdneri). Comp. Biochem. Physiol., 81B: 281-284 (1985).

Shewfelt, R. L. Fish muscle lipolysis - a review. J. Food Biochem., 5: 79-100 (1981).

Shewfelt, R. L., R. E. McDonald and H. O. Hultin. Effect of phospholipid hydrolysis on lipid oxidation in flounder muscle microsomes. J. Food Sci., 46: 1297-1301 (1981). 
Shi, Y., M. Hon, and R. M. Evans. The peroxisome proliferator-activated receptor $\delta$, an integrator of transcriptonal repression and nuclear receptor signalling. Proc. Natl. Acad. Sci. USA, 99: 2613-2618 (2002).

Shikata, T. and S. Shimeno. Metabolic response to dietary stearic acid, linoleic acid, and highly unsaturated fatty acid in carp. Fish. Sci., 60: 735-739 (1994).

Shimeno, S., H. Hosokawa and M. Takeda. Metabolic response of juvenile yellowtail to dietary carbohydrate to lipid ratios. Fish. Sci., 62: 945-949 (1996).

Shimeno, S., D. Kheyyali and T. Shikata. Metabolic response to dietary lipid to protein ratios in common carp. Fish. Sci., 61: 977-980 (1995).

Shulman, G. E. and K. K. Yakovleva. Hexaene acid and the natural mobility of fishes. Zh.Obshch. Biol., 44: 529-534 (1983).

Sidell, B. D., E. L. Crockett and W. R. Driedzic. Antarctic fish preferentially catabolize monoenoic fatty acids. J. Expt. Zool., 271: 73-81 (1995).

Sigurgisladottir, S., S. P. Lall, C. C. Parrish and R. G. Ackman. Cholestane as a digestibility marker in the absorption of polyunsaturated fatty acid ethyl esters in Atlantic salmon. Lipids, 27: 418-424 (1992).

Silversand, C., B. Norberg and C. Haux. Fatty-acid composition of ovulated eggs from wild and cultured turbot (Scophthalmus maximus) in relation to yolk and oil globule lipids. Mar. Biol., 125: 269-278 (1996).

Simpson, C. M. F. and J. R. Sargent. Inositol lipid turnover and adenosine 3,5 cyclic monophosphate in the salt-secreting rectal gland of the dogfish (Scyliorhinus canicula). Comp. Biochem. Physiol., 82B: 781$786(1985)$.

Smith, L. S. Digestive functions in teleost fishes. pp. 331-421. In: Fish Nutrition, second edition. (Halver, J. E., Ed.). San Diego: Academic Press (1989a).

Smith, W. L. The eicosanoids and their biochemical mechanisms of action. Biochem. J., 259: 315-324 (1989b).

Snyder, F. (Ed.) Platelet-Activating Factor and Related Lipid Mediators. New York, NY: Plenum Press (1987).

So, Y. P. and D. R. Idler. The ovarian incorporation of plasma proteins in addition to vitellogenin in winter flounder (Pseudopleuronectes americanus). Bull. Can. Soc. Zool., 18: 53 (1987).

Stacey, N. E. and F. W. Goetz. Role of prostaglandins in fish reproduction. Can. J. Fish Aquat. Sci., 39: 9298 (1982).

Sunarya, W., M. Fitriati and H. Mulyani. The effect of season on fat content and fatty acid profile especially n-3 of yellowfin tuna. Res. Contrib. IX Session Indo-Pacific Fishery Commission Working Party on Fish Technology and Marketing. FAO Fish. Rep., 514 Suppl: 205-209 (1995). 
Susca, V., A. Corriero, C. R. Bridges and G. DeMetrio. Study of the sexual maturity of female bluefin tuna: purification and partial characterization of vitellogenin and its use in an enzyme-linked immunosorbent assay. J. Fish Biol., 58: 815-831 (2001).

Tiku, P. E., A. Y. Gracey, A. I. MacArtney, R. J. Benyon and A. R. Cossins. Cold-induced expression of $\Delta 9$ desaturase in carp by transcription and post transitional mechanisms. Science, 271: 815-818 (1996).

Tocher, D. R. Glycerophospholipid metabolism. pp. 119-157. In: Biochemistry and Molecular Biology of Fishes, Vol. 4. Metabolic and Adaptational Biochemistry, Ch. 6. (Hochachka, P. W. and T. P. Mommsen, Eds.). Amsterdam: Elsevier Press (1995).

Tocher, D. R. and J. R. Dick. Polyunsaturated fatty acid metabolism in a cell culture model of essential fatty acid deficiency in a freshwater fish, carp (Cyprinus carpio). Fish Physiol. Biochem., 21: 257-267 (1999).

Tocher, D. R. and C. Ghioni. Fatty acid metabolism in marine fish: low activity of fatty acyl $\Delta 5$ desaturation in gilthead sea bream (Sparus auratus) cells. Lipids, 34: 433-440 (1999).

Tocher,D. R. and J. R. Sargent. Studies on triacylglycerol, wax ester and sterol ester hydrolases in intestinal caeca of rainbow trout (Salmo gairdneri, L.) fed diets rich in triacylglycerols and wax esters. Comp.Biochem.Physiol., 77B: 561-571 (1984a).

Tocher, D. R., and J. R. Sargent. Analyses of lipids and fatty acids in ripe roes of some northwest European marine fish. Lipids, 19: 492-499 (1984b).

Tocher, D. R. and J. R. Sargent. Effect of temperature on the incorporation into phospholipid classes and the metabolism via desaturation and elongation of (n-3) and (n-6) polyunsaturated fatty acids in fish cells in culture. Lipids, 25: 435-442 (1990).

Tocher, D. R. and J. R. Sargent. No relationship between morphology changes and metabolism of $\alpha$ linolenate and eicosapentaenoate in rainbow trout (Oncorhynchus mykiss) astroglial cells in primary culture. Comp. Biochem. Physiol., 106C: 211-219 (1993).

Tocher, D. R., M. Agaba, N, Hastings, J. G. Bell, J. R. Dick and A. J. Teale. Effects of dietary vegetable oil on hepatocyte fatty acid desaturation and polyunsaturated fatty acid composition of zebrafish (Danio rerio) and tilapia (Oreochromis nilotica). Fish Physiol. Biochem., In press (2001b).

Tocher, D. R., J. G. Bell, J. R. Dick and J. R. Sargent. Fatty acid desaturation in isolated hepatocytes from Atlantic salmon (Salmo salar): Stimulation by dietary borage oil containing $\gamma$-linolenic acid. Lipids, 32: 1237-1247 (1997).

Tocher, D. R., J. G. Bell, P. MacGlaughlin, F. McGhee and J. R. Dick. Hepatocyte fatty acid desaturation and polyunsaturated fatty acid composition of liver in salmonids: Effects of dietary vegetable oil. Comp. Biochem. Physiol., 130: 257-270 (2001a). 
Tocher, D. R., J. Carr and J. R. Sargent. Polyunsaturated fatty acid metabolism in cultured cell lines: differential metabolism of (n-3) and (n-6) series acids by cultured cells originating from a freshwater teleost fish and from a marine teleost fish. Comp. Biochem. Physiol., 94B: 367-374 (1989).

Tocher, D. R., A. J. Fraser, J. R. Sargent and J. C. Gamble. Fatty acid composition of phospholipids and neutral lipids during embryonic and early larval development in Atlantic herring (Clupea harengus L). Lipids, 20: 69-74 (1985a).

Tocher, D. R., A. J. Fraser, J. R. Sargent and J. C. Gamble. Lipid class composition during embryonic and early larval development in Atlantic herring (Clupea harengus L). Lipids, 20: 84-89 (1985b).

Tocher, D. R., M. J. Leaver and P. A. Hodgson, P. A. (1998). Recent advances in the biochemistry and molecular biology of fatty acyl desaturases. Progr. Lipid Res., 37: 73-117 (1998).

Tocher, D. R., G. Mourente, A, Van der Eeken, J. O. Evjemo, E. Diaz, J. G. Bell, I. Geurden, P. Lavens and Y. Olsen. Effects of dietary vitamin E on antioxidant defence mechanisms of juvenile turbot (Scophthalmus maximus L.), halibut (Hippoglossus hippoglossus L.) and sea bream (Sparus aurata L.). Aquaculture Nutr., In press (2002a).

Tocher, D.R., G. Mourente, A. Van Der Eeken, J. O. Evjemo, E. Diaz, M. Wille, J. G. Bell and Y. Olsen. Comparative study of antioxidant defence mechanisms in marine fish fed variable levels of oxidised oil and vitamin E. Aquaculture Internat., In press (2002b).

Tontonoz P., E. Hu, J. Devine, E. G. Beale and B. M. Spiegelman. PPAR gamma 2 regulates adipose expression of the phosphoenolpyruvate carboxykinase gene. Mol. Cell. Biol., 15: 351-357 (1995).

Torstensen, B.E. Transport and metabolism of lipids in Atlantic salmon, Salmo salar L. Dep. Fisheries and Marine Biology, University of Bergen, Bergen (Norway), 43 pp. (2000).

Trueman, R. J., P. E. Tiku, M. X. Caddick and A. R. Cossins. Thermal thresholds of lipid restructuring and $\Delta$ 9-desaturase expression in the liver of carp (Cyprinus carpio L.). J. Exp. Biol., 203: 641-650 (2000).

Tullis, A., B. A. Block and B. D. Sidell. Activities of key metabolic enzymes in the heater organs of scombroid fishes. Amer. Zool., 31: 56A (1991).

Uematsu, K., M. Kitano, M. Morita and N. Iijima. Presence and ontogeny of intestinal and pancreatic phospholipase $\mathrm{A}_{2}$-like proteins in the red sea bream, Pagrus major. An immunocytochemical study. Fish Physiol.Biochem., 9: 427-438 (1992).

Vayada, M. E., R. L. Londraville, R. E. Cashon, L. Costello and B. D. Sidell. Two distinct types of fatty acid-binding protein are expressed in heart ventricle of Antarctic teleost fishes. Biochem. J., 330: 375 $382(1998)$.

Vazquez, R., S. Gonzalez, A. Rodriguez and G. Mourente. Biochemical composition and fatty acid content of fertilized eggs, yolk sac stage larvae and first-feeding larvae of the Senegal sole (Solea senegalensis Kaup). Aquaculture, 119: 273-286 (1994). 
Veerkamp, J. H. and R. G. H. J. Maatman. Cytoplasmic fatty acid-binding proteins: Their structure and genes. Prog. Lipid Res., 34: 17-52 (1995).

Verreth, J., G. Custers and W. Melgur. The metabolism of neutral and polar lipids in eleuthero-embryos and starving larvae of the African catfish Clarias gariepinus. J. Fish Biol., 45: 961-971 (1994).

Voss, A., M. Reinhart, S. Sankarappa and H. Sprecher. The metabolism of 7,10,13,16,19-docosapentaenoic acid to 4,7,10,13,16,19-docosahexaenoic acid in rat liver is independent of a 4-desaturase. J. Biol. Chem., 266: 19995-20000 (1991).

Wahli, W., O. Braissant and B. Desvergne. Peroxisome proliferator activated receptors: transcriptional regulators of adipogenesis, lipid metabolism and more. Current Biology, 2: 261-266 (1995).

Wallace, R. A. Vitellogenesis and oocyte growth in non-mammalian vertebrates. pp. 127-178. In: Developmental Biology, A Comprehensive Synthesis, vol. 1. Oogenesis. (Browder, L. W., Ed.). New York: Plenum Press (1985).

Watanabe, T. Lipid nutrition in fish. Comp. Biochem. Physiol., 73B: 3-15 (1982).

Watts, J. L. and J. Browse. Isolation and characterisation of a $\Delta-5$ fatty acid desaturase from Caenorhabditis elegans. Arch. Biochem. Biophys., 362: 175-182 (1999).

Weigert, R., M. G. Silletta, S. Spano, G. Turacchio, C. Cericola, A. Colanzi, S. Senatore, R. Mancini, E. V. Polishchuk, M. Salmona, F. Facchiano, K. N. J. Burgeri, A. Mironov, A. Luni and D. Corda. CtBP/BARS induces fission of Golgi membranes by acylating lysophosphatidic acid. Nature, 402: 429433 (1999).

Wiegand, M. D. Composition, accumulation and utilization of yolk lipids inteleost fish. Rev. Fish Biol. Fish., 6: $259-286$ (1996a).

Wiegand, M. D. Utilization of yolk fatty acids by goldfish embryos and larvae. Fish Physiol. Biochem., 15: 21-27 (1996b).

Wynn, J. P. and C. Ratledge. Evidence that the rate-limiting step for the biosynthesis of arachidonic acid in Mortierella alpina is at the level of the 18:3 to 20:3 elongase. Microbiology, 146: 2325-2331 (2000).

Yada, T., T. Azuma, A. Takahashi, Y. Suzuki and S. Hirose. Effects of desacetyl- $\alpha$-MSH on lipid mobilization in the rainbow trout, Oncorhynchus mykiss. Zool. Sci., 17: 1123-1127 (2000).

Yone, Y. Essential fatty acids and lipid requirements of marine fish.pp. 43-59. In: Dietary Lipids in Aquaculture. (Jap. Soc. Sci. Fish, Eds.). Tokyo, Japan: Koseisha-Koseik-Abu (1978).

Zhang B., S. L. Marcus, F. G. Sajjadi, K. Alvares, J. K. Reddy, S. Subramani, R. A. Rachubinski and J. P. Capone. Identification of a peroxisome proliferator-responsive element upstream of the gene encoding rat peroxisomal enoyl-CoA hydratase/3-hydroxyacyl-CoA dehydrogenase. Proc. Natl. Acad. Sci. USA, 89: 7541-7545 (1992). 
Fig. 1. Structures of the 18-carbon saturated and monounsaturated fatty acids, and representative polyunsaturated fatty acids (PUFA) of the n-6 and n-3 series. All ethylenic (double) bonds are in the cis conformation.

Fig.2. A, Triacylglycerol: three fatty acids esterified to L-glycerol; B, Wax ester consisting of a fatty acid (top) esterified to a fatty alcohol (bottom); C, Phosphatidic acid, the backbone of the phosphoglycerides.

Fig. 3. Structures of head groups in the major phosphoglycerides where $\mathrm{R}=$ the phosphatidyl group (see Fig. 2C). PtdCho, Phosphatidylcholine; PtdEtn, phosphatidylethanolamine; PtdSer, phosphatidylserine; PtdIns, phosphatidylinositol.

Fig. 4. Sphingomyelin (A) and a cerebroside (B).

Fig. 5. Cholesterol.

Fig. 6. Pathways of biosynthesis of $C_{20}$ and $C_{22}$ HUFA from n-3, n- 6 and n-9 $C_{18}$ precursors. $\Delta 5, \Delta 6, \Delta 6^{*}, \Delta 9$, $\Delta 12, \Delta 15$, Fatty acyl desaturases; Elong, Fatty acyl elongases; Short, chain shortening. $\Delta 9$ desaturase is found in all animals and plants whereas $\Delta 12$ and $\Delta 15$ desaturases are generally only found in plants and so 18:2n-6 and 18:3n-3 are "essential" fatty acids (EFA) for many animals including many species of freshwater fish. Carnivores and many marine fish generally have only limited ability to carry out the conversions above due to specific deficiencies in desaturases and/or elongases and so 20:5n-3 and 22:6n-3 are their EFA. The $\Delta 6^{*}$ enzyme acting on $\mathrm{C}_{24}$ fatty acids may or may not be the same enzyme $(\Delta 6)$ that acts on $\mathrm{C}_{18}$ fatty acids.

Fig. 7. Links between dietary PUFA, tissue HUFA and eicosanoid production. Arachidonic acid, 20:4n-6, and eicosapentaenoic acid, 20:5n-3, produced by desaturation and elongation (D/E) of dietary 18:2n-6 and 18:3n-3 or obtained preformed in the diet, compete for the same cyclo-oxygenase and lipoxygenase enzymes $(\mathrm{C} / \mathrm{L})$ to produce, 2-series prostanoids and 4-series leukotrienes, and 3-series prostanoids and 5-series leukotrienes, respectively. Therefore, the ratio of 20:4n-6 :20:5n-3 determines the ratio of high activity : low activity eicosanoids. 
<smiles>CCCCCCCCCCCCCCCCCC(=O)O</smiles>

OCTADECANOIC ACID, STEARIC ACID, 18:0<smiles>CCCCCCCCC=CCCCCCCCC(=O)O</smiles>

OCTADECENOIC ACD, OLEIC ACID, 18:1(n-9)

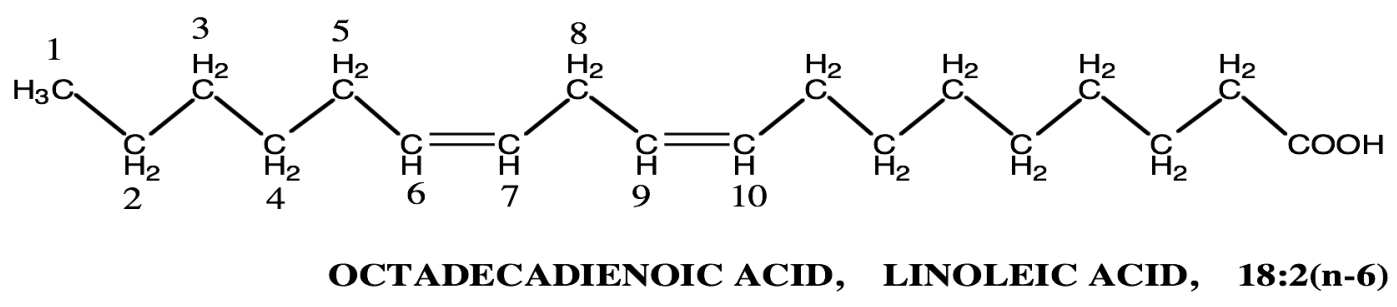<smiles>CCC=CCC=CCC=CCCCCCCCC(=O)O</smiles>

OCTADECATRIENOIC ACID, LINOLENIC ACID, 18:3(n-3) 
A

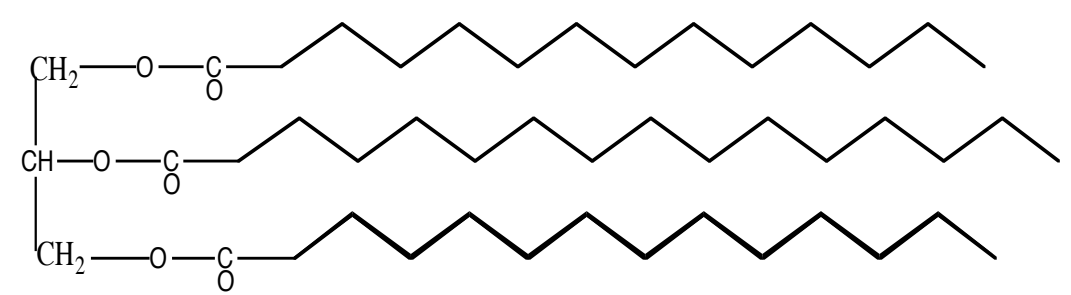

B<smiles>CCCCCCCCCCCCCCCCCCCCCCCCCCCCCC</smiles>

C

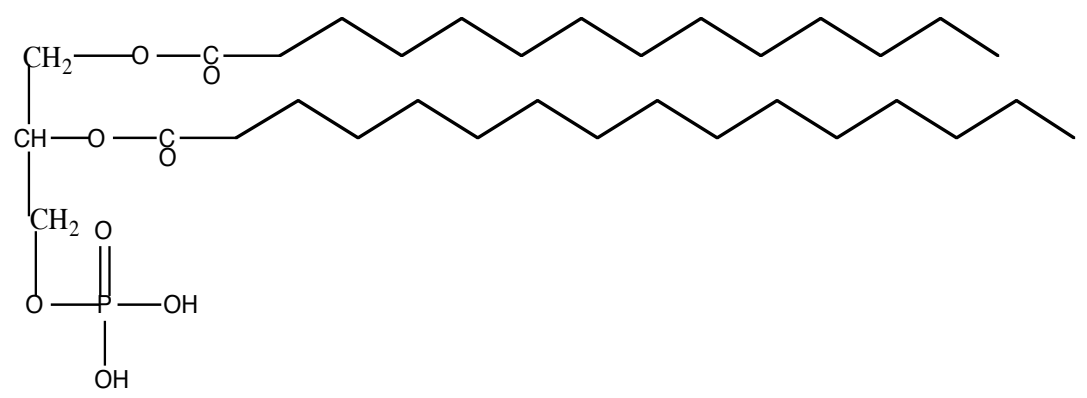




$$
\mathrm{R}-\mathrm{O}-\underset{\mathrm{H}_{2}}{\mathrm{C}}-\underset{\mathrm{H}_{2}}{\mathrm{C}}-\mathrm{N}\left(\mathrm{CH}_{3}\right)_{3}^{+}
$$

PtdCho

PtdSer

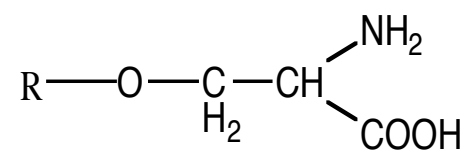

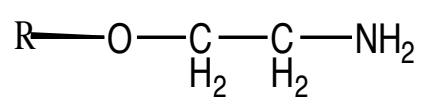

PtdEtn

PtdIns

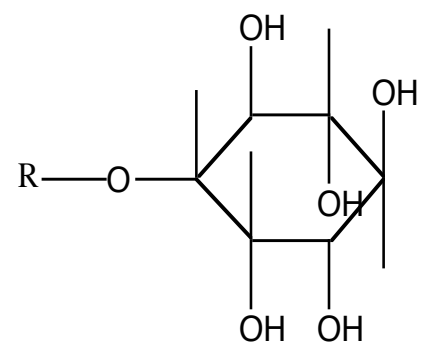


A

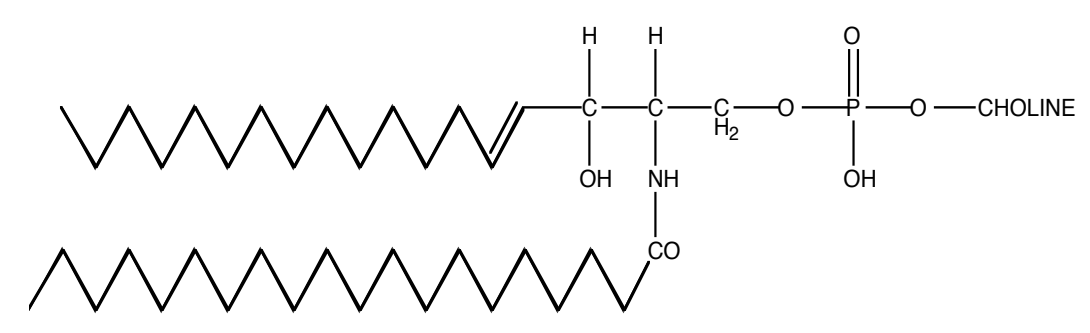

B

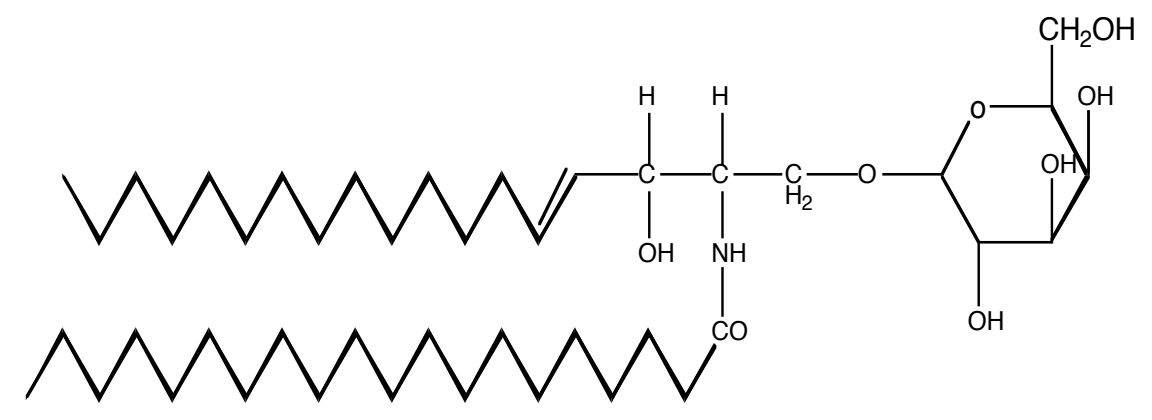




$$
w^{2} 0^{3 x^{2}}
$$




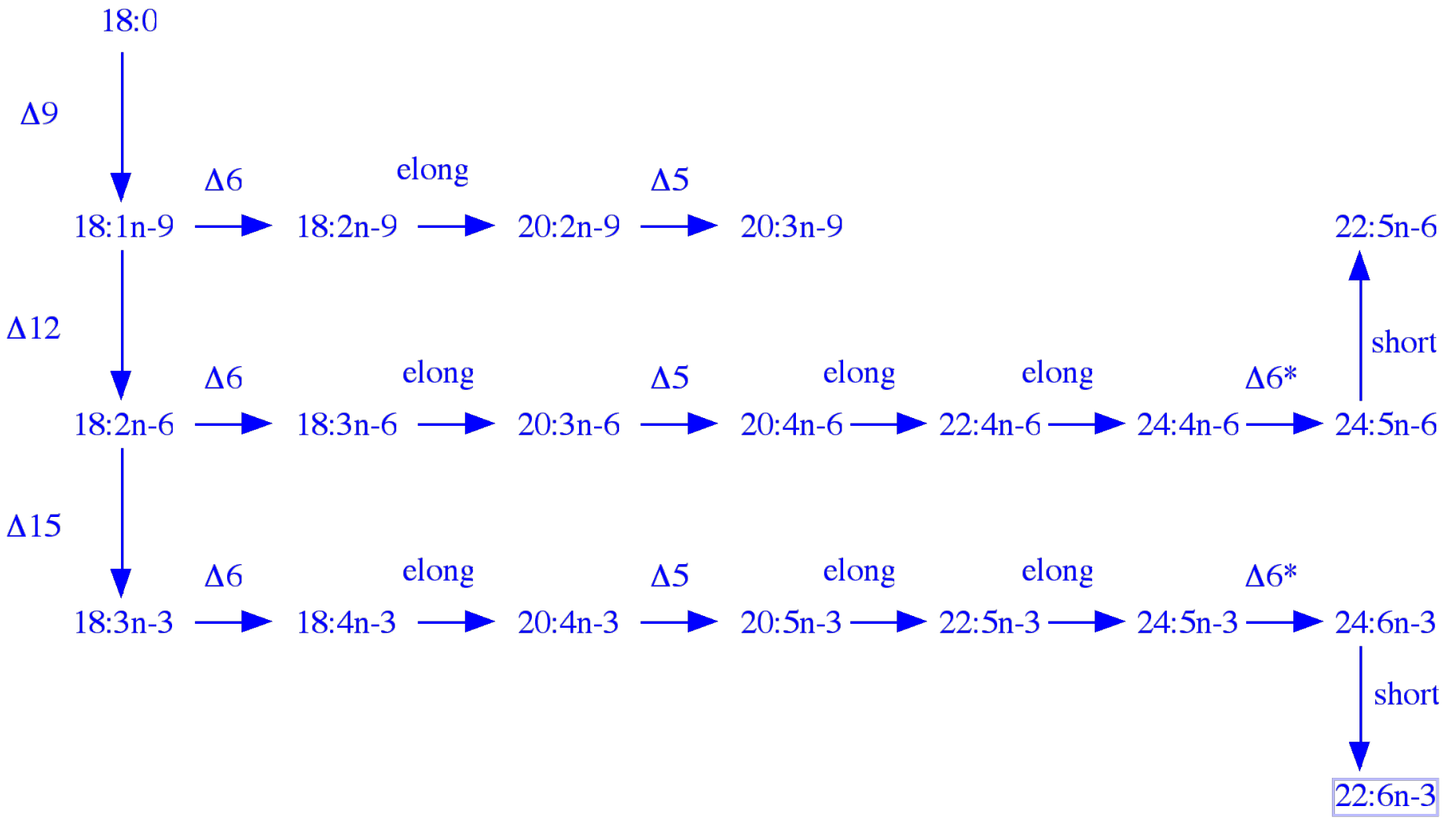



18:2n-6
DIET
18:3n-3

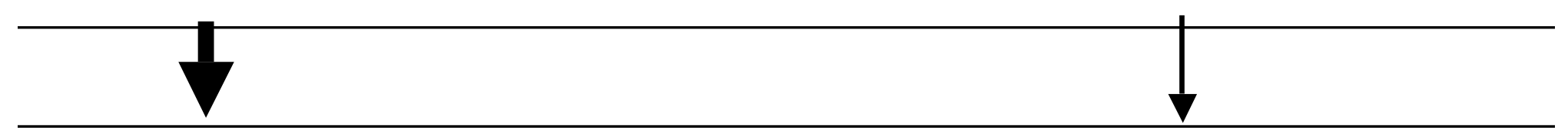

\section{8:2n-6 TISSUES}

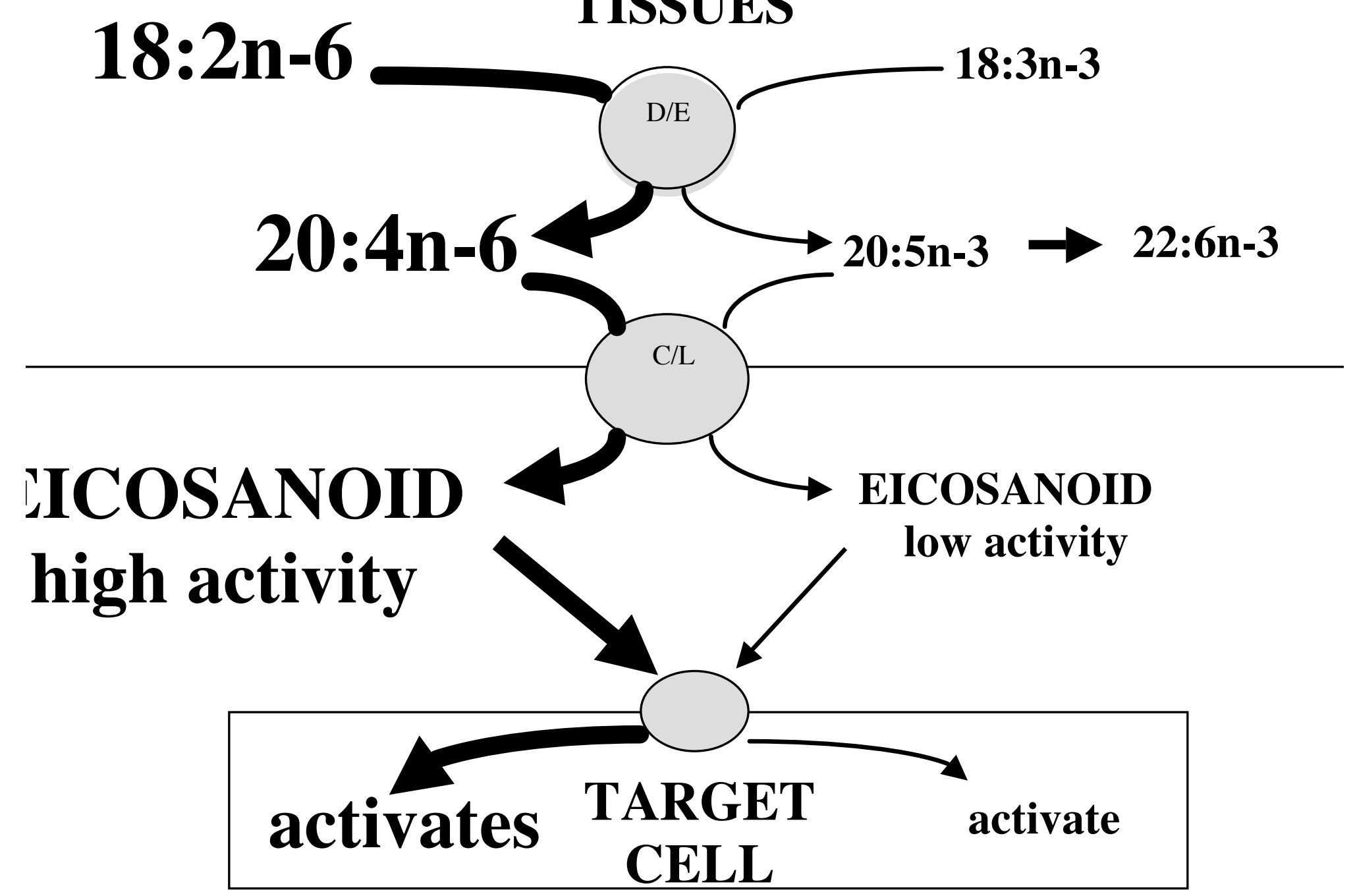

